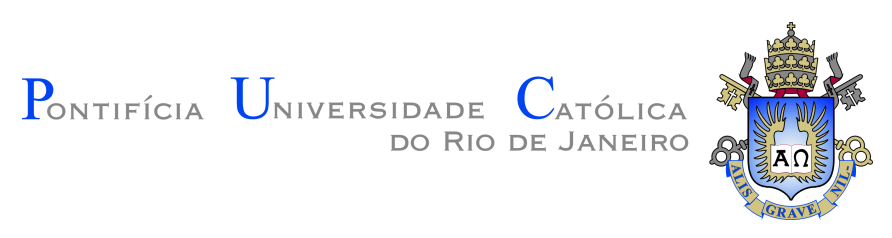

Ingrid Pires Macedo Oliveira dos Santos

\title{
Torsional Friction-Induced Vibrations in Slender Rotating Structures
}

Dissertação de Mestrado

Dissertation presented to the Programa de Pós-graduação em Engenharia Mecânica da PUC-Rio in partial fulfillment of the requirements for the degree of Mestre em Engenharia Mecânica.

Advisor: Prof. Hans Ingo Weber 


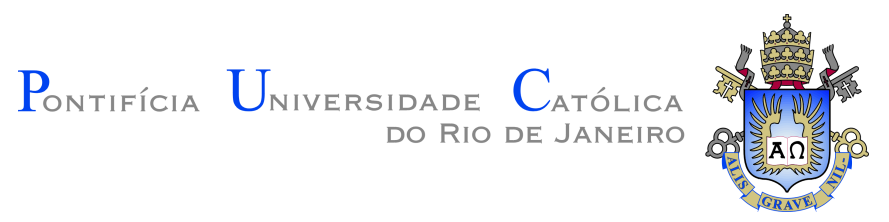

Ingrid Pires Macedo Oliveira dos Santos

\section{Torsional Friction-Induced Vibrations in Slender Rotating Structures}

Dissertation presented to the Programa de Pós-graduação em Engenharia Mecânica da PUC-Rio in partial fulfillment of the requirements for the degree of Mestre em Engenharia Mecânica. Approved by the undersigned Examination Committee.

Prof. Hans Ingo Weber Advisor Departamento de Engenharia Mecânica - PUC-Rio

Dr. Romulo Reis Aguiar Schlumberger Oilfield Services - Schlumberger Ltd.

Prof. Helon Vicente Hultmann Ayala Departamento de Engenharia Mecânica - PUC-Rio 
All rights reserved.

\section{Ingrid Pires Macedo Oliveira dos Santos}

The author graduated from Universidade Federal do Rio de Janeiro (UFRJ) in Mechanical Engineering, and has been working for the last two years in the Laboratory of Dynamics and Vibrations of the PUC-Rio on the subject of this dissertation.

Bibliographic data

Pires, Ingrid

Torsional Friction-Induced Vibrations in Slender Rotating Structures / Ingrid Pires Macedo Oliveira dos Santos; advisor: Hans Ingo Weber. - Rio de janeiro: PUC-Rio, Departamento de Engenharia Mecânica , 2019.

v., 80 f: il. ; $30 \mathrm{~cm}$

Dissertação (mestrado) - Pontifícia Universidade Católica do Rio de Janeiro, Departamento de Engenharia Mecânica .

Inclui bibliografia

vibração torsional, stick-slip, atrito seco, histerese I. Weber, Hans Ingo. II. Pontifícia Universidade Católica do Rio de Janeiro . Departamento de Engenharia Mecânica . III. Título. 


\section{Acknowledgments}

I would like to express my gratitude to my parents, siblings, and friends for their constant support and encouragement.

I would like to express my gratitude to my supervisor Professor Hans Ingo Weber for his dedication, teaching, and friendship.

During my studies, I have received useful advice and support from my colleagues from LabVib. In particular, I would like to express my gratitude to Dr. Bruno Cayres, Mariana Gomes and Professor Djenane Pamplona for their invaluable contribution and teamwork.

I would like to express my gratitude to all professors, staff, and friends from PUC-Rio.

This study was financed in part by the Coordenação de Aperfeiçoamento de Pessoal de Nível Superior - Brasil (CAPES) - Finance Code 001. 


\section{Abstract}

Pires, Ingrid; Weber, Hans Ingo (Advisor). Torsional FrictionInduced Vibrations in Slender Rotating Structures. Rio de Janeiro, 2019. 80p. Dissertação de mestrado - Departamento de Engenharia Mecânica, Pontifícia Universidade Católica do Rio de Janeiro .

Excessive drill string vibration leads to loss of the drilling process effectiveness and premature damage to the equipment. Therefore, understanding the system dynamics is essential. The complex behavior of drill strings attracted considerable attention in specialized literature. Due to the drill string slenderness, torsional vibration is present in most drilling routines, eventually reaching the stick-slip phenomenon. This torsional vibration results from the nonlinear interaction between drill-bits and rocks. Despite the complexity of the bit-rock interaction, researchers often treat the relationship between torque and bit velocity as a dry friction force in a slender system. A large number of dry friction models is used to describe the interaction between drill bits and rocks although a proper model is required for a precise interpretation of systems with friction. This contribution utilizes data from a test rig that is capable of reproducing full-scale system torsional behavior with simple brake devices to introduce friction into the system, disturbing the rotating motion. This test rig is modeled as an actuated torsional pendulum for the numerical investigations of the experimental friction. This dissertation proposes a friction model based on experimental data and analyzes various frictional phenomena observed, including hysteresis. The experimental results are used to identify the proposed model parameters. Lastly, it compares numerical simulations with the experimental results and validates the proposed friction model.

\section{Keywords}

torsional vibrations, stick-slip, dry friction, hysteresis 


\section{Resumo}

Pires, Ingrid; Weber, Hans Ingo. Vibrações Torcionais Induzidas por Atrito em Estruturas Esbeltas. Rio de Janeiro, 2019. 80p. Dissertação de Mestrado - Departamento de Engenharia Mecânica, Pontifícia Universidade Católica do Rio de Janeiro .

A vibração excessiva da coluna de perfuração leva à perda da eficácia do processo de perfuração de poços de petróleo e causa danos prematuros ao equipamento. Portanto, entender a dinâmica do sistema é essencial. O comportamento complexo das colunas de perfuração estimulou um grande número de publicações sobre a dinâmica de perfuração. A vibração torsional está presente na maioria dos processos de perfuração, eventualmente atingindo o fenômeno de stick-slip. Essa vibração torsional resulta da interação não linear entre brocas e rochas. Apesar da complexidade da interação broca-rocha, a relação entre torque e velocidade de broca é, frequentemente, tratada como uma força de atrito seco em um sistema delgado. Um grande número de modelos de atrito é usado para descrever a interação entre brocas e rochas, embora um modelo adequado seja necessário para uma interpretação precisa de sistemas com atrito. Esta contribuição utiliza dados experimentais de uma bancada de testes, capaz de reproduzir o comportamento torsional de um sistema real, equipada com dispositivos de freio simples para introduzir atrito ao sistema, perturbando o movimento de rotação. A bancada é matematicamente modelada como um pêndulo de torção atuado. Esta dissertação propõe um modelo de atrito baseado em dados experimentais e analisa vários fenômenos observados em relação ao atrito, incluindo a histerese. Os resultados experimentais são usados para identificação dos parâmetros do modelo proposto. Por fim, simulações numéricas e resultados experimentais são comparados para validação do modelo de atrito proposto.

\section{Palavras-chave}

vibração torsional, stick-slip, atrito seco, histerese 


\section{Table of contents}

$\begin{array}{lll}1 & \text { Introduction } & 15\end{array}$

$\begin{array}{lll}1.1 & \text { Motivation } & 15\end{array}$

$\begin{array}{lll}1.2 & \text { Objectives } & 16\end{array}$

$\begin{array}{lll}1.3 & \text { Scope of the dissertation } & 17\end{array}$

2 Literature review $\quad 19$

$\begin{array}{ll}2.1 \text { Introduction } & 19\end{array}$

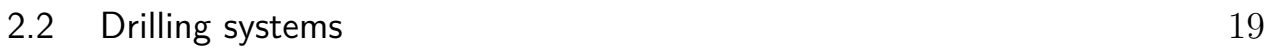

$\begin{array}{lll}2.3 & \text { Drilling dynamics } & 19\end{array}$

2.4 Torsional vibration 22

2.5 Friction Models 23

2.6 Experimental studies 26

$\begin{array}{lll}2.7 & \text { Summary } & 27\end{array}$

3 Friction models and stick-slip $\quad 28$

3.1 Introduction 28

3.2 The block-on-belt system 28

3.3 1-DOF torsional pendulum 30

3.4 The locomotive system 31

3.5 Numerical results 33

3.6 Conclusion 36

4 Experimental setup $\quad 39$

$\begin{array}{lll}4.1 & \text { Introduction } & 39\end{array}$

4.2 General overview of the test rig 39

4.3 Dynamical model 42

4.4 Physical parameters identification 44

4.5 Model validation 48

$\begin{array}{ll}4.6 \text { Conclusion } & 50\end{array}$

5 Experimental studies $\quad 51$

5.1 Introduction 51

5.2 Reduced test rig experimental results $\quad 51$

5.3 Full test rig experimental results $\quad 55$

$\begin{array}{ll}5.4 & \text { Experimental friction } \\ 5.5 & 57\end{array}$

5.5 Summary 60

$6 \quad$ Numerical studies $\quad 64$

$\begin{array}{lll}6.1 & \text { Introduction } & 64\end{array}$

6.2 Friction Models 64

6.3 Numerical studies 66

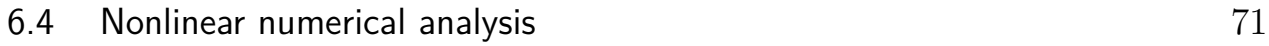

$\begin{array}{lll}6.5 & \text { Conclusions } & 73\end{array}$

$\begin{array}{lll}7 & \text { Conclusions and future work } & 74\end{array}$ 
Bibliography 


\section{List of figures}

Figure 1.1 Shares of global primary energy consumption by fuel.

Figure 2.1 Typical drilling rig schematics with the most important components.

$\begin{array}{lll}\text { Figure 2.2 Drill string's vibration modes. } & 21\end{array}$

Figure 2.3 Representation of Coulomb friction. 24

Figure 2.4 Representation of modified Coulomb friction. 25

Figure 2.5 Representation of the Stribeck curve. 25

Figure 2.6 Representation of the Wojewoda friction model with hysteresis. 26

$\begin{array}{lll}\text { Figure } 3.1 & \text { Block-on-belt system. } & 29\end{array}$

Figure 3.2 Torsional pendulum with friction torque at the bottom. 30

Figure 3.3 Locomotive system. 32

Figure 3.4 Results from block-on-belt system simulations. 34

Figure 3.5 Results from torsional pendulum system with constant top velocity simulations. $\quad 36$

Figure 3.6 Results from torsional pendulum system with sinusoidal top velocity simulations. $\quad 37$

Figure 3.7 Results from locomotive system with constant drive force simulations.

Figure 3.8 Results from locomotive system with harmonic drive force simulations.

Figure 4.1 Schematic diagram of the experimental rig. The main components of the system are: DC-motor, discs D1 and D2, flexible shafts, brake devices and sensors.

Figure 4.2 Experimental rig. $\quad 40$

Figure 4.3 Brake devices equipped with a load cells. 41

Figure 4.4 Acquisition device. 41

Figure 4.5 Schematic representation of the test rig. 42

Figure 4.6 Schematic representation of the reduced test rig. 43

Figure 4.7 Torque as a function of the angular displacement between the discs D1 and D2. 46

Figure 4.8 Torque as a function of the angular displacement between the disc D2 and the DC-motor.

Figure 4.9 Free torsional oscillations of the discs subjected to initial angular displacement.

Figure 4.10 Amplitude spectrum of the relative angular displacement between the inertia.

Figure 4.11 Numerical and experimental angular velocity of D2 time history.

Figure 4.12 Numerical current time history. 
Figure 5.1 Torsional oscillations occurring in the reduced experimental rig for $N_{2}=10 \mathrm{~N}$. The time histories of the angular velocities of D2 and D3 for (a) $\omega_{\text {ref }}=25 R P M$, (b) $\omega_{\text {ref }}=35$ $R P M,(\mathrm{c}) \omega_{r e f}=45 R P M$ and (d) $\omega_{\text {ref }}=55 R P M$.

Figure 5.2 Tridimensional bifurcation diagram presenting phase portrait as a function of $\omega_{\text {ref }}$.

Figure 5.3 Torsional oscillations occurring in the reduced experimental rig for $\omega_{\text {ref }}=55 R P M$. The time histories of the angular velocities of D2 and D3 for (a) $N_{2}=10 \mathrm{~N}$, (b) $N_{2}=30 \mathrm{~N}$, (c) $N_{2}=50 \mathrm{~N}$ and (d) $N_{2}=70 \mathrm{~N}$.

Figure 5.4 Tridimensional bifurcation diagram presenting phase portrait as a function of $N_{2}$.

Figure 5.5 Torsional oscillations occurring in the full experimental rig for $N_{1}=15 N$. The time histories of the angular velocities of D1 and D3 for (a) $\omega_{\text {ref }}=20 R P M$, (b) $\omega_{\text {ref }}=30 R P M$ and (c) $\omega_{\text {ref }}=40 R P M$.

Figure 5.6 Tridimensional bifurcation diagram presenting phase portrait as a function of $\omega_{\text {ref }}$.

Figure 5.7 Torsional oscillations occurring in the full experimental rig for $\omega_{\text {ref }}=40 R P M$. The time histories of the angular velocities of D1 and D3 for (a) $N_{1}=15 N$, (b) $N_{1}=30 N$ and (c) $N_{1}=40$ $N$.

Figure 5.8 Tridimensional bifurcation diagram presenting phase portrait as a function of $N_{1}$.

Figure 5.9 Time history of (a) the angular velocity of D2, (b) the angular acceleration of $\mathrm{D} 2,(\mathrm{c})$ friction torque, $T_{f, 2}$, and (d) contact normal force, $N_{2}$, for $\omega_{r e f}=55 R P M$ and $N_{2}=50 \mathrm{~N}$.

Figure 5.10 Normal contact force $N_{2}$ as a function of angular position difference $\delta_{23}$.

Figure 5.11 Experimental friction torque for $\omega_{\text {ref }}=55 R P M$ and $N_{2}=50 \mathrm{~N}$.

Figure 5.12 (a) friction torque versus disc D2 velocity, (b) friction torque versus disc D2 acceleration and (c) disc D2 acceleration versus velocity.

Figure 5.13 Experimental tridimensional friction torques.

Figure 5.14 Experimental tridimensional friction torques.

Figure 6.1 experimental and fitted acceleration vs. velocity curves for $\omega_{\text {ref }}=55 R P M(5.76 \mathrm{rad} / \mathrm{s})$ and $N_{2}=50 \mathrm{~N}$.

Figure 6.2 Experimental friction torque as a function of $\alpha$ for $\omega_{\text {ref }}=55 \mathrm{RPM}(5.76 \mathrm{rad} / \mathrm{s})$ and $N_{2}=50 \mathrm{~N}$.

Figure 6.3 Experimental friction coefficient as a function of $\alpha$ for $\omega_{\text {ref }}=55 \mathrm{RPM}(5.76 \mathrm{rad} / \mathrm{s})$ and $N_{2}=50 \mathrm{~N}$.

Figure 6.4 (a) Experimental (continuous) and numerical (dashed) angular velocity, and (b) experimental (continuous) and numerical (dashed) phase portraits of disc D2 for $\omega_{\text {ref }}=55 R P M(5.76$ $\mathrm{rad} / \mathrm{s}$ ) and $N_{2}=50 \mathrm{~N}$. 
Figure 6.5 (a) Experimental (continuous) and numerical (dashed) angular velocity, and (b) experimental (continuous) and numerical (dashed) phase portraits of disc D2 for $\omega_{\text {ref }}=55 R P M(5.76$ $\mathrm{rad} / \mathrm{s})$ and $N_{2}=50 \mathrm{~N}$.

Figure 6.6 Amplitude spectrum of the angular velocity of disc D2. 68

Figure 6.7 Amplitude spectrum of the residual data.

Figure 6.8 Experimental friction torque as a function of $\alpha$ for $\omega_{\text {ref }}=55 \mathrm{RPM}(5.76 \mathrm{rad} / \mathrm{s})$ and $N_{2}=10 \mathrm{~N}$.

Figure 6.9 Experimental friction coefficient as a function of $\alpha$ for $\omega_{\text {ref }}=55 R P M(5.76 \mathrm{rad} / \mathrm{s})$ and $N_{2}=10 \mathrm{~N}$.

Figure 6.10 (a) Experimental (continuous) and numerical (dashed) angular velocity, and (b) experimental (continuous) and numerical (dashed) phase portraits of disc D2 for $\omega_{\text {ref }}=55 R P M(5.76$ $\mathrm{rad} / \mathrm{s})$ and $N_{2}=10 \mathrm{~N}$.

Figure 6.11 (a) Experimental (continuous) and numerical (dashed) angular velocity, and (b) experimental (continuous) and numerical (dashed) phase portraits of disc D2 for $\omega_{\text {ref }}=55 R P M(5.76$ $\mathrm{rad} / \mathrm{s}$ ) and $N_{2}=10 \mathrm{~N}$.

Figure 6.12 Amplitude spectrum of the angular velocity of disc D2. 71

Figure 6.13 Amplitude spectrum of the residual data. 71

Figure 6.14 Bifurcation diagram with respect to reference angular velocity, $\omega_{\text {ref }}$, for $N_{2}=10 \mathrm{~N}$.

Figure 6.15 Bifurcation diagram with respect to normal contact force, $\mathrm{N}_{2}$, for $\omega_{\text {ref }}=55 R P M$. 


\section{List of tables}

Table 3.1 Simulation parameters for the block-on-belt system 33

Table 3.2 Simulation parameters for the tosional pendulum system 35

Table 3.3 Simulation parameters for the locomotive system 35

Table 4.1 Moments of inertia 44

Table 4.2 Static test results and stiffness calculations.

Table 4.3 Static test results and stiffness calculations. $\quad 45$

Table 4.4 Frequency calculations. $\quad 46$

Table 4.5 Damping calculations. $\quad 46$

Table 4.6 DC-motor electrical parameters $\quad 47$

Table 4.7 Quantitative comparison between experimental and numerical results for $\dot{\theta}_{2} . \quad 50$ 


\section{List of Symbols}

$F_{f}-$ Friction force

$v_{\text {rel }}-$ Relative velocity

$F_{e x}$ - Resultant of the external forces

$F_{N}$ - Normal force

$F_{C}$ - Coulomb friction force

$F_{S}$ - Static friction force

$\mu_{k}$ - Kinetic friction coefficient

$\mu_{s}$ - Static friction coefficient

$k$ - Stiffness

$d$ - Damping coefficient

$T_{f}$ - Friction torque

$J_{1}-$ Disc D1 moment of inertia

$J_{2}$ - Disc D2 moment of inertia

$J_{m}$ - DC-motor moment of inertia

$\theta_{i}$ - Angular displacement of the discs and motor

$\dot{\theta}_{i}-$ Angular velocity of the discs and motor

$\ddot{\theta}_{i}-$ Angular acceleration of the discs and motor

$\tau_{s}$ - Torque transmitted to the mechanical subsystem

$\tau_{m}$ - Torque provided by the DC-motor

$\eta$ - Transmission factor

$i$ - Electric current

$L$ - Armature inductance

$R$ - Resistance

$C_{m}$ - Speed regulation

$K_{T}$ - Constant torque of the motor

$K_{E}$ - Voltage constant

$T_{f m}$ - Internal friction torque

$u$ - Input voltage 
"For the Lord gives wisdom; from his mouth come knowledge and understanding."

Proverbs 2.6. 


\section{Introduction}

\section{1}

\section{Motivation}

Oil remains the world primary energy source, and the forecast is that this scenario lasts for the next decades [1]. Its continuously rising consumption drives the search for new reserves, in even more challenging environments. The technology needed to enable the exploration of these reserves is still under development, and drill strings are one of the essential components. Therefore, understanding the drill strings' complex dynamics is indispensable.

As stated in BP Statistical Review of World Energy [2], in 2017 global oil consumption growth averaged $1.8 \%$, or 1.7 million barrels per day (b/d), and global oil production rose by 0.6 million b/d. The graph in Fig. 1.1 presents the shares of global primary energy consumption by fuel. Furthermore, Brazil produced 3.24 million barrels per day of oil and other liquid fuels in 2016, placing the country as the world's ninth-largest producer [3]. Interestingly the world's most significant oil discoveries in recent years are in Brazil's offshore pre-salt basins.

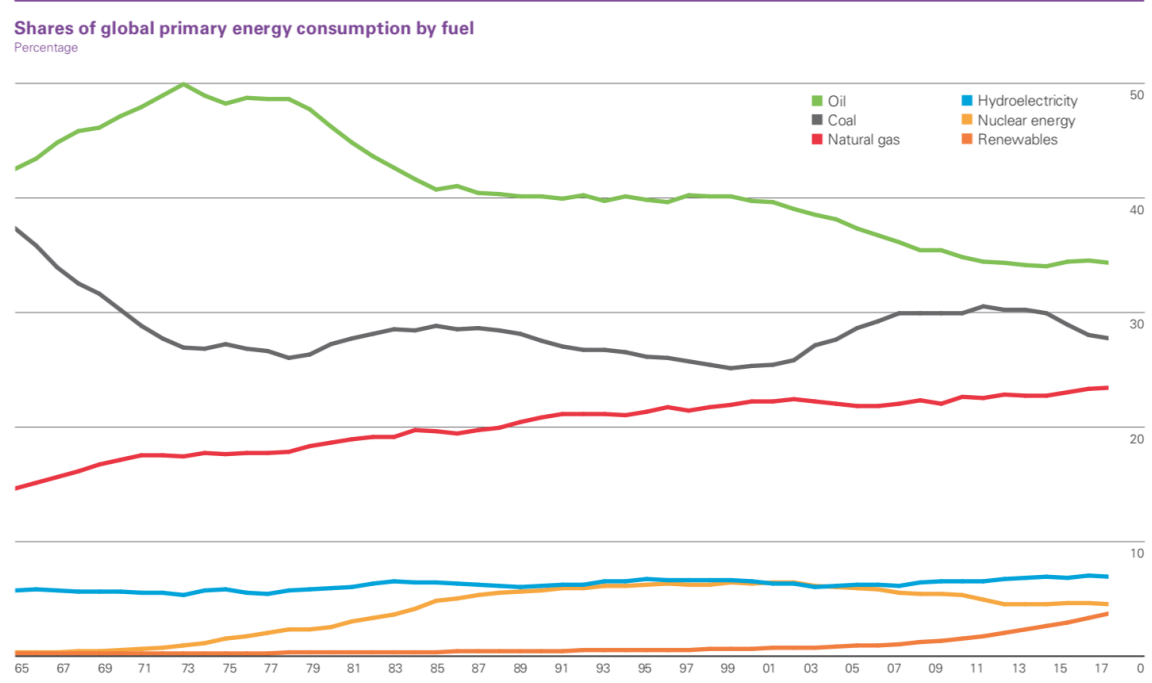

Figure 1.1: Shares of global primary energy consumption by fuel [2]. 
Due to its significant costs, drilling has become the main challenge in oil and gas exploration. Drilling operation represents an expensive phase of the oil and gas prospecting, corresponding to approximately $40 \%$ of all exploration and production costs [4].

The drilling system is, basically, composed of a rotary table, drill string, and drill bit. The rotary table or top drive is responsible for imposing rotary motion to the system, and this motion is transmitted to the bit by the drill string. This drill string is composed of drill pipes and its length can reach many kilometers, which turns it to a very slender structure. Besides motion, drill strings also transmit the required weight to the bit [5]. The ideal combination between the various drilling parameters is fundamental to achieve a maximum of efficiency and economy [6].

Ideally, the entire drilling system should rotate at a constant speed imposed by the rotary table. Due to the drill string slenderness, torsional vibration is present in most drilling routines, ultimately reaching the stick-slip phenomenon. Stick-slip is a friction-induced limit cycle. In drilling operations, stick-slip happens when friction causes a complete arrest of the drill bit (stick phase), while the top drive continues to rotate until the stored energy overcomes the friction torque and the bit is released to rotate (slip phase). Other vibration modes present during drilling are axial and lateral, and the critical phenomena related to them are bit-bounce, and whirling motion, respectively. The coupling between these phenomena increases the system dynamics complexity. Despite the high nonlinearity of the coupling mechanisms, the uncoupling of the three modes of vibration is assumed in some models as a simplifying hypothesis.

Excessive drill string vibration leads to loss of the drilling process effectiveness and premature damage to the equipment: this makes the drilling system behavior a challenge to the process enhancement. Therefore, understanding the system dynamics is essential. The drill string vibrations can either be induced by drill bit formation or drill string borehole interactions and these vibrations are usually self-induced [7]. Despite the complexity of the bit-rock interaction, researchers often treat the relationship between torque and bit velocity as a dry friction function.

\section{2}

\section{Objectives}

Significant effort has been dedicated to the analysis of drill string oscillations. Moreover, a high number of dry friction models is used to describe the interaction between the drill bit and the rock. Although an adequate model is required for a precise interpretation of systems with friction, the nonlinear 
friction characteristics make its modeling a complex task.

Recent works from PUC-Rio Dynamic and Vibration Laboratory have studied the stick-slip phenomenon, conducting numerical and experimental investigations. This contribution utilizes an experimental test rig applied in previous researches to study the torsional behavior of real systems. The test rig has simple brake devices to introduce friction to the system, disturbing the rotating motion; and it is capable of reproducing full-scale system torsional behavior including stick-slip phenomenon. Although the excellent work performed with the experimental apparatus, an adequate mathematical description of the friction torque produced by the brake devices is not yet developed.

The objectives of this dissertation involve:

1. Analyzing the experimental system conditions determining the appearance of torsional oscillations and stick-slip phenomenon.

2. Developing an experimentally based mathematical friction model to be used in the study of drill string torsional dynamics, with a focus on the stick-slip phenomenon.

3. Numerically reproducing the frictional phenomena observed in the experimental results, including hysteresis, and Stribeck effect.

4. Studying the change in the nonlinear control parameters influence in the system dynamics.

\section{3}

Scope of the dissertation

- Chapter 1 provides an introduction to this dissertation, the motivation and the objectives of the research.

- Chapter 2 presents the literature review regarding drilling systems, drilling dynamics, friction models and experimental researches.

- Chapter 3 analyses the friction model influence on the dynamics of wellknown mechanical systems.

- Chapter 4 focuses on the experimental setup used to mimic drill string oscillations. It explains the test rig components and the data acquisition procedure. Moreover, the chapter describes the dynamic mathematical model used and the identification of the system parameters.

- Chapter 5 presents and discusses the experimental results of this research. 
- Chapter 6 concentrates numerical investigations. It explains the friction model formulation and compares the simulated numerical responses to the experimentally observed behavior. Furthermore, the chapter presents a study of the control parameters influence on the system dynamics.

- Chapter 7 summarizes the main conclusions from this study and lists some recommendations for future work. 


\section{2 \\ Literature review}

\section{1}

Introduction

The complex behavior of drill strings stimulated a high number of publications in drilling dynamics, and the topic still attracts the interest of many researchers. Hence this chapter lists works that discuss the problem of drilling dynamics, works that suggest control strategies, and some studies on friction modeling. These works contributed to this dissertation development.

\section{2}

Drilling systems

Drilling systems are sets of equipment capable of making holes for oil and natural gas extraction. The rotary drilling system comprises a motor at the top of the string which imposes rotational motion to the system. The string lower part is the Bottom Hole Assembly (BHA) and comprises heavyweight drill pipes and drill collars. The cutting tool is named drill bit. Connecting the motor to the bit is the element called drill string, responsible for transmitting the rotation and the necessary weight on the bit (WOB) [5]. Figure 2.1 shows a typical rotary drilling system scheme. It illustrates drill bit, drill string and the electric drive that provides rotary motion to drill string.

\section{3}

\section{Drilling dynamics}

Three oscillation modes and the coupling between them may appear during the drilling process. The three modes are axial, lateral and torsional vibrations, as illustrated in Figure 2.2. Besides the three types of vibrations, drill strings may also present helical buckling since they are twisted and axially loaded at the same time [10]. These mechanisms are harmful to the process and may lead to premature component failures.

Axial vibration is the longitudinal motion of the drill string. Its worst stage happens when the drill bit loses contact with the formation and subsequently hits the rock and is named bit-bounce [11]. Lateral vibration is the whirling 

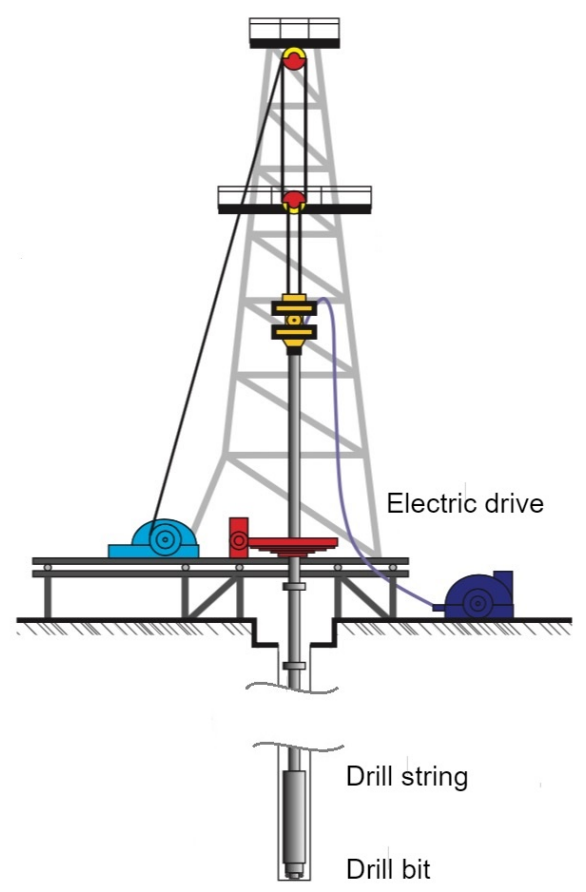

Figure 2.1: Typical drilling rig schematics with the most important components (adapted from [8]).

motion of the drill string, causing irregular borehole and damaging the BHA components [11].

Torsional vibration comprises twisting/untwisting of the drill string, mainly, because of the nonlinear bit-rock interaction. It is present in most drilling processes and may reach an undesired severe stage named stick-slip. Stick-slip is a complete arrest of the drill bit, while the top continues rotating and storing elastic torsional energy in the drill string [12]. When the accumulated torque overcomes the friction torque, it suddenly releases the drill bit. The stick-slip phenomenon may occur in approximately $50 \%$ of the total drilling time [4] and it is the primary cause of component failures.

There are two different categories of drilling researches. Part of the researches focuses on understanding the phenomena present in drilling operations. Another part proposes solutions to avoid or minimize the problems associated with these phenomena. Also, there are several numerical and experimental works.

An appropriate dynamic model of the system is essential for a good comprehension of the phenomena involved. The model has to represent the real systems well and be simple enough. Meanwhile, many researchers documented 


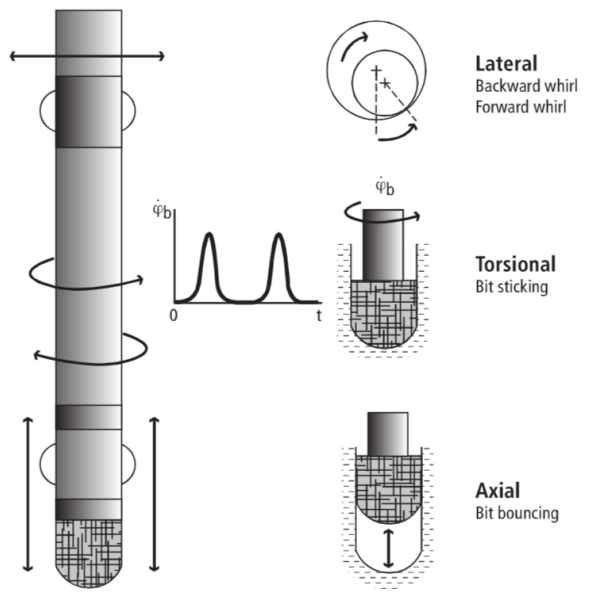

Figure 2.2: Drill string's vibration modes [9].

their modeling and analyzing contributions on drilling systems [12] [13] [14] [15] [16].

The surface measurements showing the existence of both torsional and axial vibrations inspired the first surveys on drill strings in the 1960s [17]. By that time, the BHA lateral vibrations were difficult to detect and considered irrelevant. Only in the 1980s, the first field measurements revealed the BHA lateral vibrations [18].

Recent works from PUC-Rio Dynamic and Vibration Laboratory have investigated the stick-slip phenomenon, proposing reduced mathematical models and applying numerical and experimental simulations.

In his thesis, Franca, 2004 [19], analyzed the influence of the torsional and axial vibration on the rate of penetration (ROP) and described a model to increase the ROP in hard rocks using percussive-rotary self-excited drilling. He developed an experimental apparatus to validate the numerical model proposed. So concluded that for controlled reference speeds it is possible to increase the ROP using drilling in the resonance.

Alamo (2006) [20] used Cosserat theory to develop a drilling system dynamic model that takes account of axial, lateral and torsional oscillations. His experimental study considered a curved beam to study the dynamic behavior of a simple curved drill string. The conclusion of his thesis was that the Cosserat theory shows efficiency to solve dynamic problems of slender structures using fewer nodes than the finite element method.

Cayres (2013) [21] presented a numerical and experimental analysis of the torsional vibrations. In his master's thesis, he developed an experimental 
drilling test rig. He built the experimental rig to study only torsional vibrations by eliminating coupling with other modes of vibrations. He used a nonlinear friction model to study the stick-slip phenomenon. He analyzed the experimental apparatus nonlinear behavior and compared experimental and numerical results.

As a continuation of the work mentioned above, Cayres (2018) [22] proposed two mitigation strategies for torsional vibrations. Both strategies were numerically efficient to eliminated stick-slip. However, the experimental tests only presented a time reduction of the stick phase. The physical limitations of the experimental rig explain the inability to eliminate the stick-slip phenomenon experimentally.

Ritto (2010) [23] and Cunha Jr (2015) [24] used stochastic approaches to interpret better the uncertainties existing in drilling processes. Ritto modeled a vertical drill string with the nonlinear coupling between three mechanisms of vibration. He considered uncertainties on the bit-rock interaction and how they propagate through the system. While Cunha Jr. modeled a drill string in the horizontal configuration, considering the coupled dynamics and the uncertainties on the bit-rock interaction. He also proposed an optimization problem to maximize the ROP, increasing the process efficiency.

Sampaio (2017) [25], studied two control techniques to reduce the torsional vibrations in drill strings using numerical and experimental tests. A behaviorbased open loop control and the L1 adaptive control, both techniques presented a simple and effective way to reduce stick-slip oscillations.

Ritto et al. (2017) [26] proposed a lumped parameter model for the torsional vibration of a drill string, representing the bit-rock interaction with nonlinear friction torque. The authors used field data with $50 \mathrm{~Hz}$ sample rate to fit the bit-rock interaction curve. They obtained good agreement between the response of the proposed computational model and the field data. Then, they used the numerical model to construct a torsional stability map. The authors remarked about the importance of the data available for the paper due to the data high-frequency rate.

\section{4}

\section{Torsional vibration}

There are several models to investigate the torsional vibration of drill strings. However, various studies adopt the simple torsional pendulum model. This modeling considers the BHA as a rigid body and assumes that the pipes are inertialess compared to the BHA and the rotary table ([27], [28]).

Navarro-Lopez and Cortes (2007) [29] developed a generic lumpedparameter model to analyze the sliding motion giving rise to self-excited 
stick-slip oscillations. He also studied the Hopf bifurcations in the system's vicinity equilibrium point.

Patil and Teodoriu (2013) [30] developed an uncoupled 2 DOF torsional vibration model of the drill string. They conducted a parametric study on the effect of rotating speed, WOB and drill string stiffness on the stick-slip motion of the drill string and also the effect of rock hardness on the rate of penetration and verified that the results are in line with the field trials.

Patil and Teodoriu (2013) [31] reviewed the modeling and control of torsional vibrations. They highlighted relevant works, comparing them. They analyzed several theoretical works that suggest control strategies to mitigate vibrations and theoretical resistive torque models. Their analysis also comprises the experimental researches of the drilling system. One of their conclusions was on the laboratory studies limitation in representing all possible aspects of drill string dynamics. About control strategies, they conclude that adaptive control achieves better results for mitigating the torsional vibration.

\section{5}

\section{Friction Models}

Torsional vibration results from the bit-rock interaction nonlinear characteristic. Consequently, the study of the complex characteristics of the bit-rock interaction is indispensable to the drill string dynamics analysis. Despite the complexity of this interaction, studies often treat the torque on the bit as dry friction torque.

The friction force is the resistance to the relative motion of two contact surfaces [32]. There are several friction models in the literature, classified as "static" or "dynamic" models [33]. The static friction models usually describe the steady-state behavior of the friction force while the dynamic models describe friction more realistically. There are also the acceleration-based friction models, which evaluate the friction force as a function of the relative acceleration of the contacting surfaces ([35], [36]). This section depicts the main static models.

In the sixteenth century, Leonardo da Vinci stated that the friction force is proportional to the normal force between the two contact surfaces, independent of the contact area and opposes to the motion [37]. Coulomb [38] developed the first mathematical friction model, which states that the friction opposes relative motion between contacting surfaces and its magnitude is proportional to the normal contact force. The following set of equations defines the model.

$$
F_{f}= \begin{cases}F_{C} \operatorname{sign}\left(v_{r e l}\right) & \text { if } v_{r e l} \neq 0, \\ \min \left(\left|F_{e x}\right|, F_{C}\right) \operatorname{sign}\left(F_{e x}\right) & \text { if } v_{r e l}=0,\end{cases}
$$


where $F_{f}$ is the friction force, $F_{C}=\mu_{k} F_{N}$ is the magnitude of Coulomb friction, $v_{r e l}$ is, from the perspective of the body, the relative tangential velocity between the contacting surfaces, $F_{e x}$ represents the resultant of the external forces, $F_{N}$ is the normal force, and $\mu_{k}$ is the kinetic friction coefficient. This model presents a dependence on the velocity by the signal function. Figure 2.3 shows the Coulomb friction model curve.

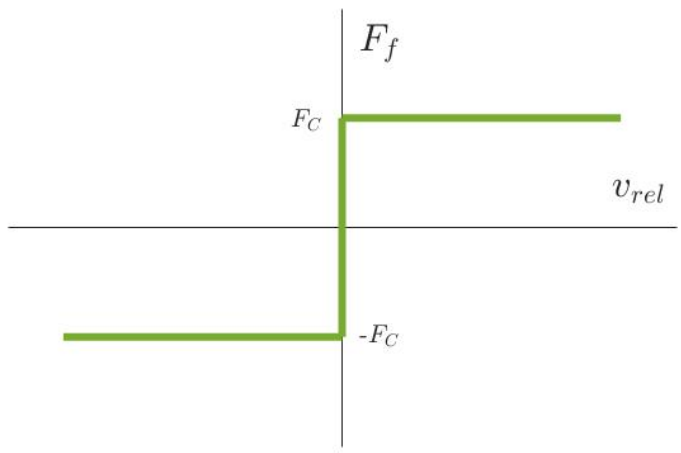

Figure 2.3: Representation of Coulomb friction.

Several studies suggest modifications of the Coulomb model [33]. One of the modified Coulomb approaches named Coulomb model with stiction takes account of the higher friction forces at a null velocity. This friction model uses two different friction coefficients as follows.

$$
F_{f}= \begin{cases}F_{C} \operatorname{sign}\left(v_{r e l}\right) & \text { if } v_{r e l} \neq 0, \\ \min \left(\left|F_{e x}\right|, F_{S}\right) \operatorname{sign}\left(F_{e x}\right) & \text { if } v_{r e l}=0,\end{cases}
$$

where $F_{S}=\mu_{s} F_{N}$ is the magnitude of static friction force and $\mu_{s}$ denotes the static coefficient of friction, which is higher than $\mu_{k}$. Figure 2.4 shows the variation of the friction force with the relative velocity.

Stribeck [39] experimentally proved that friction decreases with the increase in the relative velocity for low velocities. Which implies a continuous drop of friction force, the Stribeck curve describes this behavior. Several works propose mathematical expressions to describe this curve [36]. Its generic mathematical expression is

$$
F_{f}=\left(F_{C}+\left(F_{S}-F_{C}\right) g\left(v_{r e l}\right)\right) \operatorname{sign}\left(v_{r e l}\right),
$$

where $g\left(v_{r e l}\right)$ is a nonlinear function that describes the Stribeck curve. Figure 2.5 presents the friction model with Stribeck effect.

Karnopp [40] suggested an approach that considers the relative velocity being null within a velocity range. This model eliminates the discontinuity at 


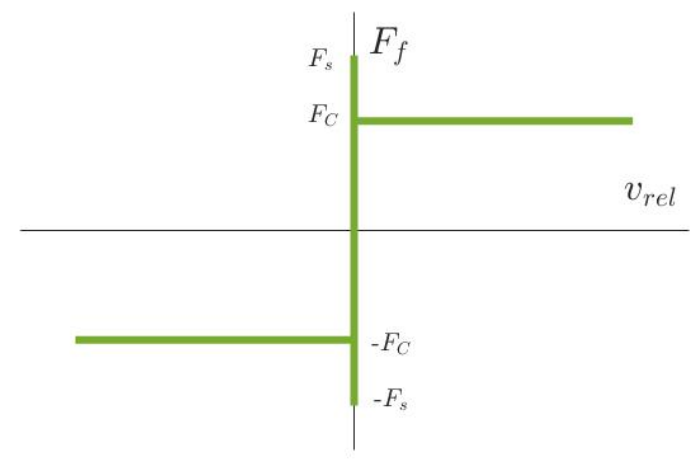

Figure 2.4: Representation of modified Coulomb friction.

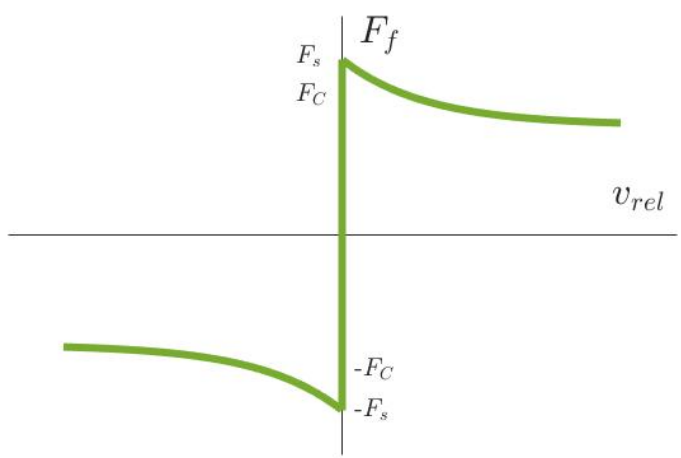

Figure 2.5: Representation of the Stribeck curve.

zero velocity, and it can capture stick-slip motion. Karnopp model is usually used along with the Coulomb model and has the form:

$$
F_{f}= \begin{cases}F\left(v_{r e l}\right) & \text { if }\left|v_{r e l}\right|>v_{t}, \\ \min \left(\left|F_{e x}\right|, F_{S}\right) \operatorname{sign}\left(F_{e x}\right) & \text { if }\left|v_{r e l}\right| \leq v_{t},\end{cases}
$$

where $v_{t}$ is the tolerance for zero velocity and $F\left(v_{r e l}\right)$ is friction force function.

To overcome some numerical instability of Karnopp model, Leine et al. [41] proposed the "switch model".

Besides nonlinearities, some studies argue that there are lower values of friction force for decreasing velocities than increasing velocities [32]. According to [36], there are three different types of hysteretic effects accompanying frictional processes: one that can arise during sticking, one that can arise during the switch between stick and slip phases, and one that can occur during oscillations with pure sliding. Recently, Wojewoda et al. [36] proposed a friction 
model for dry contact of the hysteretic type with a stochastic component. This model has three different states, one for sticking and two for sliding (acceleration and deceleration), as follows.

$$
F\left(v_{r e l}, v_{r e l}^{\cdot}\right)= \begin{cases}F_{s t} \operatorname{sign}\left(v_{r e l}\right) & \text { if } F_{s t}<F_{d+}, \operatorname{sign}\left(v_{r e l} d o t v_{r e l}\right)>0, \\ F_{d+} \operatorname{sign}\left(v_{r e l}\right) & \text { if } F_{s t}>F_{d+}, \operatorname{sign}\left(v_{r e l} v_{r e l}\right)>0, \\ F_{d-} \operatorname{sign}\left(v_{r e l}\right) & \text { if } \operatorname{sign}\left(v_{r e l} v_{r e l}\right)<0,\end{cases}
$$

with

$$
\begin{gathered}
F_{s t}=\frac{1}{2} k_{s} \frac{v^{2}}{\left|v_{r e l}\right|}-F_{0}, \\
F_{d+}=F_{C}+\left(F_{S}(v)-F_{C}\right)\left(g\left(v_{r e l}, v_{r e l}^{\cdot}\right)+f_{r}\left(x, v_{r e l}\right)\right), \\
F_{d-}=F_{C}-\left(F_{S}(v)-F_{C}\right)\left(g\left(v_{r e l}, v_{r e l}\right)+f_{r}\left(x, v_{r e l}\right)\right),
\end{gathered}
$$

where $F_{s t}$ is the friction for the sticking phase, $F_{d+}$ and $F_{d-}$ represent the friction force in acceleration and deceleration, respectively, $k_{s}$ is the contact stiffness, $F_{0}$ denotes the initial value for sticking force, $f_{r}\left(x, v_{r e l}\right)$ is a stochastic function and $g\left(v_{r e l}, v_{r e l}^{\cdot}\right)$ expresses a function to model the Stribeck curve. The graph in Fig. 2.6 represents a generic curve of this model.

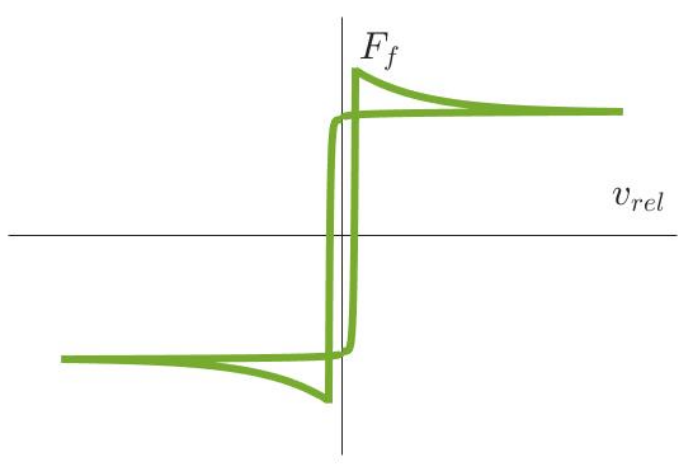

Figure 2.6: Representation of the Wojewoda friction model with hysteresis.

\section{6}

\section{Experimental studies}

Over the years, researchers developed many experimental rigs for drill string dynamics investigations. In [42] the first experimental tests lead the authors to develop a numerical bit dynamics model to predict the PDC drill bit performance under conditions of a full-scale drilling test. In [43], the authors 
present a mathematical method for the computation of torsional resonance frequencies in a drill string, comparing the theory with the data recorded in a $1000 \mathrm{~m}$ deep, nearly vertical well.

Mihajlović et al. (2004) [44] use an experimental drill string setup to observe torsional vibrations with and without stick-slip. They propose a discontinuous static friction model and compare numerical and experimental steady-state responses of the drill string system. They also compare the bifurcation diagrams to validate the proposed model.

In his Ph.D. thesis, Kapitaniak (2012) [45] worked with an experimental rig with real industrial drill bits and rock samples. He used TOB speed curves to identify frictional and cutting components of the bit-rock interaction. He modeled his system using the finite element method. He identified the combinations of the nonlinear control parameters: WOB and top angular speed, where the most dangerous phenomenon, stick-slip, occurs. This thesis also investigates the initial conditions and the friction between the BHA and the borehole influence in the system response.

Real et al. (2018) [46] used a laboratory test rig to reproduce the phenomena observed in deepwater drilling. They extracted one stick-slip cycle and analyzed it. They also presented other cycles to show the experimental data variability. Last, they proposed a hysteric model for the bit-rock interaction.

\section{7 Summary}

There are several works published in drilling system dynamics with great discussions on friction models. This scientific review of the literature presents simple and complex models to study drill string oscillations. It also reviews numerical and experimental works.

A large number of dry friction models is used to describe the interaction between the drill bit and the rock. The non-smooth friction characteristic is an obstacle to modeling friction. However, an adequate friction model is necessary for a reliable analysis of systems under friction dynamics. Therefore, the experimental and numerical analysis of this dissertation focused on various phenomena characterizing the dry friction processes, including hysteretic effects. The scientific review on friction-induced vibrations and friction models enabled the formulation of the friction model proposed in this dissertation. 


\section{Friction models and stick-slip}

\section{1}

Introduction

Simple mechanical systems are useful to examine the primary vibration modes of drill strings separately. The low degree-of-freedom lumped parameter models for axial vibrations, whirling or torsional vibrations are the most common models. This chapter aims to observe the influence of the different friction force models on the dynamic response of simple systems that experience stick-slip oscillations.

This chapter compares three friction models in the literature, the Coulomb, the modified Columb, and the Stribeck friction models. For this purpose, we use three application examples, the traditional block-on-belt system, the torsional pendulum, and a locomotive system. The block-on-belt system is extensively used to study dry friction stick-slip oscillations ([47],[48],[49]). Hence, this chapter gives a brief review of the block-on-belt. The torsional pendulum is a typical representation of a drill string, its equation of motion with angular coordinates is equivalent to the equation of motion of the block-on-belt system with linear coordinates.

Although these simple models fail in reproducing the complex dynamics of the drilling system fully, they allow the investigation of the main characteristics of the stick-slip phenomenon.

\section{2}

\section{The block-on-belt system}

The block-on-belt system is a simple oscillator consisting of a mass $\mathrm{m}$, supported by a moving belt, connected to a fixed support by a linear elastic spring and by a linear damper (Fig. 3.1). The belt imposes a friction force to the mass due to the dry contact between them. The belt moves at a constant speed $v_{b}$, introducing energy into the system, which it is transferred to the mass by the static friction force. If the friction force is enough to move the block with the belt, the spring will start to accumulate elastic potential energy. Then, when the spring force achieves a value greater than the maximum friction force, 
the block will start sliding. The structural damping continuously dissipates energy. Furthermore, the dynamic friction force may either introduce energy into the system if it has the same sign as the velocity of the block or dissipates energy if the signs of the friction force and the velocity of the block are different.

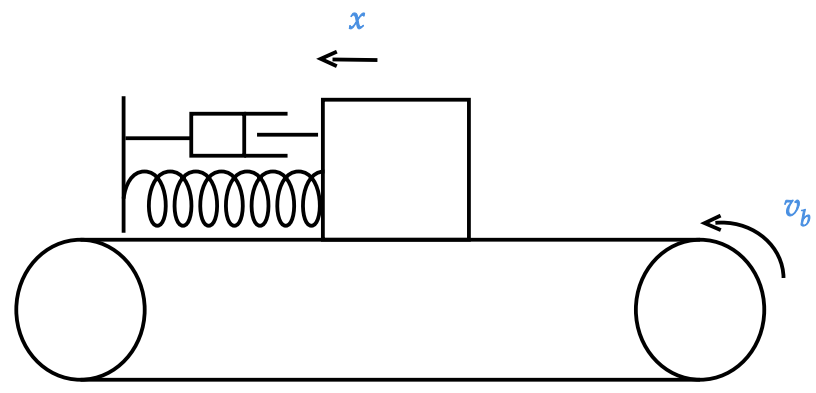

Figure 3.1: Block-on-belt system.

If the initial condition is given as a slip condition, the governing equation of motion of the system, initially, is

$$
m \ddot{x}+d \dot{x}+k x=F_{f},
$$

where $x$ is the block displacement from the position in which the spring assumes its natural length, $d$ is the damping coefficient, $k$ is the stiffness of the spring and $F_{f}$ the friction force which depends on the relative velocity between the block and the belt. The overdot denotes differentiation concerning time.

When the block is moving together with the belt $\left(\dot{x}=v_{b}\right)$ the forces in the system are in equilibrium. Hence during this stick phase the static friction force $F_{f}$ varies according to the equation below.

$$
d \dot{x}+k x=F_{f} .
$$

This relationship will remain until the spring and damping forces overcome the maximum friction force. The static friction varies in the interval:

$$
-F_{f, \max } \leq F_{f} \geq F_{f, \max }
$$

where $F_{f, \max }=\mu_{s} F_{N}$ is the maximum static friction force.

Previous equations are simplified by introducing the following dimensionless variables:

$$
\tau=\omega t, X=\frac{k}{F_{f, \max }} x,
$$

then the non-dimensional equation is 


$$
X^{\prime \prime}+2 \zeta X^{\prime}+X=F_{\text {fric }} .
$$

The upper prime now indicates differentiation with respect to the dimensionless time $\tau, \omega=\sqrt{k / m}$ is the undamped frequency, $\zeta=d / 2 m \omega$ is the dimensionless damping, and $F_{\text {fric }}=F_{f} / F_{f, \max }$.

\section{3}

\section{1-DOF torsional pendulum}

The torsional pendulum being rotated at the top (Fig. 3.2) is a simple representation of a drill string. The top rotation represents the top drive, and the friction torque applied to the bottom executes the torque-on-bit function. In this simple model, we assume that the BHA is the inertia at the bottom, and the drill pipes are the torsional spring. There is also viscous damping in the system.

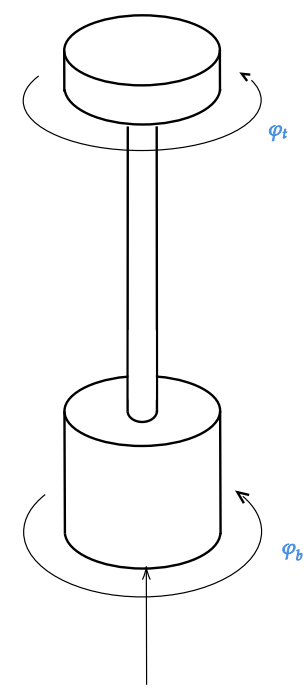

Figure 3.2: Torsional pendulum with friction torque at the bottom.

The torsional pendulum governing equation of motion is equivalent to the aforementioned block-on-belt system equation of motion. The main differences are the use of angular coordinates instead of linear and the reference of the velocity since the energy input is due to rotational motion. The equation of motion for the torsional pendulum system is

$$
J_{0} \ddot{\varphi}_{b}+d_{0} \dot{\varphi}_{b}+k_{0}\left(\varphi_{b}-\varphi_{t}\right)=T_{f},
$$


where $J_{0}$ is the equivalent BHA moment of inertia, $d_{0}$ is the equivalent damping coefficient along the drill string, $k_{0}$ is the equivalent drill pipes torsional stiffness, $\varphi_{b}$ is the angular position of the drill bit, $\varphi_{t}$ is the rotary table angular position, $T_{f}$ is the torque-on-bit and overdot denotes differentiation over time. Using $\varphi=\varphi_{b}-\varphi_{t}$, equation $3-5$ becomes

$$
J_{0} \ddot{\varphi}_{b}+d_{0} \dot{\varphi}_{b}+k_{0}(\varphi)=T_{f} .
$$

Introducing the dimensionless variables:

$$
\tau=\omega_{0} t, \Phi=\frac{k_{0}}{T_{f, \max }} \varphi
$$

we get the non-dimensionalised equation:

$$
\Phi_{b}^{\prime \prime}+2 \zeta_{0} \Phi_{b}^{\prime}+\Phi=T_{\text {fric }}
$$

where $\zeta_{0}=d_{0} / 2 J_{0} \omega_{0}$ is the dimensionless damping, $\omega_{0}=\sqrt{k_{0} / J_{0}}$ is the undamped frequency, and $T_{\text {fric }}=T_{f} / T_{f, \max }$.

For the analysis, we first considered the angular velocity of the rotary table to be constant. Nonetheless, field data shows that the rotary table velocity oscillates around the nominal velocity when the bit is in torsional oscillations. Then, in a second analysis, we considered that real systems excitation results in a harmonic motion of the rotary table velocity, in the form:

$$
\Phi_{t}^{\prime}=B+A \cos \omega_{e} \tau
$$

where $A$ and $\omega_{e}$ are the amplitude and frequency of the oscillations, respectively.

\section{4}

The locomotive system

Figure 3.3 presents the locomotive system to be analyzed in this section. The analysis of this system was the first step taken to understand the problem of the experimental rig since the linear coordinate system simplifies the phenomenon investigation. The system consists of three blocks, with masses $m_{1}, m_{2}$, and $m_{3}$, coupled via springs with stiffnesses $k_{1}$ and $k_{2}$ and dampers with coefficients $d_{1}$ and $d_{2}$.

The block with mass $m_{3}$ represents the rotary table and is excited by the sinusoidal $F_{3}$ force. Spring $k_{2}$ connects the blocks $m_{3}$ and $m_{2}$, which stands for the drill string components above the drill bit assembly. The block with mass $m_{1}$ represents the drill bit and is subjected to the friction force $F f_{1}$, an adaptation of the interactions between the drill bit and the rock surface. The system governing equations of motion are 


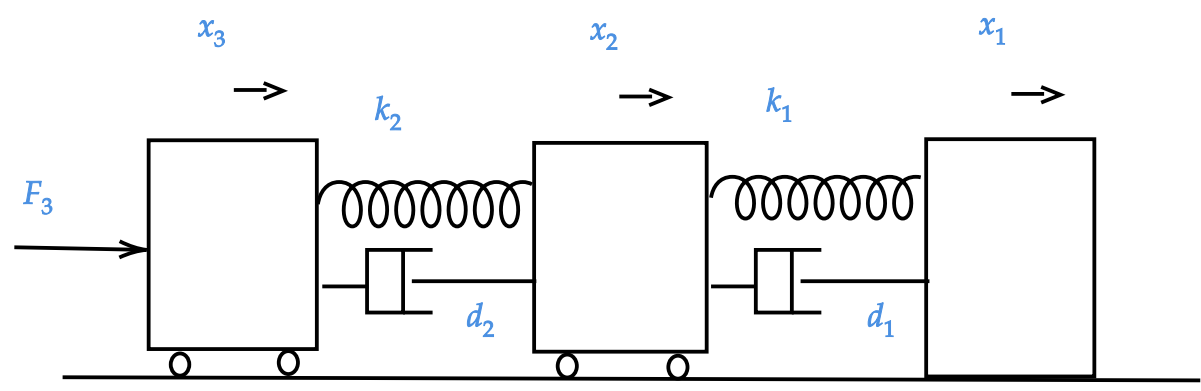

Figure 3.3: Locomotive system.

$$
\begin{array}{r}
m_{1} \ddot{x}_{1}+d_{1}\left(\dot{x}_{1}-\dot{x}_{2}\right)+k_{1}\left(x_{1}-x_{2}\right)=-F_{f, 1}-k_{1} l_{1}, \\
m_{2} \ddot{x}_{2}+d_{1}\left(\dot{x}_{2}-\dot{x}_{1}\right)+d_{2}\left(\dot{x}_{2}-\dot{x}_{3}\right)+k_{1}\left(x_{2}-x_{1}\right)+k_{2}\left(x_{2}-x_{3}\right)=k_{1} l_{1}-k_{2} l_{2}, \\
m_{3} \ddot{x}_{3}+d_{2}\left(\dot{x}_{3}-\dot{x}_{2}\right)+k_{2}\left(x_{3}-x_{2}\right)=F_{3}+k_{2} l_{2},
\end{array}
$$

$l_{1}$ and $l_{2}$ are the characterist length of spring $k_{1}$ and $k_{2}$, respectively. The sinusoidal $F_{3}$ force has the form:

$$
F_{3}=A_{f} \sin \left(\omega_{f} t\right)+B_{f}
$$

In the above equation, $A_{f}$ is the $F_{3}$ amplitude of oscillation, $B_{f}$ is the static force, and $\omega_{f}$ is the oscillation frequency of $F_{3}$.

Adopting the following dimensionless variables:

$$
\begin{gathered}
\tau=\omega t, X=\frac{k_{1}}{F_{f, \max }} x, L=\frac{k_{1}}{F_{f, \text { max }}} l, \\
M_{12}=\frac{m 1}{m 2}, M_{13}=\frac{m 1}{m 3}, M_{23}=\frac{m 2}{m 3}, q=\frac{\omega_{1}}{\omega_{2}},
\end{gathered}
$$

with $\omega_{1}=\sqrt{k_{1} / m_{1}}$ and $\omega_{2}=\sqrt{k_{2} / m_{2}}$. We obtain the set of non-dimensionalised governing equations:

$$
\begin{array}{r}
X_{1}^{\prime \prime}+2 \zeta_{1}\left(X_{1}^{\prime}-X_{2}^{\prime}\right)+\left(X_{1}-X_{2}\right)=-F_{f r i c, 1}-L_{1}, \\
X_{2}+2 \zeta_{1} M_{12}\left(X_{2}^{\prime}-X_{1}^{\prime}\right)+2 \zeta_{2} q\left(X_{2}^{\prime}-X_{3}^{\prime}\right)+M_{12}\left(X_{2}-X_{1}\right)+q^{2}\left(X_{2}-X_{3}\right) \\
=M_{12} L_{1}-q^{2} L_{2}, \\
X_{3}^{\prime \prime}+2 \zeta_{2} q M_{23}\left(X_{3}^{\prime}-X_{2}^{\prime}\right)+q^{2} M_{23}\left(X_{3}-X_{2}\right)=M_{13} F_{i n, 3}+q^{2} M_{23} L_{2} .
\end{array}
$$


For simplicity, we rewrite the above set of equations in the matrix form:

$$
\begin{array}{r}
{\left[\begin{array}{lll}
1 & 0 & 0 \\
0 & 1 & 0 \\
0 & 0 & 1
\end{array}\right]\left[\begin{array}{l}
X_{1}^{\prime \prime} \\
X_{2}^{\prime \prime} \\
X_{3}^{\prime \prime}
\end{array}\right]+\left[\begin{array}{ccc}
2 \zeta_{1} & -2 \zeta_{1} & 0 \\
-2 \zeta_{1} M_{12} & 2 \zeta_{1} M_{12}+2 \zeta_{2} q & -2 \zeta_{2} q \\
0 & -2 \zeta_{2} q M_{23} & 2 \zeta_{2} q M_{23}
\end{array}\right]\left[\begin{array}{l}
X_{1}^{\prime} \\
X_{2}^{\prime} \\
X_{3}^{\prime}
\end{array}\right]} \\
+\left[\begin{array}{ccc}
1 & -1 & 0 \\
-M_{12} & M_{12}+q^{2} & -q^{2} \\
0 & -q^{2} M_{23} & q^{2} M_{23}
\end{array}\right]\left[\begin{array}{l}
X_{1} \\
X_{2} \\
X_{3}
\end{array}\right]=\left[\begin{array}{c}
-F_{\text {fric }, 1}-L_{1} \\
M_{12} L_{1}-q^{2} L_{2} \\
M_{13} F_{\text {in }, 3}+q^{2} M_{23} L_{2}
\end{array}\right]
\end{array}
$$

\section{5}

\section{Numerical results}

Our first numerical application was the block-on-belt system detailed in section 3.2. The mechanical and friction parameters adopted are in Table 3.1. We simulated the system dynamics using the MATLAB ode15s with a time step of $10^{-6}$ and a relative error tolerance of $10^{-8}$.

Table 3.1: Simulation parameters for the block-on-belt system

\begin{tabular}{cc}
\hline Parameter & Value \\
\hline$\zeta$ & 0 \\
$F_{f, d}$ & 0.98 \\
$F_{f, s}$ & 1.47 \\
$V_{b}$ & 0.096 \\
$V_{s}$ & 0.005 \\
\hline
\end{tabular}

Initially, the block has zero velocity and displacement. Figure 3.4 presents the main results from the simulations with three different friction models Coulomb model, Coulomb with stiction model and Stribeck model.

The simulation with the Coulomb model presents an adhesion phase associated with the initial conditions. In other words, the Coulomb friction force magnitude is higher than the spring force at the beginning of the simulation, until $\tau=10.5$. After this, the block behaves as an undamped spring-mass system. In the results of the two other models, we can observe well-defined stick and slip phases. Figure 3.4(b) presents a sequence of stick and slip phases; during the former, the block velocity is equal to the belt velocity $\left(X^{\prime}=V_{b}\right)$, and during the latter, the block velocity is always smaller than the belt velocity $\left(X^{\prime}<V_{b}\right)$. Despite the similar system responses presented by modified Coulomb and Stribeck friction models, with a better look at the velocity response (Fig. $3.4(\mathrm{c})$ ), it is possible to notice that the slip phase lasts longer in the simulation with Stribeck model. 


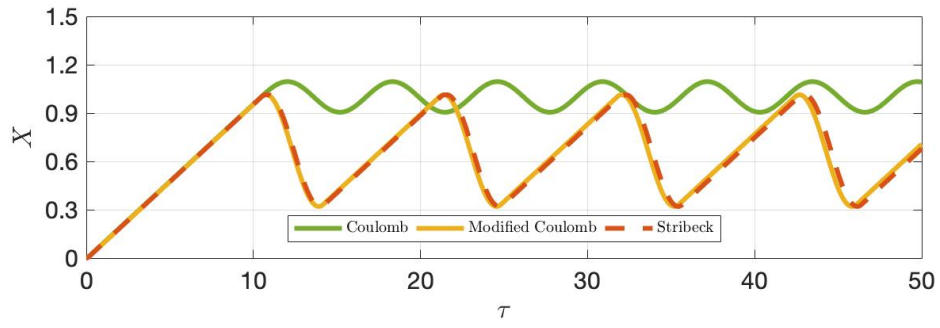

3.4(a): Block displacement

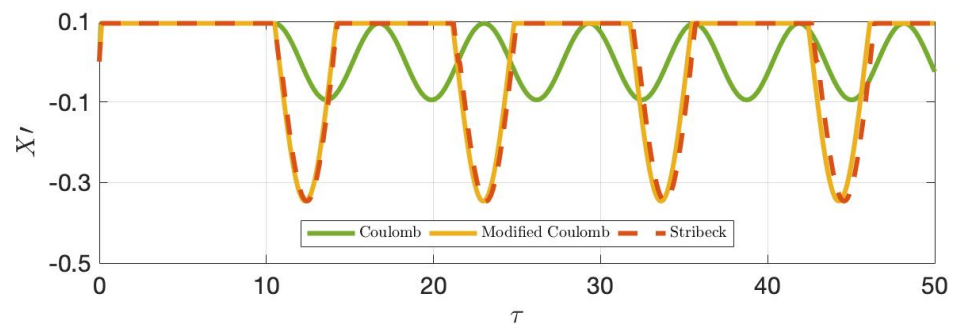

3.4(b): Block velocity

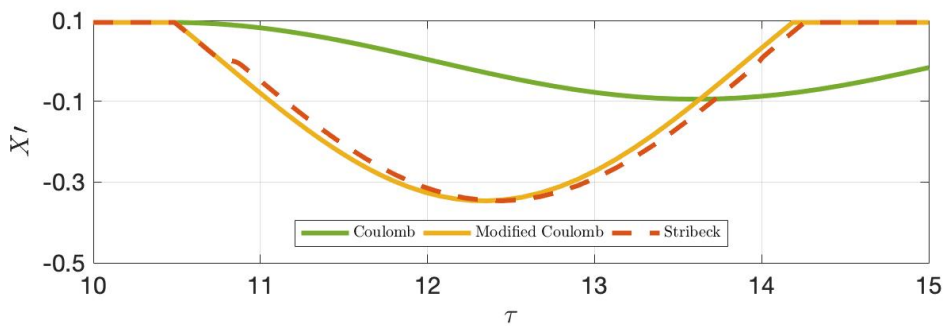

3.4(c): Block velocity

Figure 3.4: Results from block-on-belt system simulations.

Likewise, Fig. 3.5 and 3.6 present the main results of the numerical simulations of the torsional pendulum system with the parameters presented in Table 3.2. For these simulations, we used the MATLAB ode23s with a time step of $10^{-5}$ and a relative error tolerance of $10^{-5}$. Figure 3.5 corresponds to the case of constant top angular velocity and Fig. 3.6 corresponds to the case of sinusoidal top angular velocity.

From Fig. 3.5, we see that, in this simulation, the Coulomb model does not capture the stick-slip phenomenon once the inertia velocity is never constant and equals to zero. Moreover, the modified Coulomb model reaches the static friction point only after the first peak, and it does not stick again. For these system conditions, Stribeck model was the only friction model capable of reproducing stick-slip oscillations.

As expected, in these simple simulations, we obtain different responses when the driven velocity is not constant (Fig. 3.6). These different behaviors can easily be understood from simple energy considerations [50]. Under this 
Table 3.2: Simulation parameters for the tosional pendulum system

\begin{tabular}{cc}
\hline Parameter & Value \\
\hline$\zeta_{0}$ & 0 \\
$T_{f, d}$ & 0.98 \\
$T_{f, s}$ & 1.47 \\
$\Phi^{\prime}$ & 0.096 \\
$\omega_{s}$ & 0.005 \\
$A$ & 0.009 \\
$B$ & 0.0096 \\
$\omega_{e}$ & 1 \\
\hline
\end{tabular}

condition, the system exhibits a stick-slip response for the three adopted friction models. With the Columb model, the system experiences only torsional vibrations without stick-slip until $\tau=36.4$ and stick-slip phenomenon after this. The other two models capture the phenomenon from the beginning of the simulation. Furthermore, the Coulomb model results in velocity oscillations with a smaller amplitude than the modified Coulomb and Stribeck models.

Lastly, we performed the same comparison for the locomotive system detailed in section 3.4 with the parameters presented in Table 3.3. For these simulations, we used the MATLAB ode23s with a time step of $10^{-5}$ and a relative error tolerance of $10^{-5}$. Figure 3.7 corresponds to the case where the applied force, $F_{3}$, is constant and Fig. 3.8 corresponds to the case where the applied force $F_{3}$ is harmonic.

Table 3.3: Simulation parameters for the locomotive system

\begin{tabular}{cccc}
\hline Parameter & Value & Parameter & Value \\
\hline$\zeta_{1}$ & 0.075 & $F_{f, d}$ & 0.98 \\
$\zeta_{2}$ & 0.075 & $F_{f, s}$ & 1.47 \\
$M_{12}$ & 1 & $F_{3}$ (case 1$)$ & 1.2 \\
$M_{13}$ & 1 & $V_{s}$ & 0.025 \\
$M_{23}$ & 1 & $A$ & 0.6 \\
$L_{1}$ & 0.3 & $B$ & 1.1 \\
$L_{2}$ & 0.3 & $\omega_{e}$ & 1 \\
$q$ & 1 & & \\
\hline
\end{tabular}

None of the friction models is capable of inducing stick-slip oscillations when $F_{3}$ is constant (Fig. 3.7). Different from what happens when a harmonic force is applied to $m_{3}$. Figure 3.8 shows that $m_{1}$ sticks and slips in the three simulations. It is important to mention that the amplitude of velocity oscillations for the simulation with Coulomb increases with time while modified Coulomb and Stribeck have similar responses. 


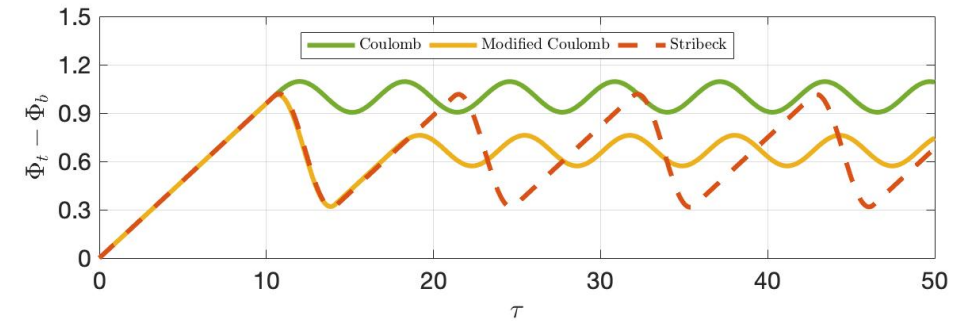

3.5(a): Pendulum angular displacement

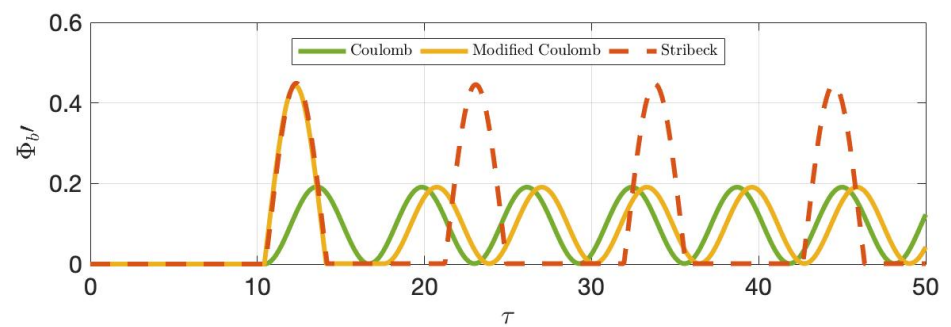

3.5(b): Pendulum angular velocity

Figure 3.5: Results from torsional pendulum system with constant top velocity simulations.

\section{6}

\section{Conclusion}

A large number of dry friction models is used to describe the interaction between the drill bit and the rock. Therefore, this chapter compared three dry friction models - Coulomb, modified Coulomb, and Stribeck - to determine the friction function complexity influence on the system response.

We used three application examples, namely the block-on-belt, the torsional pendulum, and the locomotive system. The block-on-belt system is a classical model to study stick-slip oscillations. From this first example, we observed that the main difference between friction models is the ability to capture the stick-slip motion. The torsional pendulum is a simplified model for drill strings. This system is very similar to the classical block-on-belt system utilized to study stick-slip oscillations on a linear oscillator. Lastly, we proposed the locomotive system as another simplification of the drilling system.

We performed numerical simulations to observe the dynamical responses of the systems. From the simple analysis of this chapter, we conclude that the friction force model can significantly influence the simulated dynamic response of mechanical systems with friction. 


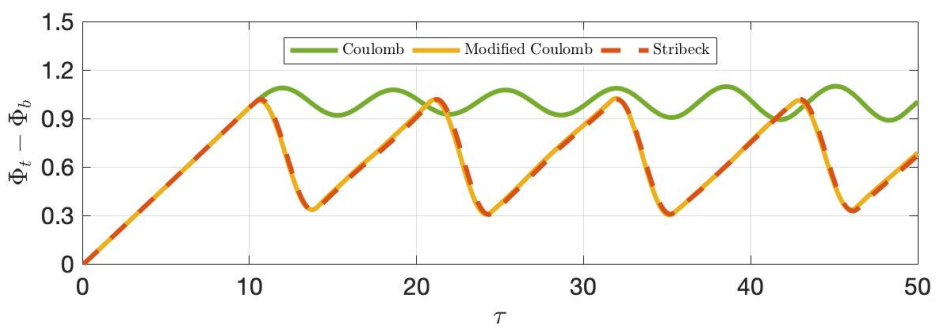

3.6(a): Pendulum angular displacement

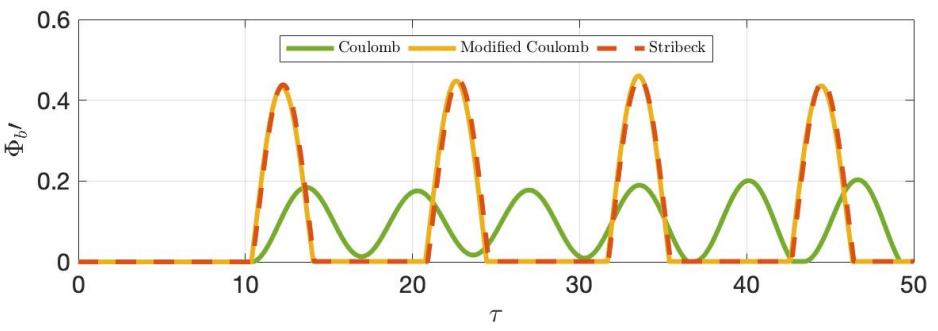

3.6(b): Pendulum angular velocity

Figure 3.6: Results from torsional pendulum system with sinusoidal top velocity simulations.

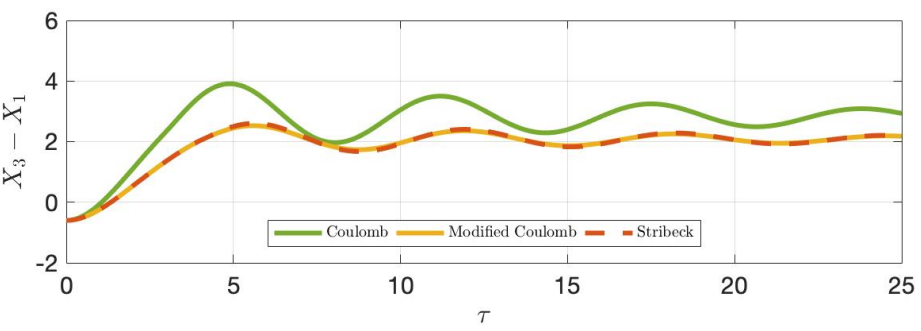

3.7(a): Mass $m_{1}$ relative displacement

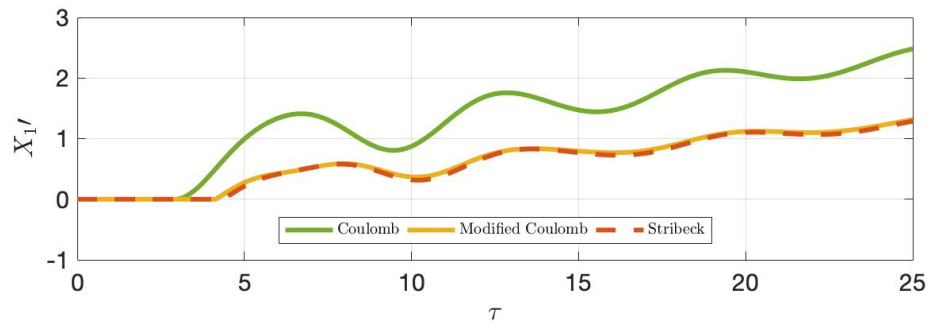

3.7(b): Mass $m_{1}$ velocity

Figure 3.7: Results from locomotive system with constant drive force simulations. 


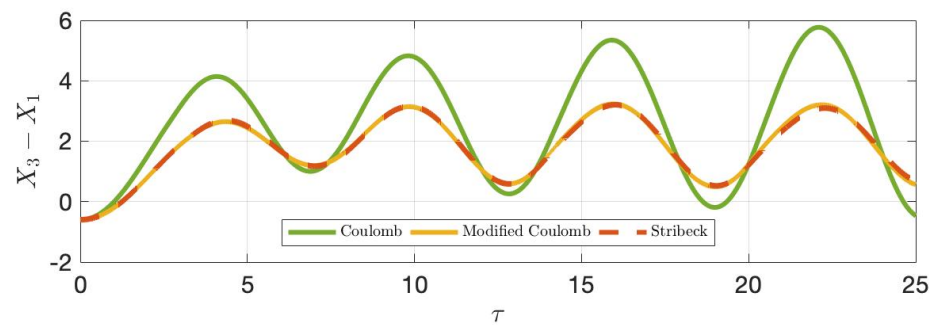

3.8(a): Mass $m_{1}$ relative displacement

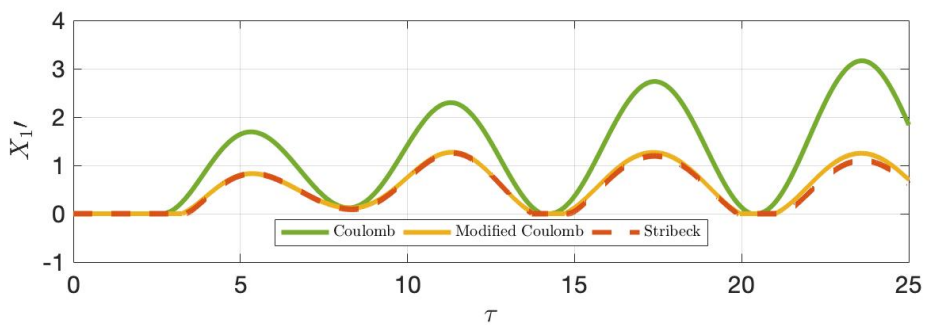

3.8(b): Mass $m_{1}$ velocity

Figure 3.8: Results from locomotive system with harmonic drive force simulations. 


\section{Experimental setup}

\section{1}

Introduction

This chapter describes the experimental test rig, developed at Dynamic and Vibration Laboratory of Pontifícia Universidade Católica do Rio de Janeiro. The test rig is capable of replicating torsional vibrations observed during the drilling process. The second section introduces the main components of the test rig and sensors, as well as the rig operational description. The third section is concerned with the mathematical model adopted in this dissertation analysis. Next, we explain the mechanical system parameters identification, which includes the rotors moments of inertia, and stiffnesses and dampings of the flexible shaft. Lastly, we perform qualitative and quantitative comparisons between experimental and numerical data to ensure the mathematical representation of the rig. We utilize LabView and MatLab for data acquisition and data processing along with this research.

\section{2}

General overview of the test rig

The experimental apparatus utilized in this dissertation analysis was designed and constructed at the Dynamic and Vibration Laboratory of Pontifícia Universidade Católica do Rio de Janeiro [21]. This slender experimental structure was designed to simulate a drill string in a reduced scale, providing comprehensive research of the undesired torsional vibrations associated with the drilling process. The rig was intended to isolate the torsional mode from lateral and axial modes of vibration.

Figure 4.1 shows the schematic of the experimental rig, it presents the main components of the setup. The rig is a horizontal apparatus composed of an ENGEL GNM5480-G6.1 DC motor, a planetary gearbox with a reduction ratio of 8:1 coupled to the DC motor, two solid discs, D1 and D2, and two low-stiffness shafts, that transmits the rotation from the DC-motor to the discs. The discs are free to rotate, and bearings constrain their lateral motion. We may independently apply resistive torques to the discs. The picture of the test 
is shown in Fig. 4.2.

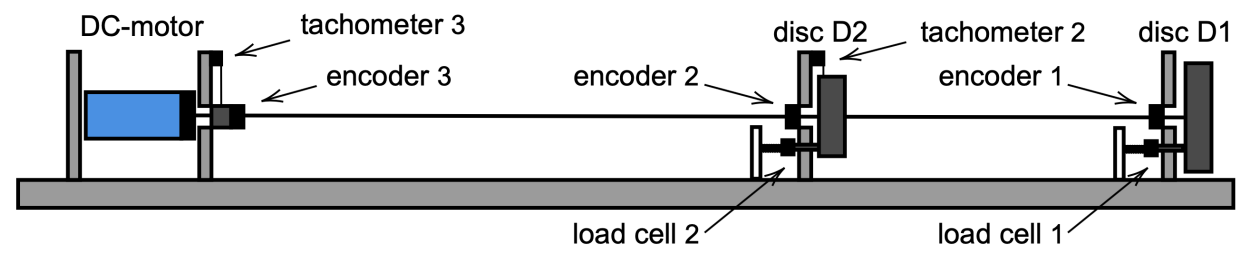

Figure 4.1: Schematic diagram of the experimental rig. The main components of the system are: DC-motor, discs D1 and D2, flexible shafts, brake devices and sensors.

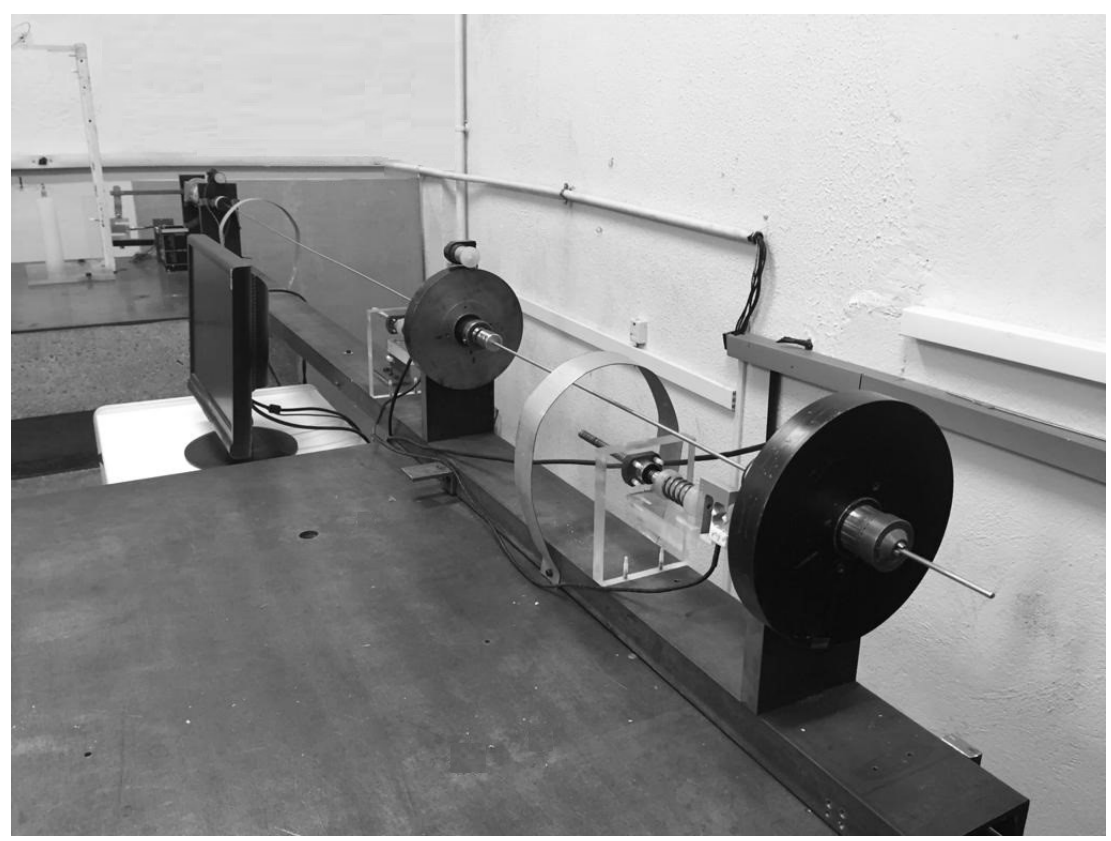

Figure 4.2: Experimental rig.

There are two brake devices in the system to induce friction torque, placed on discs D1 and D2. They consist of pins that pass through the bearing support and come in contact with the discs. The dry contact between the pins and the discs produces friction torque, leading the system to experience torsional vibrations and stick-slip. Figure 4.3 shows the brake device placed on the discs. 


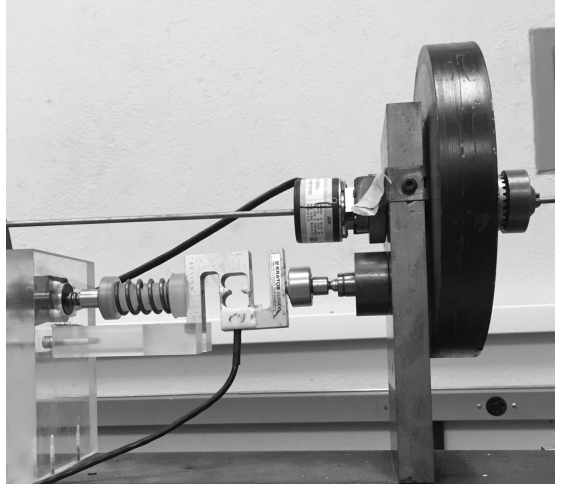

4.3(a): Disc D1

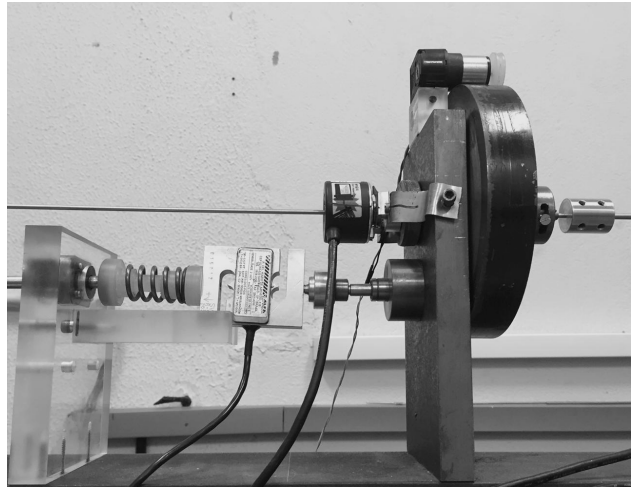

4.3(b): Disc D2

Figure 4.3: Brake devices equipped with a load cells.

The angular displacement measurements of the discs and the motor are taken using three LS Mecapion H40-8-1000VL encoders. The encoders are of optical quadrature type and have a resolution of 1000 ticks per revolution. Two AVAGO tachometers measure the motor and the intermediary disc angular velocities. Disc D1 angular displacement is differentiated to obtain this disc angular velocity. Load cells S10 R9 255 from Kratos equipamentos and SV50 R-5 from Alpha Instrumentos measure the normal force on discs D1 and D2, respectively (see Fig. 4.3).

The National Instruments cDAQ- 9174 USB with four slots performs the data acquisition and recording, with a sampling time of $10 \mathrm{~ms}$ (milliseconds)(Fig. 4.4). It has a connection with LabView for data real-time visualization and saving. Once we save the data, we can easily export them to Matlab for post-processing.

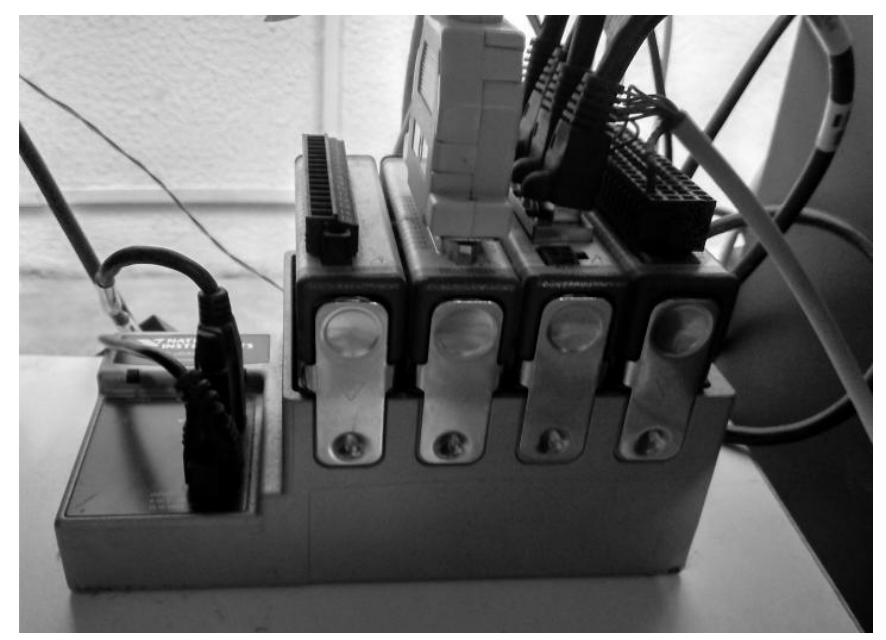

Figure 4.4: Acquisition device [22]. 


\section{3}

\section{Dynamical model}

The drill string setup is an electromechanical system. We attain a simple model of the system dynamics by assuming that the experimental rig behaves as a torsional pendulum. Figure 4.5 illustrates the dynamical rig model.

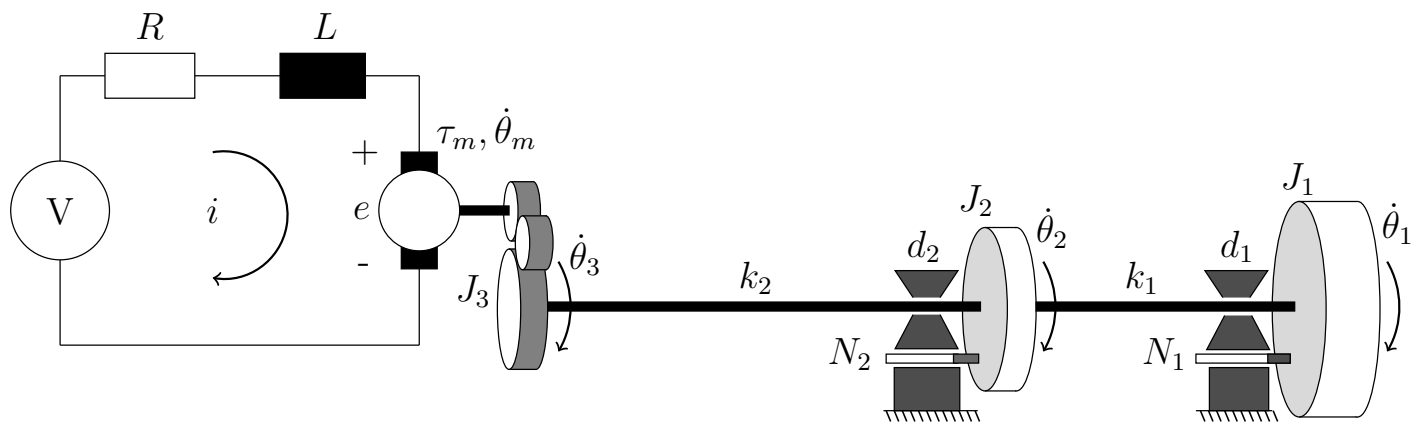

Figure 4.5: Schematic representation of the test rig (adapted from [22]).

The mechanical subsystem is composed of the two discs, D1 and D2, and the shafts connecting them to the DC motor. Discs D1 and D2 have moments of inertia $J_{1}$ and $J_{2}$, respectively. The shafts linear stiffness are denoted by $k_{1}$ and $k_{2}$, and the linear damping are denoted by $c_{1}$ and $c_{2}$. The parameters $k_{1}$ and $c_{1}$ correspond to stiffness and damping between the disc D1 and the disc $\mathrm{D} 2$, while $k_{2}$ and $c_{2}$, correspond to stiffness and damping between the disc D2 and the motor. Thus, the system mathematical expression is

$$
\begin{array}{r}
J_{1} \ddot{\theta}_{1}+c_{1}\left(\dot{\theta}_{1}-\dot{\theta}_{2}\right)+k_{1}\left(\theta_{1}-\theta_{2}\right)=-T_{f 1}, \\
J_{2} \ddot{\theta}_{2}+c_{1}\left(\dot{\theta}_{2}-\dot{\theta}_{1}\right)+c_{2}\left(\dot{\theta}_{2}-\dot{\theta}_{3}\right)+k_{1}\left(\theta_{2}-\theta_{1}\right)+k_{2}\left(\theta_{2}-\theta_{3}\right)=0, \\
c_{2}\left(\dot{\theta}_{3}-\dot{\theta}_{2}\right)+k_{2}\left(\theta_{3}-\theta_{2}\right)=\tau_{s},
\end{array}
$$

where $\theta, \dot{\theta}$, and $\ddot{\theta}$ are angular displacement, angular velocity and angular acceleration, respectively. $\tau_{s}$ is the torque transmitted to the mechanical subsystem.

The electric subsystem is modeled as a voltage source connected in series with a resistor and an inductor, providing torque $\tau_{m}$. The angular velocity $\dot{\theta_{m}}$ imposed by $\tau_{m}$ is eight times greater than the angular velocity $\dot{\theta}_{3}$ transmitted to the mechanical subsystem due to the transmission factor $\eta=8: 1$. Mathematically, the electric subsystem may be expressed as:

$$
\begin{array}{r}
L \frac{d i}{d t}=u-R i-K_{E} \dot{\theta}_{m}, \\
\tau_{m}=K_{T} i-C_{m} \dot{\theta}_{m}-T_{f m}-J_{m} \ddot{\theta}_{m},
\end{array}
$$


where $i$ denotes electric current of the DC-motor. $L$ and $R$ are the armature inductance and resistance, respectively. The angular velocity $\dot{\theta_{m}}$ is the velocity of the inertia of the DC-motor $J_{m}$. $C_{m}$ is the speed regulation; $K_{T}$, the constant torque of the motor; $K_{E}$, the voltage constant; and $T_{f m}$, the internal friction torque. The input voltage is denoted by $u$.

The relations between the mechanical and electrical subsystems are given by the following equations.

$$
\begin{gathered}
\tau_{s}=\eta \tau_{m}, \\
\dot{\theta_{m}}=\eta \dot{\theta_{3}} .
\end{gathered}
$$

The coupling of the mechanical and electrical systems results in the following set of equations:

$$
\begin{array}{r}
J_{1} \ddot{\theta}_{1}+c_{1}\left(\dot{\theta}_{1}-\dot{\theta}_{2}\right)+k_{1}\left(\theta_{1}-\theta_{2}\right)=-T_{f 1}, \\
J_{2} \ddot{\theta}_{2}+c_{1}\left(\dot{\theta}_{2}-\dot{\theta}_{1}\right)+c_{2}\left(\dot{\theta}_{2}-\dot{\theta}_{3}\right)+k_{1}\left(\theta_{2}-\theta_{1}\right)+k_{2}\left(\theta_{2}-\theta_{3}\right)=0, \\
c_{2}\left(\dot{\theta}_{3}-\dot{\theta}_{2}\right)+k_{2}\left(\theta_{3}-\theta_{2}\right)=\eta\left(K_{T} i-C_{m} \eta \dot{\theta}_{3}-T_{f m}-J_{m} \eta \ddot{\theta}_{3},\right. \\
L \frac{d i}{d t}+R i+K_{E} \eta \dot{\theta}_{3}=u .
\end{array}
$$

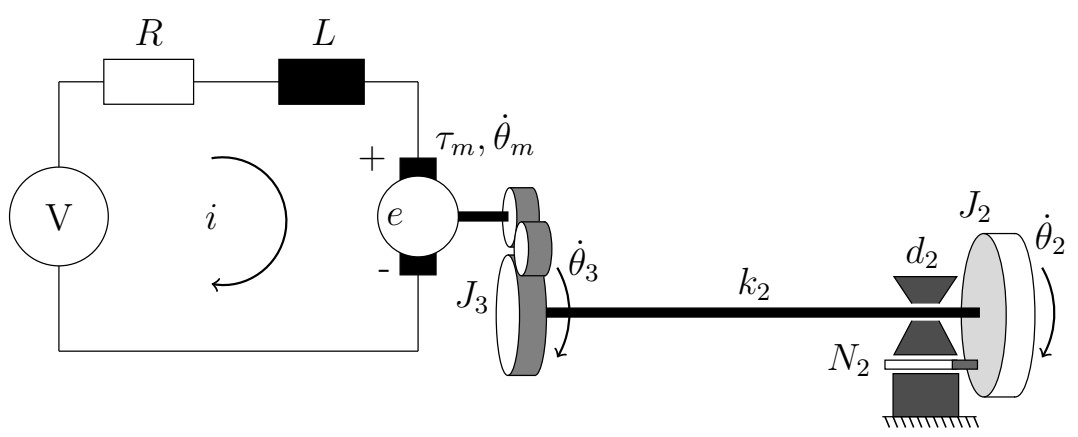

Figure 4.6: Schematic representation of the reduced test rig (adapted from [22]).

A reduced version of the test rig depicted in Fig. 4.2 is investigated in this dissertation. This reduced rig comprises the intermediary disc D2, the DC-motor and the shaft connecting them. Its dynamical model is in Fig. 4.6. The reduced system may be mathematically expressed by

$$
\begin{array}{r}
J_{2} \ddot{\theta}_{2}+c_{1}\left(\dot{\theta}_{2}-\dot{\theta}_{1}\right)++k_{1}\left(\theta_{2}-\theta_{1}\right)=T_{f 2}, \\
c_{2}\left(\dot{\theta}_{3}-\dot{\theta}_{2}\right)+k_{2}\left(\theta_{3}-\theta_{2}\right)=\eta\left(K_{T} i-C_{m} \eta \dot{\theta}_{3}-T_{f m}-J_{m} \eta \ddot{\theta}_{3},\right. \\
L \frac{d i}{d t}+R i+K_{E} \eta \dot{\theta}_{3}=u .
\end{array}
$$




\section{4}

\section{Physical parameters identification}

Good agreements between experimental observations and numerical predictions require accurate estimation of physical parameters of the experimental apparatus. This section details the mechanical parameter identification and presents the cataloged electrical parameters.

For the moments of inertia estimation, we considered the discs rigid bodies and weighed them. Then, the following relation was applied.

$$
J_{i}=\frac{m_{i} r_{i}^{2}}{2},
$$

where $m_{i}$ and $r_{i}$ are mass and radius of the discs, respectively. Table 4.1 presents the measured parameters and the calculated moments of inertia.

\begin{tabular}{cccc} 
& \multicolumn{3}{c}{ Table 4.1: Moments of inertia } \\
\hline disc & $m_{i}[\mathrm{~kg}]$ & $r_{i}[\mathrm{~m}]$ & $J_{i}\left[\mathrm{~kg} \cdot \mathrm{m}^{2}\right]\left(10^{-4}\right)$ \\
\hline 1 & 6.40 & 0.095 & 288 \\
2 & 4.56 & 0.081 & 149 \\
\hline
\end{tabular}

Flexible shafts are used to simulate the mechanical characteristics of slender structures like drills strings. In our study, we use two different flexible shafts, connecting the two discs to the DC-motor.

We took two different approaches in order to determine the torsional stiffnesses and viscous dampings of the shafts. First, we performed a static test. This initial test consisted of applying a known weight tangentially to the discs and saving the measured angular displacement. We repeated this procedure for different weight values. We performed these tests so that the values of angular displacement observed in the dynamic tests were within the range of static test values.

We calculated the stiffnesses $k_{1}$ and $k_{2}$ by the Hooke's law:

$$
T=w g r=k \delta,
$$

where $g=9.81 \mathrm{~m} / \mathrm{s}^{2}$ is the gravity acceleration, $r$ is the disc radius, and $w$ is the applied weight in $\mathrm{kg}$. The angular displacements between discs 1 and 2, and discs 2 and 3 are $\delta_{12}=\theta_{1}-\theta_{2}$ and $\delta_{23}=\theta_{2}-\theta_{3}$, respectively.

The static test results are in Table 4.2 and Table 4.3.

The stiffnesses calculated averages are $k_{1}=2.3358 \mathrm{Nm} / \mathrm{rad}$ and $k_{2}=$ $0.3482 \mathrm{Nm} / \mathrm{rad}$. Figure 4.7 plots the calculated torques versus the collected angular displacements for the shaft connecting the two discs and the estimated curve $T=k_{1} \delta_{12}$, using the average stiffness $k_{1}$. In the same way, Fig. 4.8 plots 
Table 4.2: Static test results and stiffness calculations.

\begin{tabular}{ccc}
\hline Torque $[\mathrm{Nm}]$ & $\delta_{12}[\mathrm{rad}]$ & $k_{1}[\mathrm{Nm} / \mathrm{rad}]$ \\
\hline 0.0795 & 0.0283 & 2.8132 \\
0.2478 & 0.1257 & 1.9716 \\
0.3679 & 0.1759 & 2.0912 \\
0.4474 & 0.2042 & 2.1912 \\
0.5268 & 0.2356 & 2.2359 \\
0.7667 & 0.3142 & 2.4405 \\
1.1713 & 0.4492 & 2.6071 \\
\hline & & $\mu=2.3358$ \\
& & $\sigma=0.2988$ \\
\hline
\end{tabular}

Table 4.3: Static test results and stiffness calculations.

\begin{tabular}{ccc}
\hline Torque $[\mathrm{Nm}]$ & $\delta_{23}[\mathrm{rad}]$ & $k_{2}[\mathrm{Nm} / \mathrm{rad}]$ \\
\hline 0.0398 & 0.1257 & 0.3168 \\
0.0795 & 0.2262 & 0.3516 \\
0.1589 & 0.4178 & 0.3803 \\
0.3679 & 1.0681 & 0.3444 \\
0.3980 & 1.1750 & 0.3388 \\
0.4474 & 1.2378 & 0.3615 \\
0.5360 & 1.5582 & 0.3440 \\
\hline & & $\mu=0.3482$ \\
& & $\sigma=0.0197$ \\
\hline
\end{tabular}

the data for the shaft connecting the intermediary disc to the motor and the estimated curve $T=k_{2} \delta_{23}$, using the average stiffness $k_{2}$.

Next, we applied initial angular displacements, separately, to the discs and recorded the decaying free torsional oscillations. Then, Fig. 4.9 plots both shafts responses. It is worth to mention that the DC-motor was mechanically locked to get the disc D2 response, likewise, to get the response of disc D1, the rotation of D2 was restricted. The free responses are then used to the estimation of the damped and natural frequencies, and the damping coefficients.

We computed the damping ratio, $\xi$, using the logarithmic decrement described in Eq. 4-8 and Eq.4-9 [51].

$$
\begin{gathered}
v=\ln \left(\frac{\delta_{i}}{\delta_{i+1}}\right), \\
\xi=\frac{v}{\sqrt{(2 \pi)^{2}+v^{2}}},
\end{gathered}
$$

where $\delta_{i}$ and $\delta_{i+1}$ are the $i t h$ and $i t h+1$ amplitude peaks, respectively.

We calculated the natural frequencies and the damping coefficients using Eq. 4-10 and Eq. 4-11, respectively [51]. 


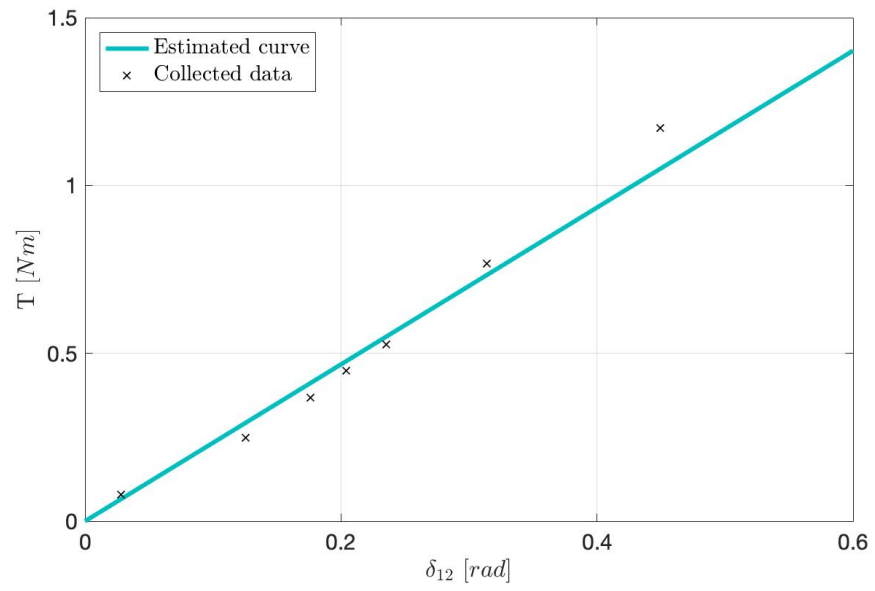

Figure 4.7: Torque as a function of the angular displacement between the discs D1 and D2.

$$
\begin{gathered}
\omega_{n}=\frac{\omega_{d}}{\sqrt{1-\xi^{2}}} . \\
d=\xi\left(2 J \omega_{n}\right)
\end{gathered}
$$

Table 4.4 contains the natural and damped frequencies, and table 4.5, the damping ratios and coefficients estimations.

Table 4.4: Frequency calculations.

\begin{tabular}{cccc}
\hline & $\omega_{d}[\mathrm{rad} / \mathrm{s}]$ & $\omega_{n}[\mathrm{rad} / \mathrm{s}]$ & $f_{n}[\mathrm{~Hz}]$ \\
\hline 1 & 10.037 & 10.044 & 1.5986 \\
2 & 4.8074 & 4.8080 & 0.7652 \\
\hline
\end{tabular}

Table 4.5: Damping calculations.

\begin{tabular}{ccc}
\hline & $\xi$ & $d[N s / m]$ \\
\hline 1 & 0.02323 & 0.0214 \\
2 & 0.0986 & 0.0022 \\
\hline
\end{tabular}

We also calculated the Fast Fourier Transform (FFT) of the collected data in order to compare the system frequency responses with the estimated frequency values. The frequency response function (FRF) is plotted in Fig. 6.6. The graph in Fig 6.6 provides $f_{n 1}=1.572[\mathrm{~Hz}]$ and $f_{n 2}=0.7743[\mathrm{~Hz}]$.

The electrical parameters, obtained from the manufacturer datasheet [52], are in Table 4.6. Once we have not identified the electrical parameters, but rather taken them from the motor catalog, it is not possible to guarantee their accuracy. 


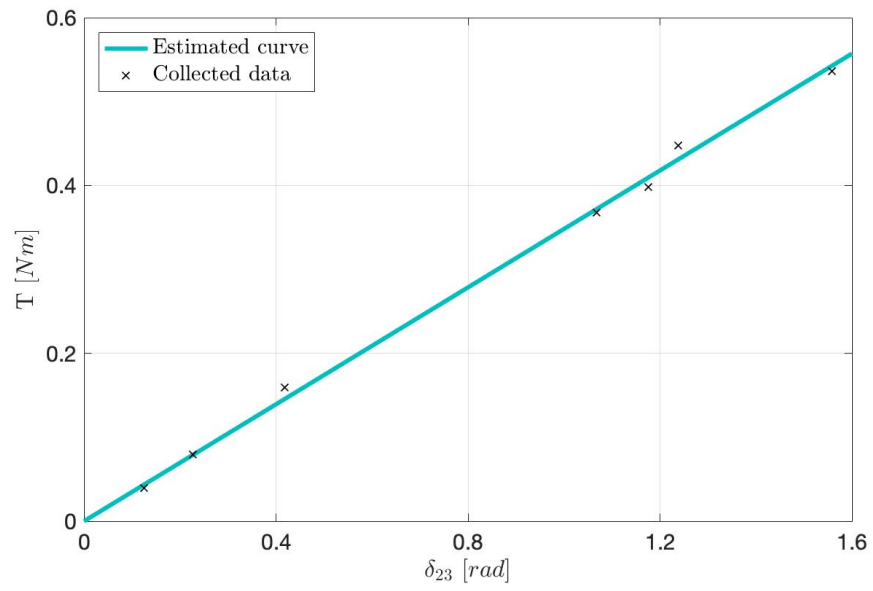

Figure 4.8: Torque as a function of the angular displacement between the disc D2 and the DC-motor.

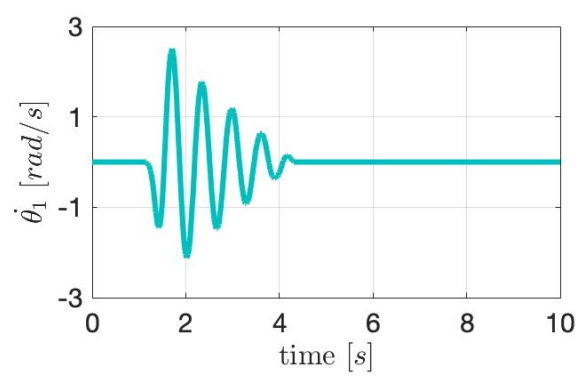

4.9(a): Shaft between discs

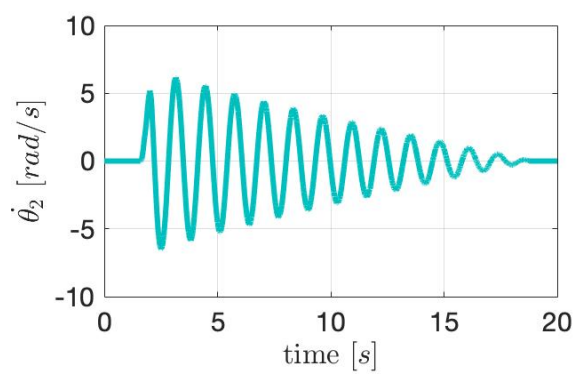

4.9(b): Shaft between disc and motor

Figure 4.9: Free torsional oscillations of the discs subjected to initial angular displacement.

Table 4.6: DC-motor electrical parameters

\begin{tabular}{ccc}
\hline Parameter & Value & Unit \\
\hline$L$ & $8.437\left(10^{-4}\right)$ & $H$ \\
$R$ & 0.33 & $\Omega$ \\
$K_{T}$ & 0.126 & $\mathrm{Nm} / \mathrm{A}$ \\
$K_{E}$ & 0.0602 & $\mathrm{~V} / \mathrm{rad} / \mathrm{s})$ \\
$T_{f}$ & 0.1196 & $\mathrm{Nm}$ \\
$C_{m}$ & $1.784\left(10^{-4}\right)$ & $\mathrm{Nm} / \mathrm{rad} / \mathrm{s})$ \\
$\kappa_{p}$ & 2.800 & - \\
$\kappa_{i}$ & 3.500 & - \\
\hline
\end{tabular}




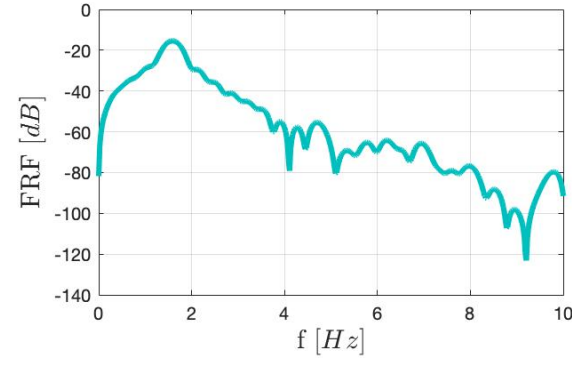

4.10(a): Shaft between discs

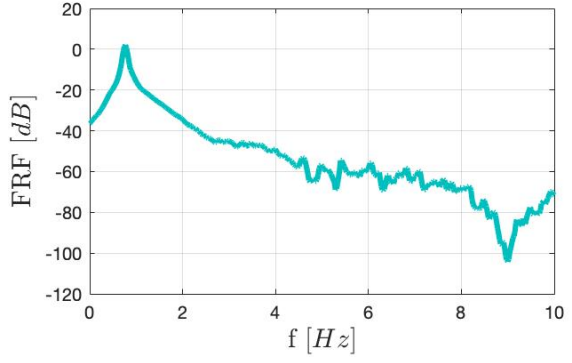

4.10(b): Shaft between disc and motor

Figure 4.10: Amplitude spectrum of the relative angular displacement between the inertia.

\section{5}

\section{Model validation}

Once we have all the parameters required to utilize the mathematical model described in Section 4.3, we can conduct qualitative and quantitative comparisons in order to verify the agreement between numerical and experimental results. We use these comparisons to validate the mathematical model.

For this purpose, using the reduced test rig, we impose the voltage related to $2.09,3.14,4.19$, and $5.24 \mathrm{rad} / \mathrm{s}(20,30,40$ and $50 R P M)$ to the DC-motor, and compare the angular velocity responses of the model with the experimental data. The system is initially at rest. Figure 4.11 depicts the numerical and experimental transient oscillations of the angular velocity of disc D2 for all four cases, where numerical and collected data present similar behavior.

From Fig. 4.11, we can see that the numerical and experimental angular velocity of disc D2 oscillate nearly in the same frequency but with different amplitudes in all four investigated situations. The oscillatory steady-state behavior noticed in the experimental response may result from a source of dry friction in the system, even when the normal force applied to the disc is zero.

Quantitatively, the numerical model presents good results. To measure the agreement between numerical and experimental results, we use three methods: Root Mean Square Error (RMSE), Pearson Correlation $(P C)$, and Amplitude Pulse Level $(A P L)$ [53]. Table 4.7 presents the calculated indicators for the angular velocity $\dot{\theta}_{2}$ of the performed simulations.

The small RMSE and normalized RMSE values indicate the good correspondence between the collected data and the numerical simulations. Since $P C=1$ means a perfect match between the results and $P C=0$ means a total mismatch, we can observe that the numerical simulations present good results. Lastly, the APL indicators also indicate the match between the data, once $A P L=0$ means a perfect match while $A P L=1$ means a total mismatch [53]. 


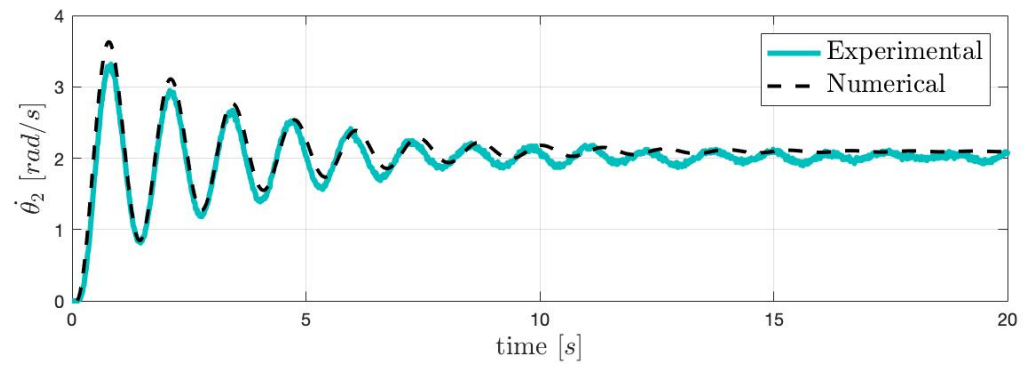

4.11(a): $\omega_{\text {ref }}=20 R P M$

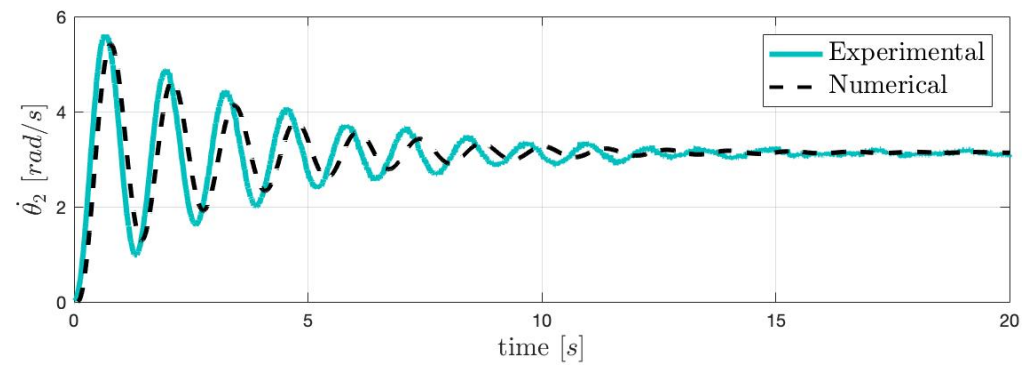

$4.11(\mathrm{~b}): \omega_{\text {ref }}=30 R P M$

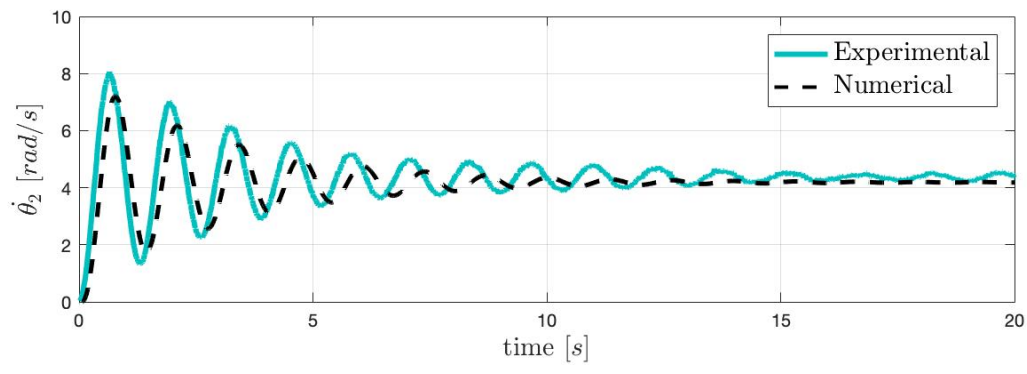

4.11(c): $\omega_{\text {ref }}=40 R P M$

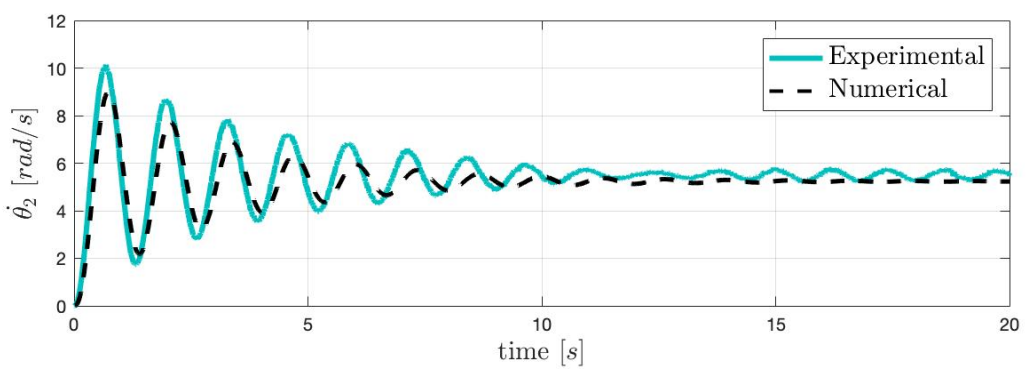

$4.11(\mathrm{~d}): \omega_{\text {ref }}=50 R P M$

Figure 4.11: Numerical and experimental angular velocity of D2 time history.

The DC-motor described in Section 4.2 is not strong enough and its dynamics is influenced by the mechanical subsystem. Figure 4.12 displays the numerical armature current time response for all four cases. This figure shows that the armature current exhibits large oscillations during torsional 
Table 4.7: Quantitative comparison between experimental and numerical results for $\dot{\theta_{2}}$.

\begin{tabular}{ccccc}
\hline$\omega_{\text {ref }}[\mathrm{rad} / \mathrm{s}]$ & $R M S E[\mathrm{rad} / \mathrm{s}]$ & $R M S E / \omega_{\text {ref }}$ & $P C$ & $A P L$ \\
\hline 2.09 & 0.134 & 0.064 & 0.97 & 0.113 \\
3.14 & 0.347 & 0.110 & 0.78 & 0.058 \\
4.19 & 0.552 & 0.131 & 0.76 & 0.104 \\
5.24 & 0.534 & 0.102 & 0.90 & 0.112 \\
\hline
\end{tabular}

vibrations, confirming the influence of the mechanical subsystem on the electrical subsystem.
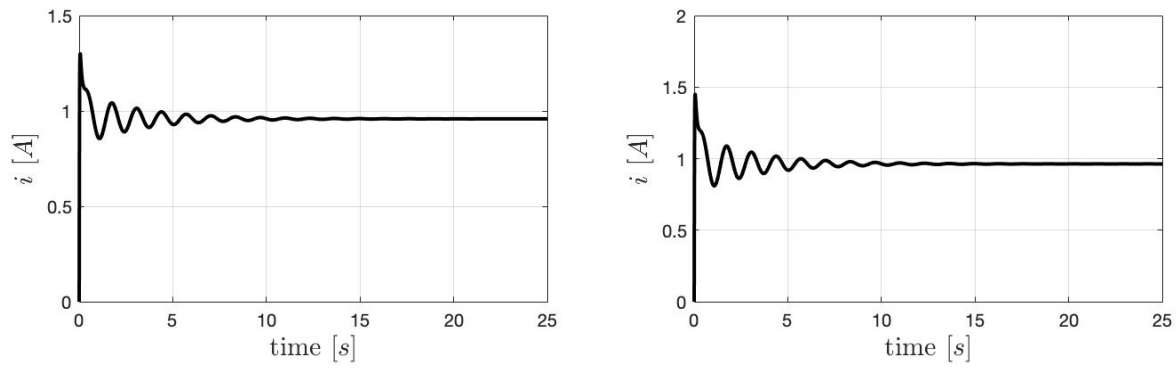

4.12(a): $\omega_{\text {ref }}=20 R P M$

4.12(b): $\omega_{\text {ref }}=30 R P M$
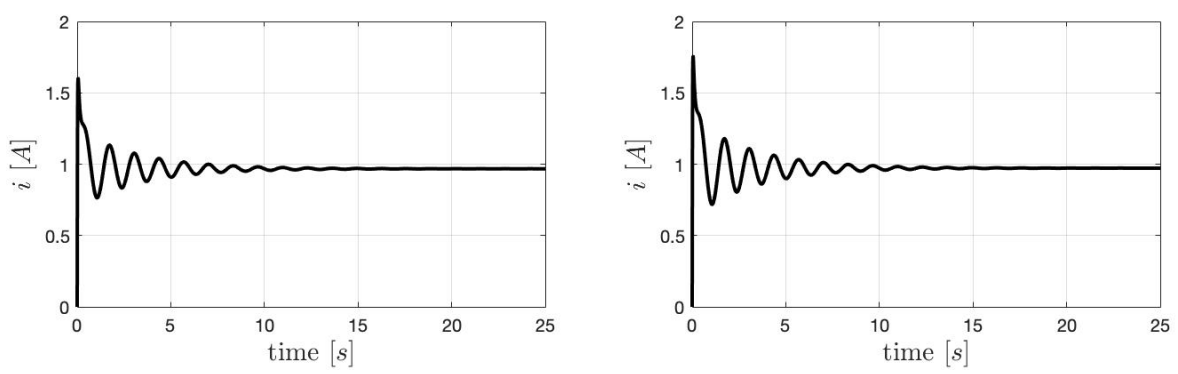

$4.12(\mathrm{c}): \omega_{\text {ref }}=40 R P M$

$4.12(\mathrm{~d}): \omega_{\text {ref }}=50 R P M$

Figure 4.12: Numerical current time history.

\section{6}

\section{Conclusion}

This chapter introduced the experimental setup, describing its main components and its operation. Although the experimental apparatus limitations, it is capable of replicating full-scale system torsional behavior. We mathematically modeled the rig by the lumped parameters method and reported the system mechanical parameters estimation. 


\section{5 \\ Experimental studies}

\section{1}

Introduction

This chapter presents and discusses the experimental results of this research. These results prove the test rig capability to simulate real drill string's torsional oscillations. We investigate the dynamics of the two different rig configurations presented in chapter 4; that is, we consider both full and reduced rig. Furthermore, we conduct tests for several different combinations of the nonlinear control parameters (normal contact force and reference angular velocity). The primary purpose of this research is to develop experimentally calibrated friction models. Thus, we use the recorded data for this purpose.

\section{2}

\section{Reduced test rig experimental results}

The reduced version of the test rig comprises the intermediary disc D2, the DC-motor and the shaft connecting them. This section investigates the experimentally observed torsional vibrations experienced by the reduced system, primarily the stick-slip phenomenon. This severe stage of torsional vibrations exists for different system conditions; in other words, different combinations of the nonlinear control parameters (normal contact force and reference angular velocity). Moreover, the system exhibits different stick-slip responses depending on the control parameters combination.

Different values of angular velocity imposed to the system result in completely different disc D2 responses. Therefore, the change of the reference angular velocity is a simple practice of suppressing stick-slip. To observe the influence of the reference angular velocity on the torsional vibrations of the rig, we varied $\omega_{\text {ref }}$ from 25 (2.62) to 55 (5.76) $R P M(\mathrm{rad} / \mathrm{s})$, in steps of 10 $R P M(1.05 \mathrm{rad} / \mathrm{s})$.In these tests, we impose the voltage related to the angular velocity reference, $\omega_{r e f}$, to the DC-motor. The tests start with the system at rest and we record approximately 5 minutes of data for each system condition. In this chapter, we only present part of the data collected and restrict our analysis to the steady-state response. 

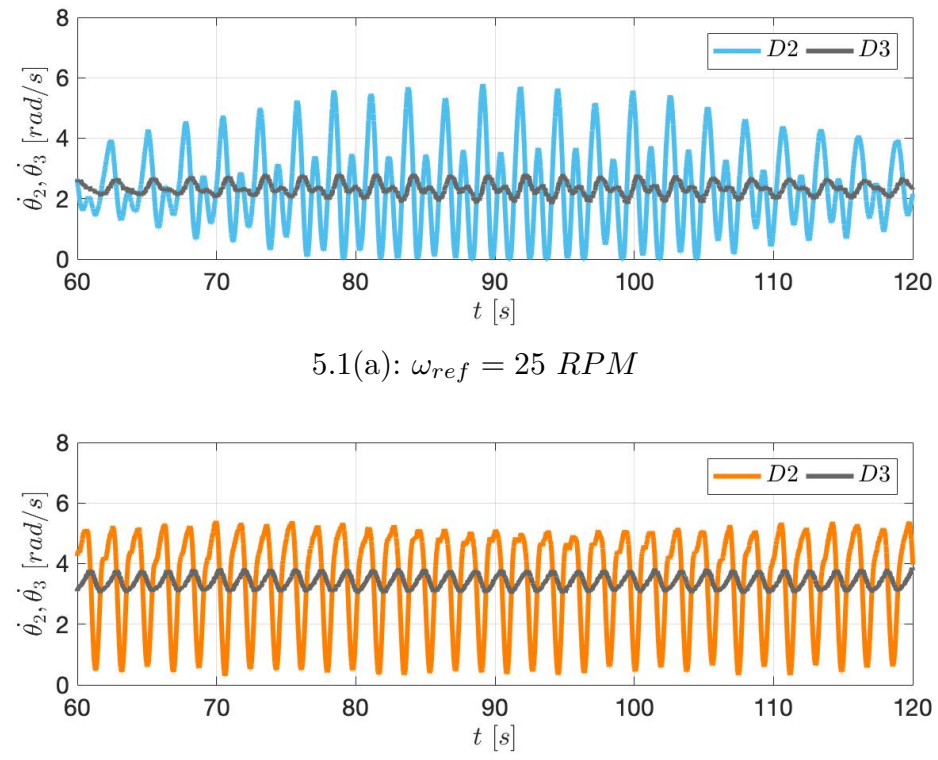

5.1(b): $\omega_{\text {ref }}=35 R P M$

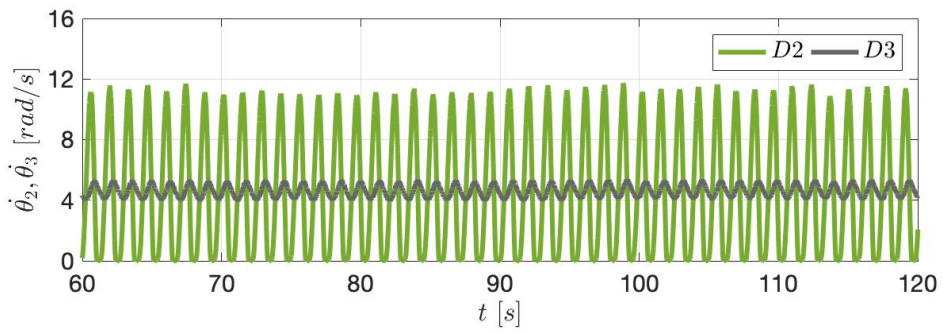

5.1(c): $\omega_{\text {ref }}=45 R P M$

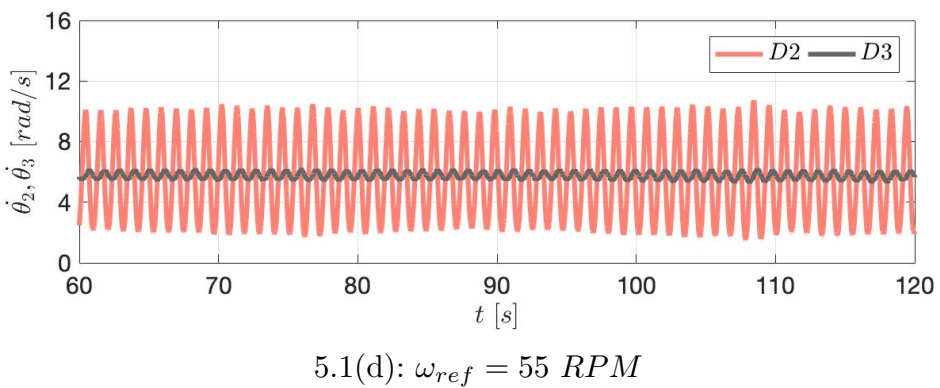

Figure 5.1: Torsional oscillations occurring in the reduced experimental rig for $N_{2}=10 N$. The time histories of the angular velocities of D2 and D3 for (a) $\omega_{\text {ref }}=25 R P M$, (b) $\omega_{r e f}=35 R P M$, (c) $\omega_{\text {ref }}=45 R P M$ and (d) $\omega_{\text {ref }}=55$ $R P M$.

Figure 5.1 presents the different rig torsional behaviors. In Fig. 5.1(a), one may notice that the system exhibits stick-slip phenomenon, i.e. the torque produced by the brake device is able to stop disc D2 for a few moments, with different amplitudes of oscillations. Figure 5.1(c) presents stick-slip motion with constant amplitude. In Fig. 5.1(b) and Fig. 5.1(d), we can see torsional 
vibrations, but we do not observe stick-slip. From these results, we can see an interchanging stick-slip and oscillatory solutions region around $\omega_{\text {ref }}=35 R P M$. This interchanging region may be a result of the high nonlinear characteristic of the system. Although, it is worth to point out that the $\omega_{\text {ref }}=45 R P M$ $(0.75 \mathrm{~Hz})$ is close to the reduced system natural frequency, $0.7652 \mathrm{~Hz}$, which may explain the increase in the velocity amplitude of oscillation.

We acquired the system responses displayed in Fig. 5.1 for the same value of the normal contact force between the brake device and the disc D2, $N_{2}=10$ $N$. In all four cases, we observe the oscillation of the angular velocity in the output of the DC-motor, $\dot{\theta}_{3}$. From Fig. 5.1 we can conclude that stick-slip phenomenon vanishes for high values of $\omega_{\text {ref }}$. Moreover, one may notice that small values of $\omega_{r e f}$ lead to more complex vibration time histories. In all cases of Fig. 5.1, we can observe the small oscillations in the speed of the output of the motor.

Figure 5.2 presents a tridimensional bifurcation diagram corresponding to the cases of Fig. 5.1 with phase portraits as function of $\omega_{\text {ref }}$. From this figure, one can notice that as the reference angular velocity, $\omega_{r e f}$, increases, so does the amplitude of the stick-slip phenomenon until stick-slip does not occur anymore.

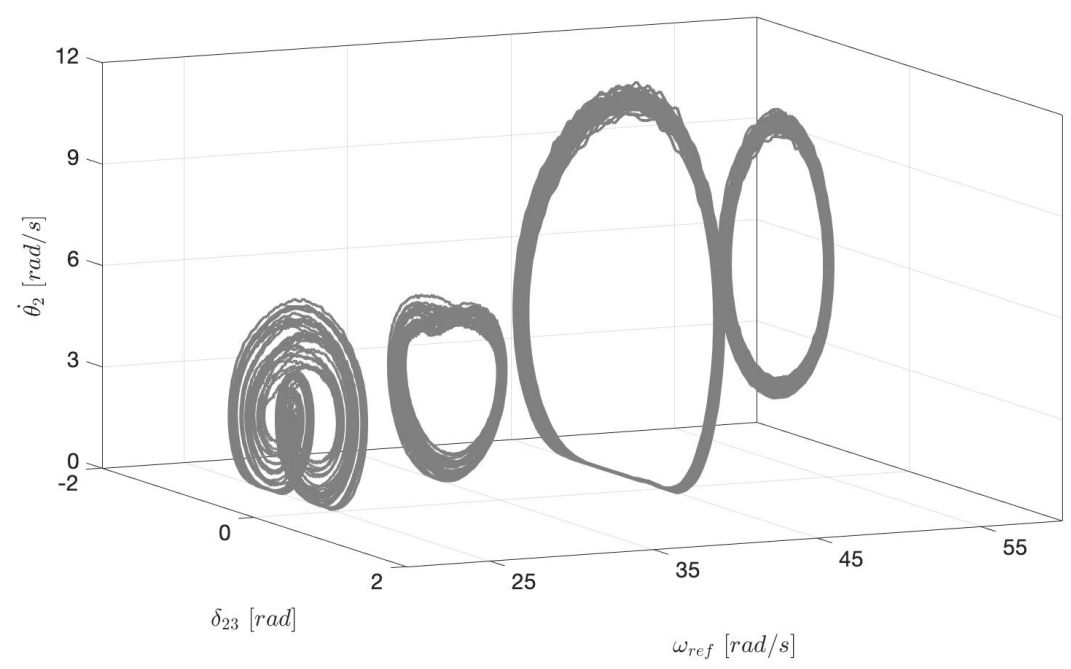

Figure 5.2: Tridimensional bifurcation diagram presenting phase portrait as a function of $\omega_{\text {ref }}$.

We repeated the analysis presented above to observe the influence of the normal contact force, $N_{2}$, on the system response. To do this we varied $N_{2}$ from 10 to $70 \mathrm{~N}$, in steps of $20 \mathrm{~N}$ while $\omega_{\text {ref }}=55 \mathrm{RPM}(5.76 \mathrm{rad} / \mathrm{s})$ was held constant (Fig. 5.3). Once again, we can observe four different types of 

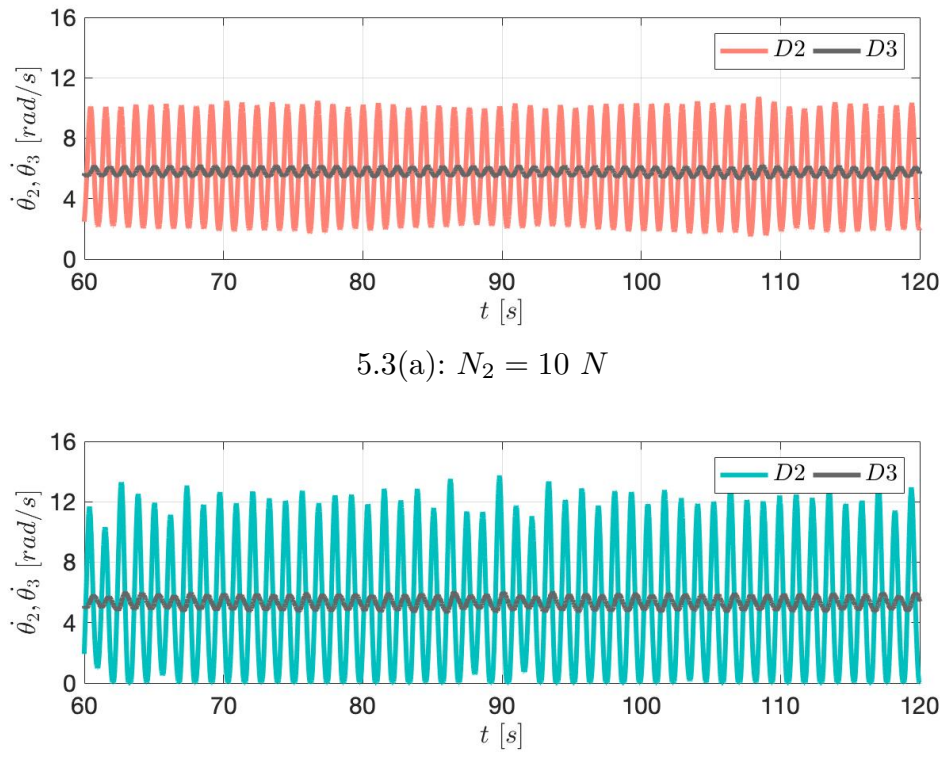

5.3(b): $N_{2}=30 \mathrm{~N}$

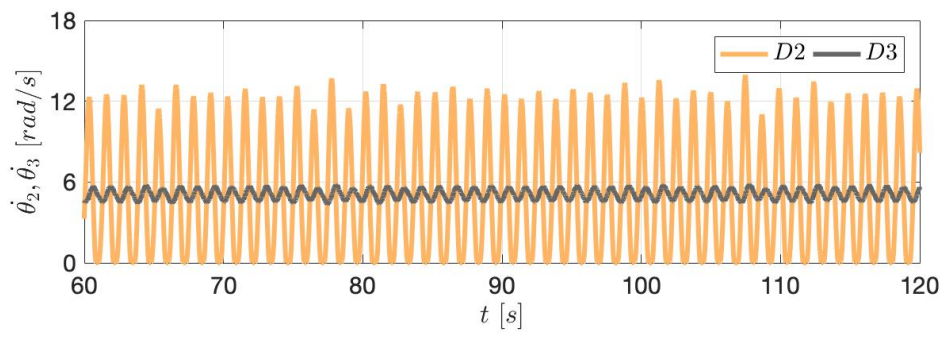

5.3(c): $N_{2}=50 \mathrm{~N}$

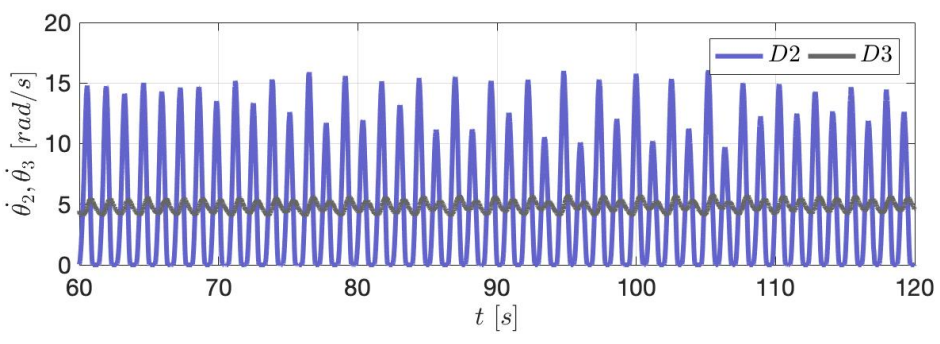

$5.3(\mathrm{~d}): N_{2}=70 \mathrm{~N}$

Figure 5.3: Torsional oscillations occurring in the reduced experimental rig for $\omega_{\text {ref }}=55 R P M$. The time histories of the angular velocities of D2 and D3 for (a) $N_{2}=10 \mathrm{~N}$, (b) $N_{2}=30 \mathrm{~N}$, (c) $N_{2}=50 \mathrm{~N}$ and (d) $N_{2}=70 \mathrm{~N}$.

oscillations. In the case of Fig. 5.3(a), there is torsional vibration, but disc D2 speed is never zero. Stick-slip phenomenon only occurs in the cases of Fig. $5.9(\mathrm{a}), 5.9(\mathrm{c})$ and $5.9(\mathrm{~d})$. It is worthy to mention that the amplitude of the oscillations is almost constant in Fig. 5.3(a) and varies in Fig. 5.9(a), 5.9(c) and $5.9(\mathrm{~d})$.

As we can see in Fig. 5.3, likewise small values of $\omega_{\text {ref }}$, high values of 
$N_{2}$ results in complex velocity time histories. We can also notice that the velocity of the output of the motor exhibits small oscillations for all parameters combinations of Fig. 5.3. Figure 5.4 present the tridimensional bifurcation diagram corresponding to the cases displayed in Fig. 5.3. The bifurcation parameter, in this analysis, is the value of $N_{2}$. We observe that for the lowest value of $N_{2}$, there are only torsional vibrations with small amplitude. As the normal contact force increases, we can see the stick-slip phenomenon occurring. This simple analysis proves the importance of $N_{2}$ as a nonlinear control parameter of the system.

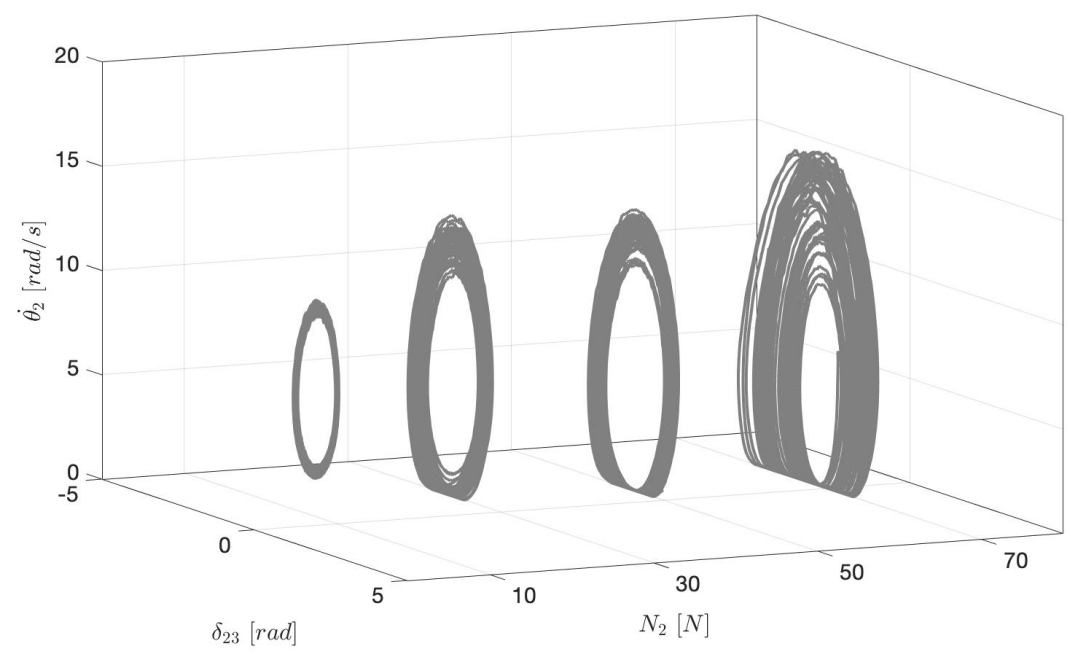

Figure 5.4: Tridimensional bifurcation diagram presenting phase portrait as a function of $N_{2}$.

\section{3}

\section{Full test rig experimental results}

As stated in the previous chapter, the original configuration of the test rig comprises the two discs, the motor, and the shafts connecting them [21]. Then, we replicated the experimental analysis described in Section 5.2 for the full rig. Similarly, we observed the different phenomena occurring in the system. First, we performed a sweep with respect to the reference angular velocity, $\omega_{\text {ref }}$, varying $\omega_{\text {ref }}$ from $20(2.09)$ to 40 (4.19) $R P M(\mathrm{rad} / \mathrm{s})$, in steps of 10 $R P M(1.05 \mathrm{rad} / \mathrm{s})$ to observe the effect of the change in the reference angular velocity on the torsional vibrations of the full test rig. The system responses displayed in Fig. 5.5 were acquired for the same value of the normal contact force between the brake device and the disc D1, $N_{1}=15 \mathrm{~N}$.

Figure 5.5 presents discs D1 and D3 velocity responses. In Fig. 5.5(a) and Fig. 5.5(c), we observe that disc D1 angular velocity oscillates but is never 


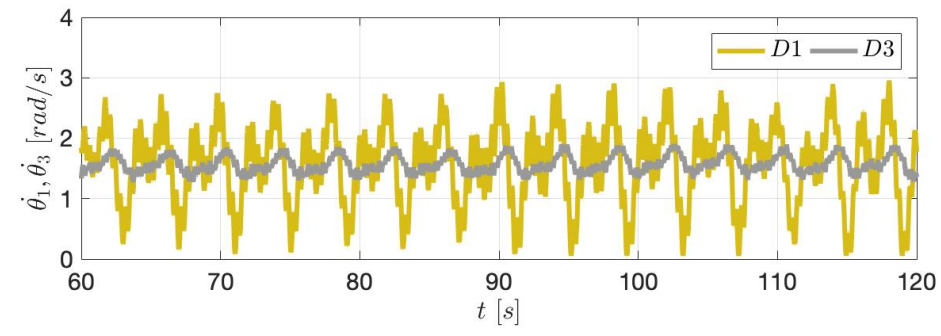

$5.5(\mathrm{a}): \omega_{\text {ref }}=20 R P M$

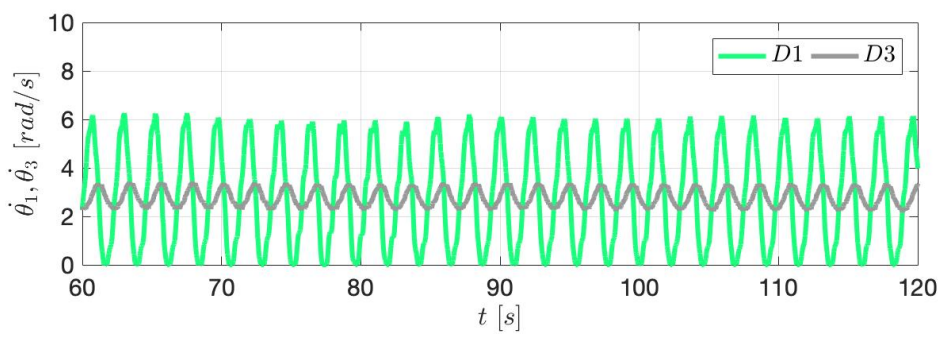

$5.5(\mathrm{~b}): \omega_{\text {ref }}=30 R P M$

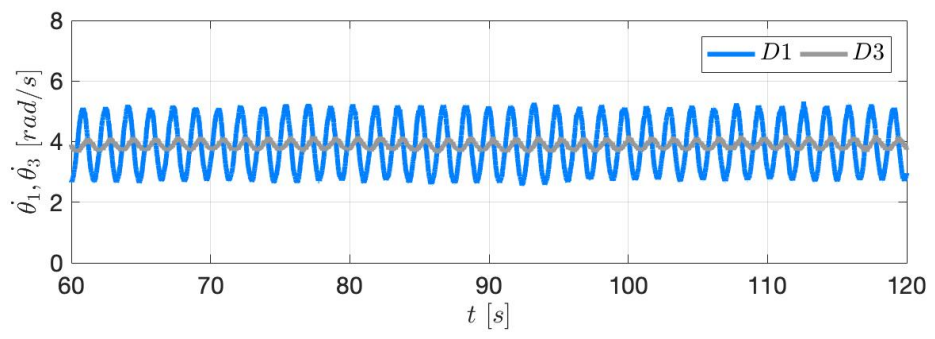

$5.5(\mathrm{c}): \omega_{\text {ref }}=40 R P M$

Figure 5.5: Torsional oscillations occurring in the full experimental rig for $N_{1}=15 N$. The time histories of the angular velocities of D1 and D3 for (a) $\omega_{\text {ref }}=20 R P M$, (b) $\omega_{\text {ref }}=30 R P M$ and (c) $\omega_{\text {ref }}=40 R P M$.

null, i. e. there is no stick phase. Only the case of Fig. 5.5(b) exhibits stick-slip. From these responses, we can see an interchanging stick-slip and oscillatory solutions region. As the reference angular velocity increases from $\omega_{\text {ref }}=20$ $R P M(2.09 \mathrm{rad} / \mathrm{s})$ to $\omega_{r e f}=30 R P M(3.14 \mathrm{rad} / \mathrm{s})$, there is a change in the system behavior and stick-slip appear. As the reference angular velocity increases from $\omega_{\text {ref }}=30 \mathrm{RPM}(3.14 \mathrm{rad} / \mathrm{s})$ to $\omega_{\text {ref }}=40 \mathrm{RPM}(4.19 \mathrm{rad} / \mathrm{s})$, there is another change in the system behavior and only oscillatory solutions occur. Figure 5.6 presents a tridimensional bifurcation diagram corresponding to the cases of Fig. 5.7 with phase portraits as function of $\omega_{\text {ref }}$. From this figure, we can have the same conclusions described above. Once again, we see that small values of $\omega_{\text {ref }}$ lead to more complex vibration time histories.

Next, we repeated the investigation in the range of the normal contact force, $N_{1}$ to observe its influence on the system response. We used $N_{1}=15$ 


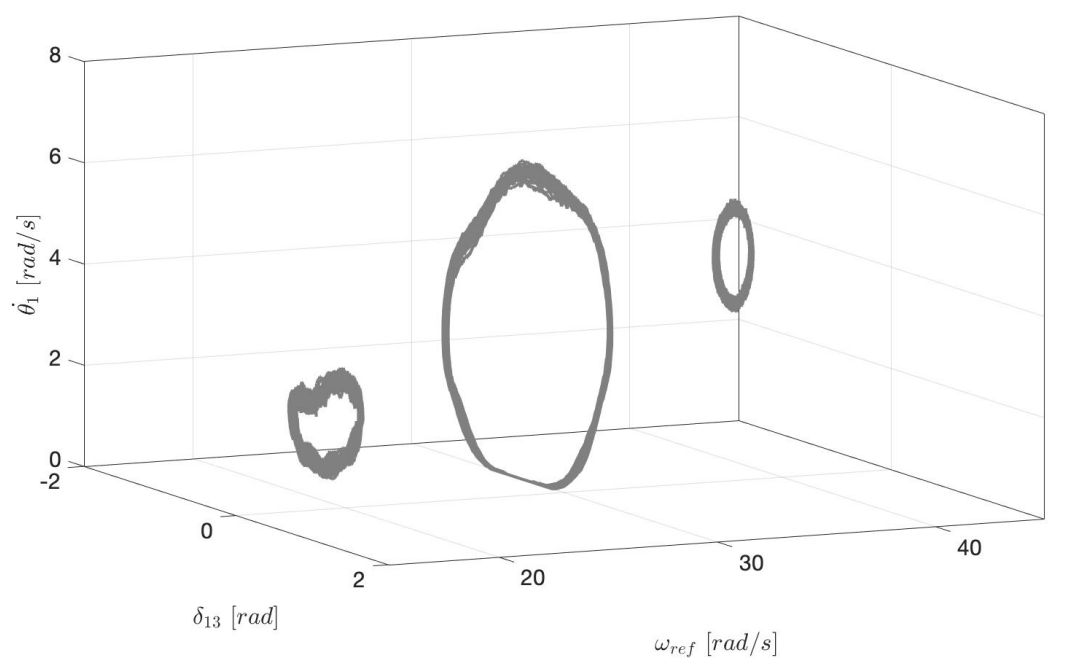

Figure 5.6: Tridimensional bifurcation diagram presenting phase portrait as a function of $\omega_{\text {ref }}$.

$N, N_{1}=30 N$ and $N_{1}=40 N$ with $\omega_{\text {ref }}=40 R P M(4.19 \mathrm{rad} / \mathrm{s})$. Figure 5.7 presents the system responses. As observed in the reduced system responses, stick-slip only occurs for higher values of normal contact force, in this case, $N_{1}$ (Fig. 5.7(c)).

Figure 5.8 present the tridimensional bifurcation diagram corresponding to Fig. 5.7 responses. The bifurcation parameter is the value of $N_{1}$. Again, we observe that for the lower values of $N_{1}$, there are only torsional vibrations and for higher values of $N_{1}$, the stick-slip phenomenon occurs.

\section{4}

\section{Experimental friction}

The primary intent of this research is the formulation and validation of a friction model capable of reproducing undesired torsional vibrations observed in experimental tests. For this purpose, we consider a stick-slip response presented in Section 5.2, where the torque-velocity hysteretic characteristic is evident, for further analysis. We perform the analysis for the response of the reduced test rig with a reference angular velocity of $\omega_{\text {ref }}=55 \mathrm{RPM}(5.76 \mathrm{rad} / \mathrm{s})$ and an imposed normal force of $N_{2}=50 \mathrm{~N}$.

We determined the friction torque on disc D2 indirectly on the basis of the simplified rig mathematical model presented in Eq. 4-5. According to Eq. 4-5, an indirect friction force estimation requires three variables and three system parameters. The required variables are the relative displacement, $\theta_{2}-\theta_{3}$, the relative velocity, $\dot{\theta}_{2}-\dot{\theta}_{3}$, disc D2 acceleration, $\ddot{\theta}_{2}$. The required parameters 

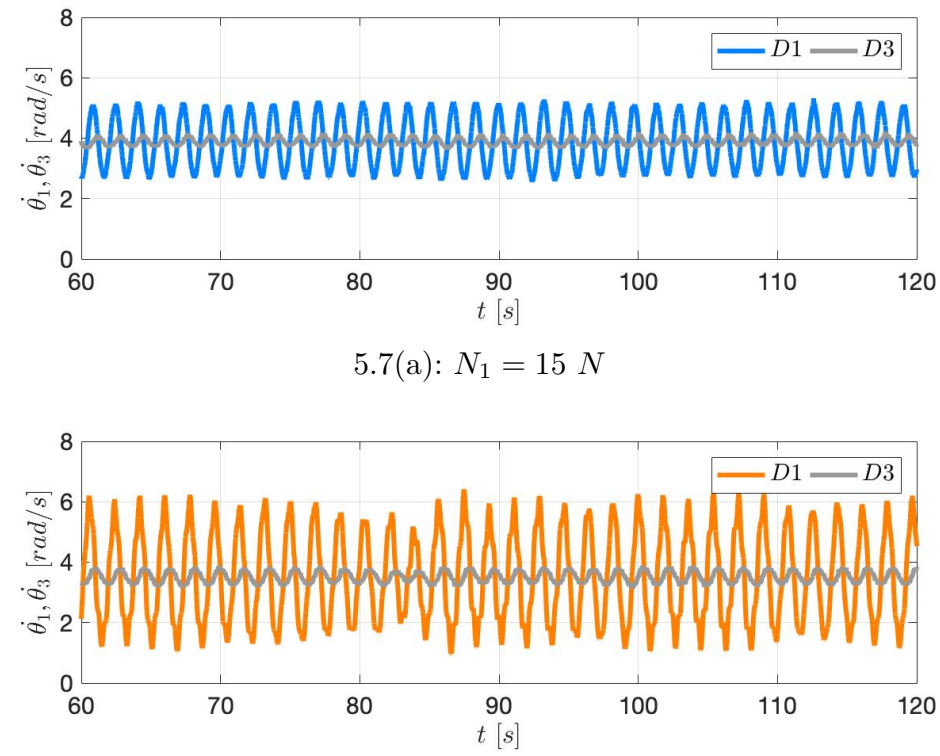

$5.7(\mathrm{~b}): N_{1}=30 \mathrm{~N}$

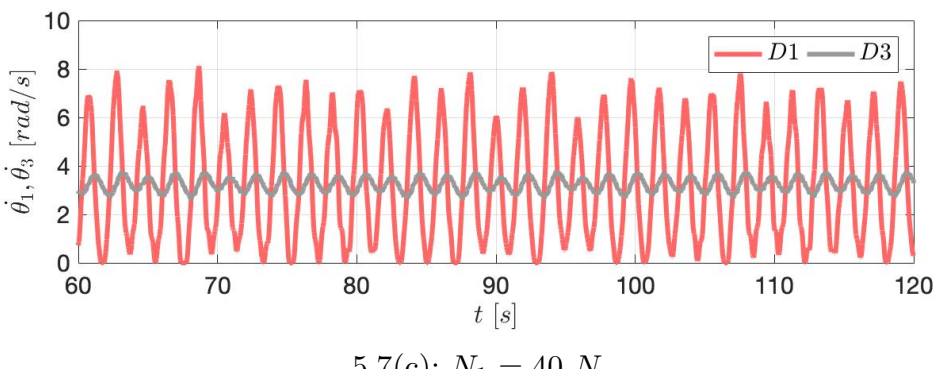

Figure 5.7: Torsional oscillations occurring in the full experimental rig for $\omega_{\text {ref }}=40 R P M$. The time histories of the angular velocities of D1 and D3 for (a) $N_{1}=15 \mathrm{~N}$, (b) $N_{1}=30 \mathrm{~N}$ and (c) $N_{1}=40 \mathrm{~N}$.

were identified in chapter 4 .

In Fig. 5.9, we present the time history response of disc D2 angular velocity, disc D2 angular acceleration, friction torque, $T_{f, 2}$, and contact normal force, $N_{2}$. As expected, there is a variation of the friction torque as a consequence of the stick-slip phenomenon. Examining the time history of $T_{f, 2}$ (Fig. c) carefully, we observe that on the onset of sticking phase, $T_{f, 2}$ increases until its maximum value, the static friction torque. Then it decreases with the increase in velocity due to the Stribeck effect.

It is important to observe that the value of normal force $N_{2}$ varies along with the performed test. Since ball bearings support the disc, there exists a small deviation between the disc and the plane orthogonal to the shaft. In other words, the disc rotates out of the plane of contact between disc and pin, leading to a fluctuation of the normal force magnitude. Figure 5.10 presents the 


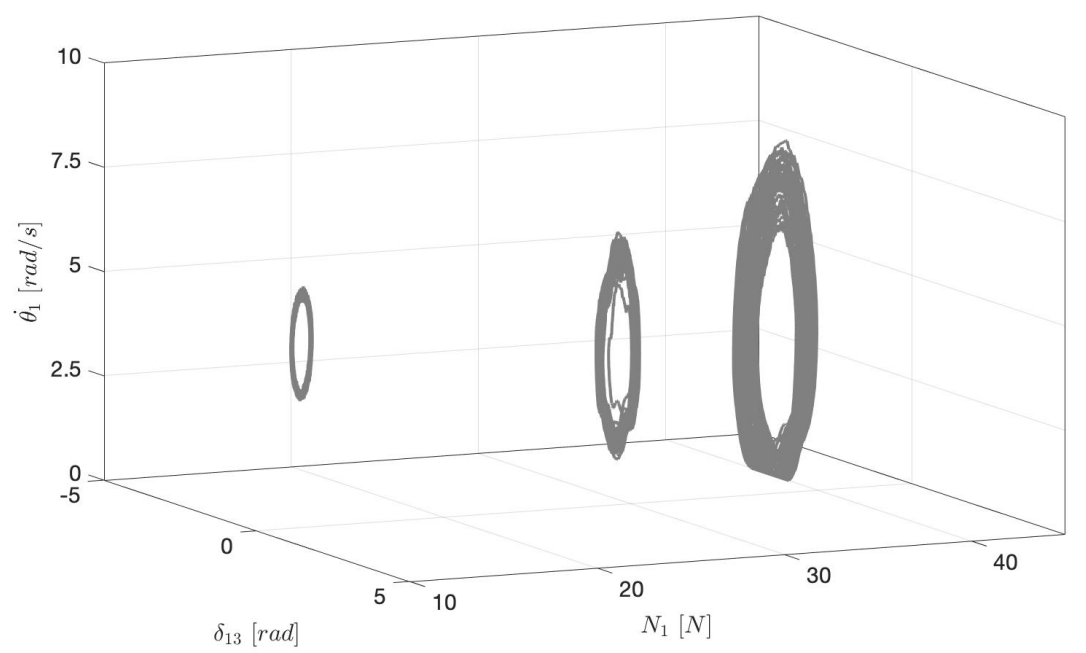

Figure 5.8: Tridimensional bifurcation diagram presenting phase portrait as a function of $N_{1}$.

normalized normal contact force $\left(N_{2} / N_{2, \text { mean }}\right)$ as a function of the the angular position difference $\delta_{23}$.

To better interpret the resistive friction torque, we adopted a tridimensional representation. The tridimensional graph is in Figure 5.11 and shows that friction varies with both disc D2 velocity and acceleration. The representation velocity vs. acceleration is considered an extension of the concept of phase plane, therefore the tridimensional graph shows the variation of the friction torque with the orbit in this phase plane.

Figure 5.12(a) plots the friction torque versus disc D2 speed. This graph is often used to characterize bit-rock interaction in drill strings torsional vibrations. The Stribeck effect, which is the decrease in friction torque with the increase in velocity, is present. We can also identify the hysteresis effect, i.e., torque decreases when disc D2 speed increases in a different path then it increases while disc D2 speed decreases. We argue that friction torque not only varies with the relative velocity but also with the relative acceleration, thus Fig. 5.12(b) plots the torque versus disc D2 acceleration. At last, Fig. 5.12(c) plots the disc D2 acceleration versus its velocity.

The tridimensional representation of the friction torque for all the cases of Fig. 5.1 and Fig. 5.3 are presented in Fig. 5.13 and Fig. 5.14. From these figures, we can see that the friction torque fluctuations are related to the complexity of the time histories. 


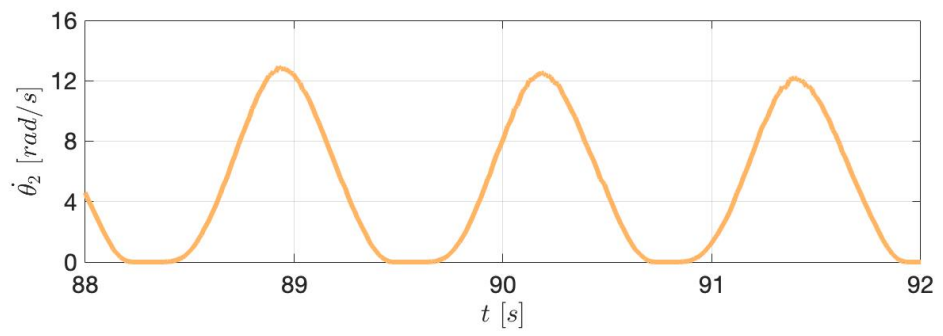

5.9(a): D2 velocity

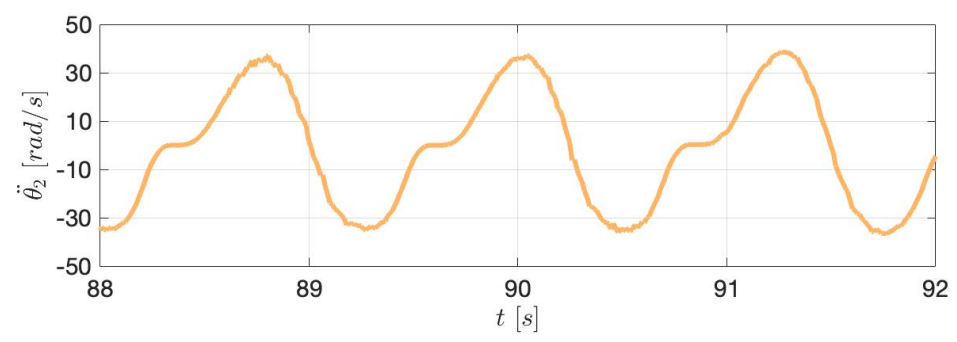

5.9(b): D2 acceleration

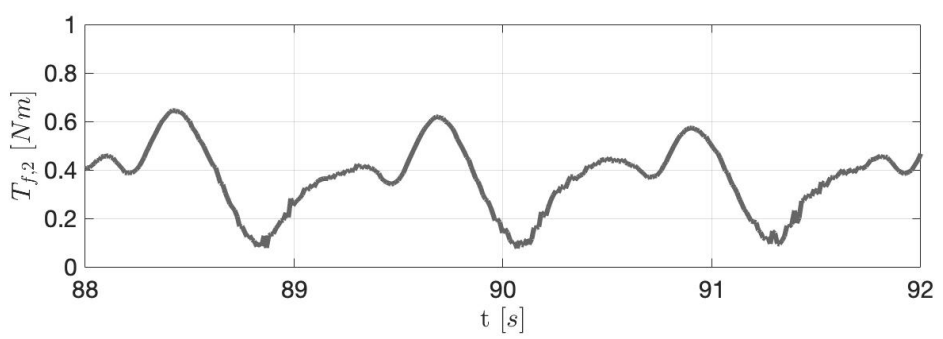

5.9(c): Friction torque

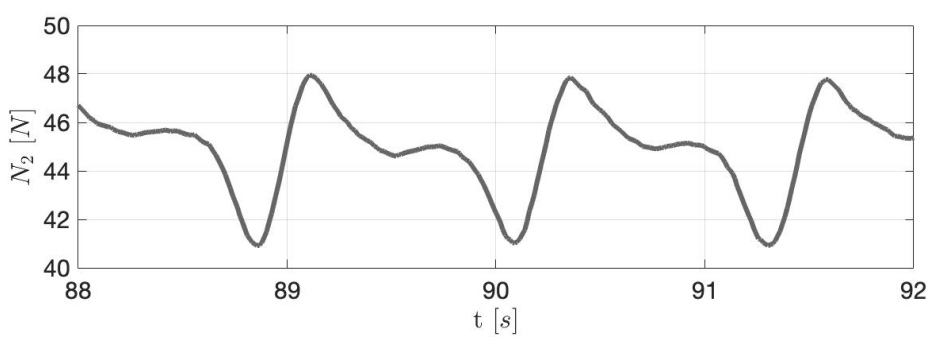

5.9(d): Normal force

Figure 5.9: Time history of (a) the angular velocity of D2, (b) the angular acceleration of D2, (c) friction torque, $T_{f, 2}$, and (d) contact normal force, $N_{2}$, for $\omega_{r e f}=55 R P M$ and $N_{2}=50 \mathrm{~N}$.

\section{5}

\section{Summary}

In this chapter, we presented the experimental results, proving the test rig capability to simulate real systems dynamics. The test rig used to study drill strings was investigated in two configurations: full and reduced one. We 


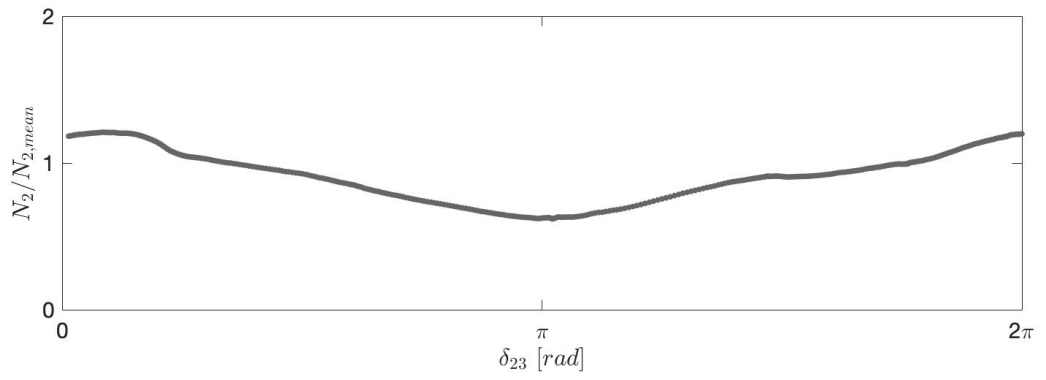

Figure 5.10: Normal contact force $N_{2}$ as a function of angular position difference $\delta_{23}$.

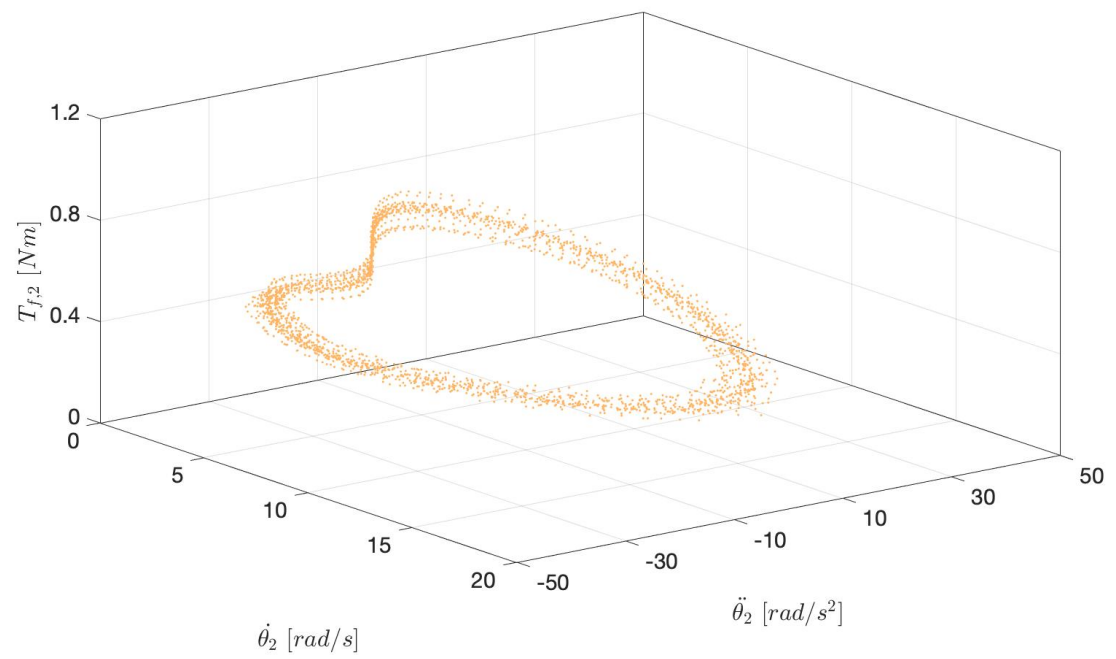

Figure 5.11: Experimental friction torque for $\omega_{\text {ref }}=55 R P M$ and $N_{2}=50 \mathrm{~N}$.

conducted experiments for various combinations of nonlinear control parameters. Then, we analyzed the influence of these parameters on the system behavior. In both of the analysis, one can conclude that the stick-slip phenomenon occurs for lower values reference angular velocity and higher values of normal contact force. Finally, we studied the experimental friction torque using the data acquired, proving that the system dynamics depend not only on the relative speed between the contact surfaces but also on the relative acceleration. 


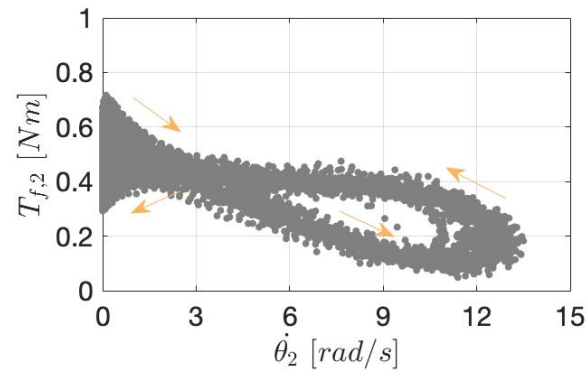

5.12(a): Torque vs. velocity

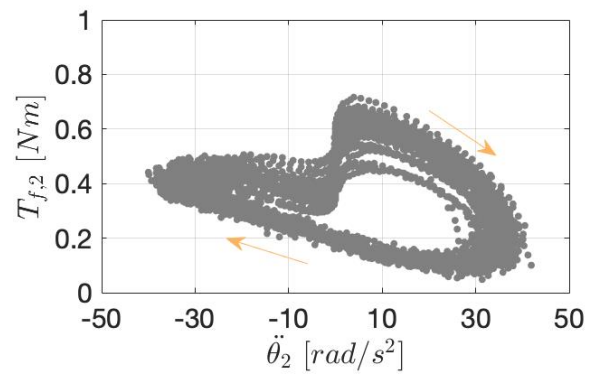

5.12(b): Torque vs. acceleration

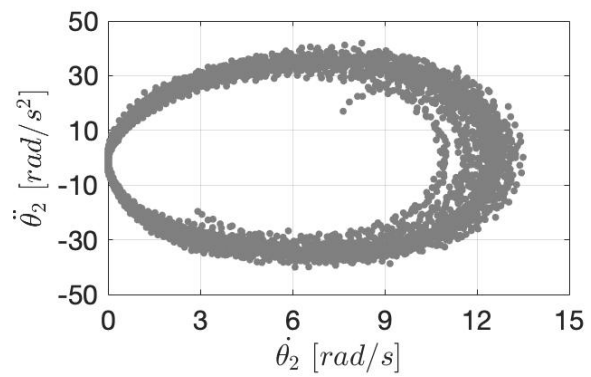

5.12(c): Acceleration vs. velocity

Figure 5.12: (a) friction torque versus disc D2 velocity, (b) friction torque versus disc D2 acceleration and (c) disc D2 acceleration versus velocity.

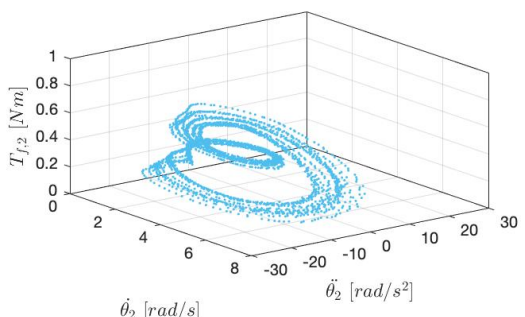

$5.13(\mathrm{a}): \omega_{\text {ref }}=25 R P M$

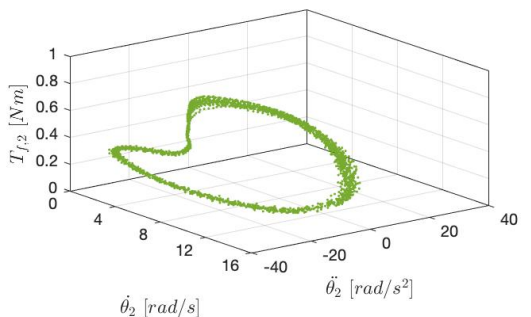

5.13(c): $\omega_{\text {ref }}=45 R P M$

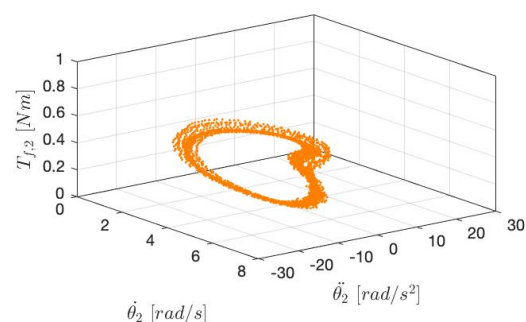

5.13(b): $\omega_{\text {ref }}=35 R P M$

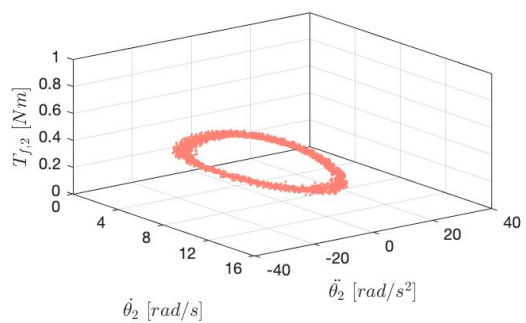

$5.13(\mathrm{~d}): \omega_{\text {ref }}=55 R P M$

Figure 5.13: Experimental tridimensional friction torques. 


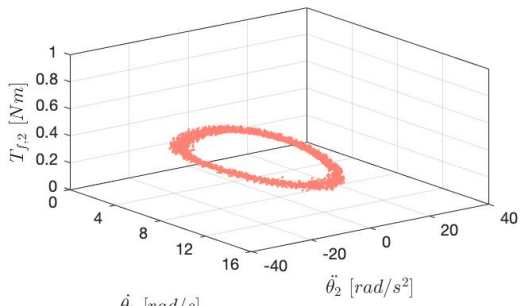

$\dot{\theta}_{2}[\mathrm{rad} / \mathrm{s}]$

5.14(a): $N_{2}=10 \mathrm{~N}$

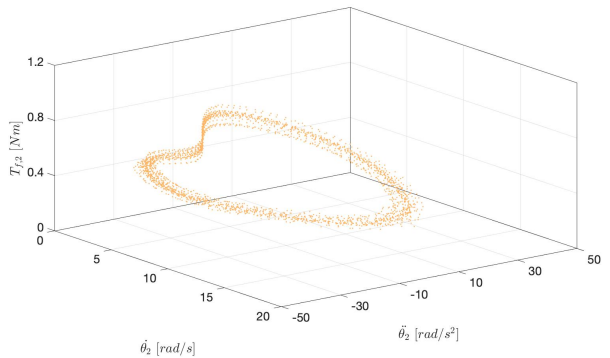

5.14(c): $N_{2}=50 \mathrm{~N}$

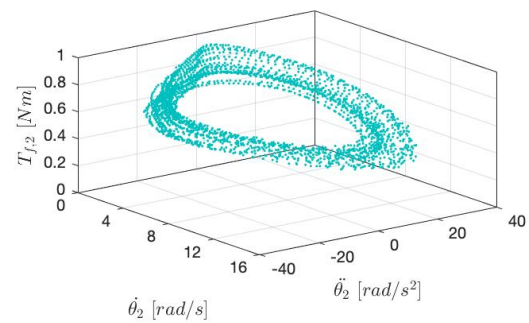

5.14(b): $N_{2}=30 N$

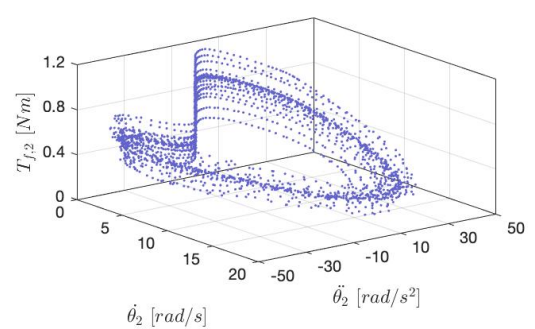

5.14(d): $N_{2}=70 \mathrm{~N}$

Figure 5.14: Experimental tridimensional friction torques. 


\section{6 \\ Numerical studies}

\section{1}

Introduction

The primary purpose of this research is to develop an experimentally based friction model, with particular attention to the phenomena of the hysteretic behavior observed during experiments. To formulate the model, we utilize the experimentally recorded data, for the reduced test rig, presented in the previous chapter and conduct numerical simulations. The experimental results are compared with the numerical simulations for the proposed friction model. The comparisons demonstrate that it is possible to achieve a qualitative agreement between the experiments and the simulations. Finally, we numerically investigate the influence of the change in nonlinear control parameters in the system dynamics.

\section{2}

Friction Models

The formulation and validation of a mathematical model based on experimental observations is the primary objective of this chapter. As a consequence, we intend to investigate the complex dynamical phenomena occurring, making possible future development of control strategies. Whereas, to propose control strategies, it is essential to understand the system dynamics due to all parameters and inputs.

The mathematical description of dry friction is a critical step in the modeling of dry friction systems dynamics. Friction is often represented by friction-velocity curves, which need to be correctly modeled. The hysteretic behavior observed in the experimental friction-velocity curves motivated us to elaborate a new proposal of dry friction model. Our goal was to formulate a model to describe friction phenomena with higher precision.

From the experiments, we noticed that the phase space formed by the velocity and the acceleration of the disc D2 has an elliptical shape (Fig.5.12(c)). Thus, we will analyze friction torque not only as a function of velocity and acceleration but as a function of its position on the extended phase plane, given 
by an angle $\alpha$. Figure 6.1 shows the experimental and fitted phase space formed by velocity and acceleration and how angle $\alpha$ is defined.

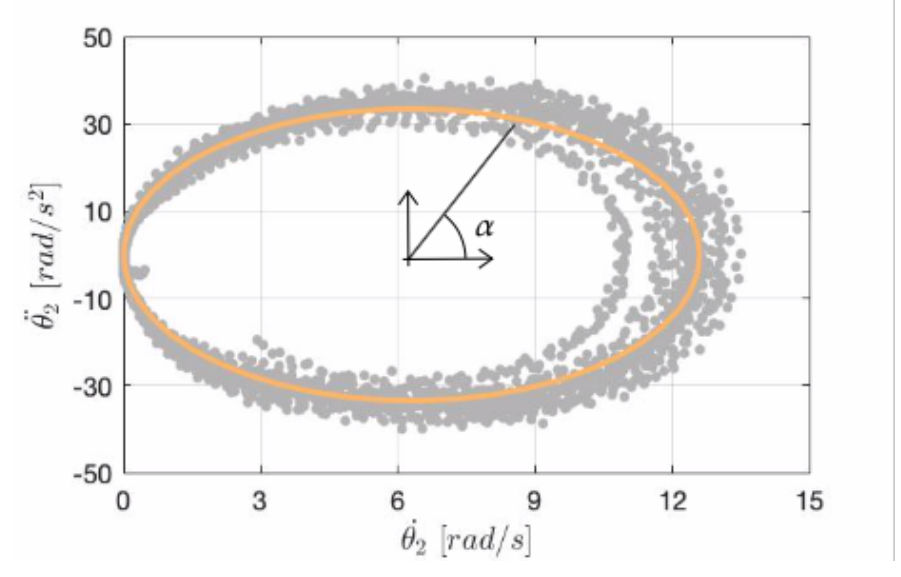

Figure 6.1: experimental and fitted acceleration vs. velocity curves for $\omega_{\text {ref }}=55$ $R P M(5.76 \mathrm{rad} / \mathrm{s})$ and $N_{2}=50 \mathrm{~N}$.

We consider that $\alpha=0$ corresponds to the point where the velocity is maximal, $\alpha=-\pi$ corresponds to the point where the disc sticks and $\alpha=\pi$ corresponds to the point where the disc goes from stick to slip.

Figure 6.2 presents a planar representation of the phase plane ellipse where the experimental friction varies with respect to the angle $\alpha$. Therefore, the friction torque produced by the disc-pin contact will depend on the relative velocity and the relative acceleration between disc and pin. Hence, we can compute the reaction torque as follows:

$$
T_{f, 2}= \begin{cases}a \dot{\theta}_{2} & \text { if }\left|\dot{\theta}_{2}\right| \leq \omega_{s}, \\ a 1 e^{\left(-((\alpha-b 1) / c 1)^{2}\right)}+a 2 e^{\left(-((\alpha-b 2) / c 2)^{2}\right)} & \text { if }\left|\dot{\theta}_{2}\right|>\omega_{s},\end{cases}
$$

where $\omega_{s}=10^{-3}$.

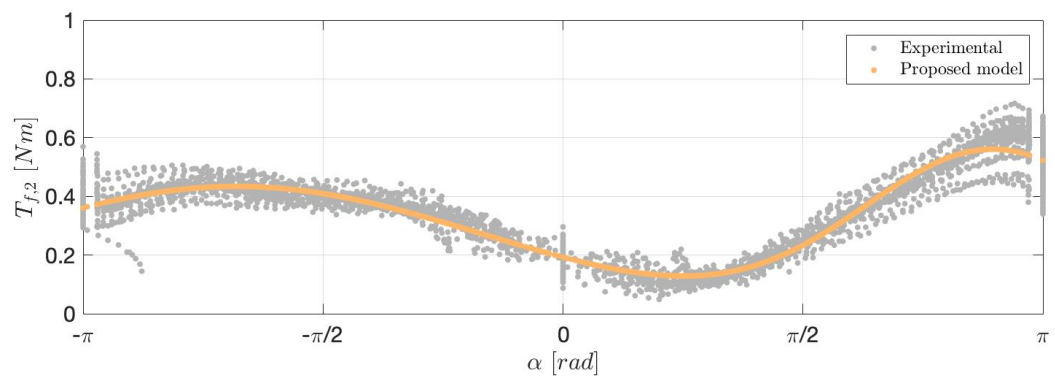

Figure 6.2: Experimental friction torque as a function of $\alpha$ for $\omega_{r e f}=55 R P M$ $(5.76 \mathrm{rad} / \mathrm{s})$ and $N_{2}=50 \mathrm{~N}$. 
Next, we performed a curve fitting of the experimental friction torque (See Fig. 6.2) to Eq. 6-1, to obtain all necessary parameters corresponding to the friction torque curve.

The choice for representing the torque as a function of both, velocity and acceleration, is explained by the different characteristics of the experimental curves for acceleration and deceleration. That is, the friction torque decreases with the increase in velocity as a function of velocity and acceleration and increases with the decrease in velocity as another function of the same state variables.

In the same way, we can analyze the friction coefficient, $\mu$, as a function of the angle of the ellipse. Figure 6.3 presents the graph of the experimental friction coefficient with respect to the angle of the ellipse, $\alpha$, and the proposed model curve. Once again, the friction coefficient at any point of the disc-pin contact will depend on both relative velocity and relative acceleration between the parts. The friction torque mathematical description, in this case, has the form:

$$
T_{f, 2}= \begin{cases}a \dot{\theta_{2}} & \text { if }\left|\dot{\theta}_{2}\right| \leq \omega_{s}, \\ N_{2} \cdot r \cdot\left(a 1 e^{\left(-((\alpha-b 1) / c 1)^{2}\right)}+a 2 e^{\left(-((\alpha-b 2) / c 2)^{2}\right)}\right) & \text { if }\left|\dot{\theta}_{2}\right|>\omega_{s},\end{cases}
$$

where $\omega_{s}=10^{-3}$ and $r$ is the distance between the contact point and the rotation center of the disc D2.

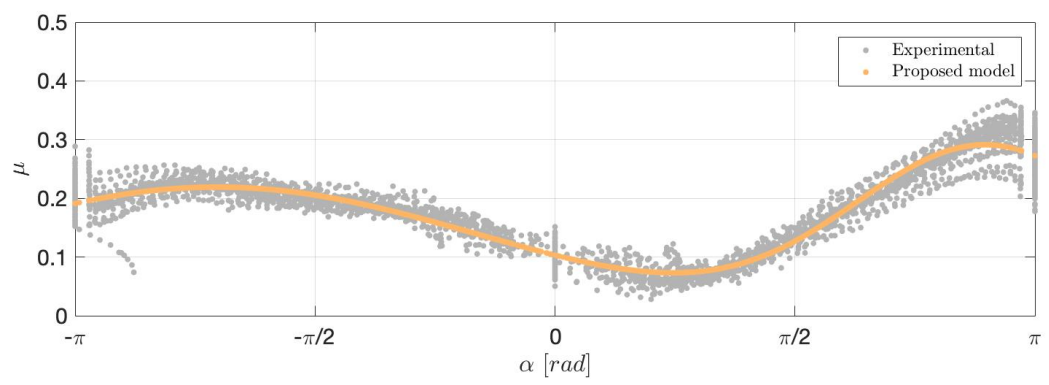

Figure 6.3: Experimental friction coefficient as a function of $\alpha$ for $\omega_{\text {ref }}=55$ $R P M(5.76 \mathrm{rad} / \mathrm{s})$ and $N_{2}=50 \mathrm{~N}$.

Equations 6-1 and 6-2 describe the first and the second proposed friction models,respectively.

\section{3}

\section{Numerical studies}

Firstly, we consider a response of the stick-slip oscillations of disc D2, for a reference angular velocity of $\omega_{\text {ref }}=55 R P M(5.75 \mathrm{rad} / \mathrm{s})$ and a normal 
contact force value of $N_{2}=50 \mathrm{~N}$. In order to perform the numerical simulations, we used the mechanical parameters presented in chapter 4 . For both analyzed models, the system responses are in agreement with each other as we can see in Fig. 6.4 and Fig. 6.5, respectively.

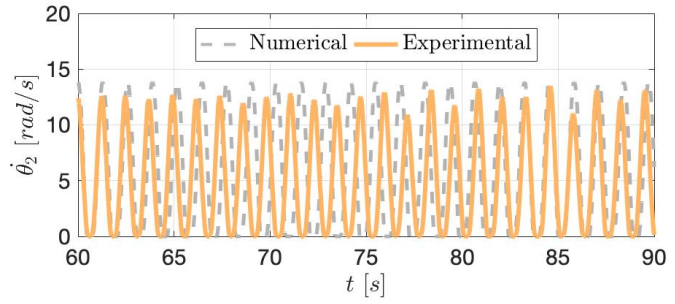

6.4(a): D2 velocity

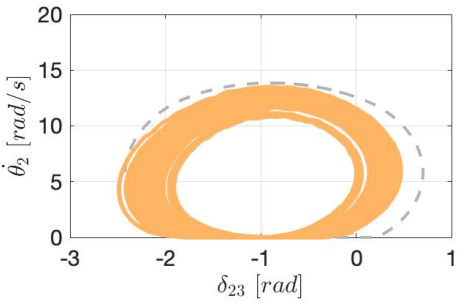

6.4(b): D2 phase portrait

Figure 6.4: (a) Experimental (continuous) and numerical (dashed) angular velocity, and (b) experimental (continuous) and numerical (dashed) phase portraits of disc D2 for $\omega_{r e f}=55 R P M(5.76 \mathrm{rad} / \mathrm{s})$ and $N_{2}=50 \mathrm{~N}$.

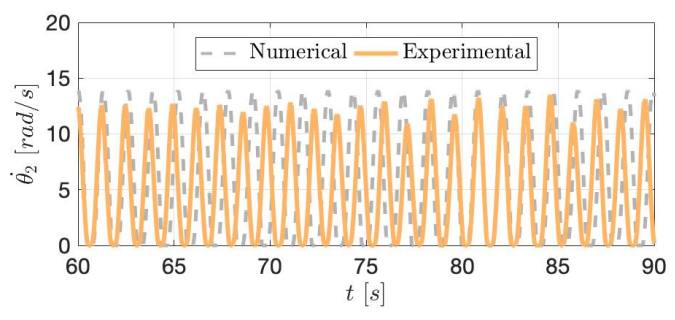

6.5(a): D2 velocity

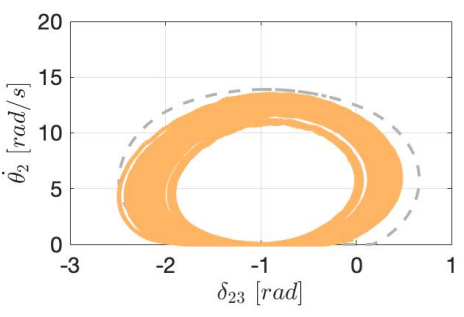

6.5(b): D2 phase portrait

Figure 6.5: (a) Experimental (continuous) and numerical (dashed) angular velocity, and (b) experimental (continuous) and numerical (dashed) phase portraits of disc D2 for $\omega_{r e f}=55 R P M(5.76 \mathrm{rad} / \mathrm{s})$ and $N_{2}=50 \mathrm{~N}$.

From Fig. 6.4, we see that there are small differences in the amplitude and frequency of oscillation, the numerical simulation presents a period of oscillation $6 \%$ higher than the experimental and an oscillation amplitude $4.9 \%$ higher than the maximum experimental one. We can analyze the results obtained with the second model in the same way, in Fig. 6.5 we see the differences between the results. The numerical results for the second model present oscillation period and amplitude 7.2 and $4.9 \%$ higher than the observed from experiments, respectively. The root mean square error between the experimental data and the numerical simulation using the first model is equal to $6.4277 \mathrm{rad} / \mathrm{s}$, and between the experimental data and the numerical simulation using the second model is equal to $6.6135 \mathrm{rad} / \mathrm{s}$. These high values of RMSE happen because the signals come in and out of phase. 
Although the differences between the numerical and experimental results, and between the models, both models present good agreement with the experimental observations. It is essential to observe that the numerical simulations exhibit stick-slip oscillations with constant amplitude, whereas in the experimental results we see small variations of this amplitude.

The Fast Fourier Transform (FFT) of disc D2 angular velocity data confirms the agreement between experiments and numerical predictions. Figure 6.6 presents the amplitude spectrum of the angular velocity $\dot{\theta}_{2}$ recorded and simulated. In this figure, it is possible to see that there is a major peak around $f=0.81 \mathrm{~Hz}$ for the experimental response, which is visible also for the numerical responses obtained using first and second friction models.

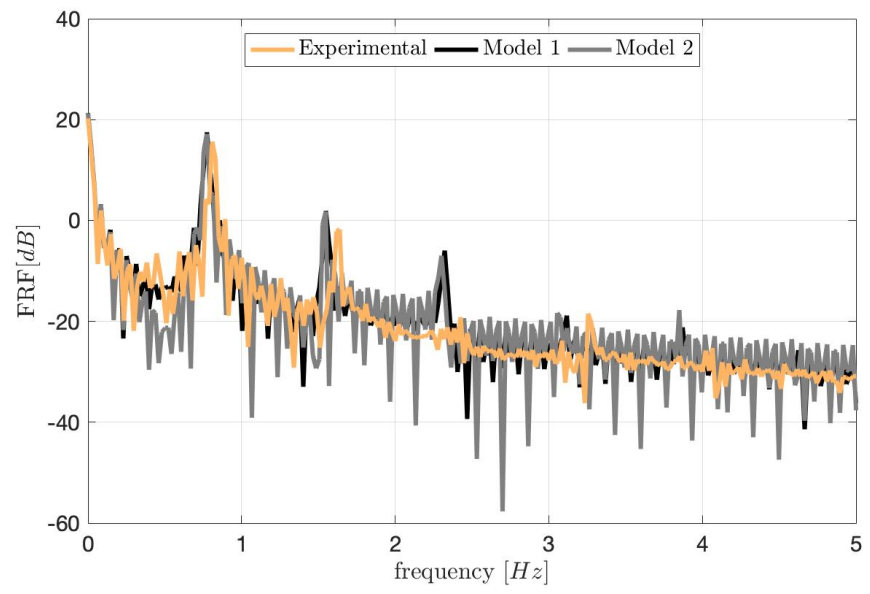

Figure 6.6: Amplitude spectrum of the angular velocity of disc D2.

Figure 6.7 presents the amplitude spectrum of the residual between the recorded and simulated results. From this graph, we note that the first major peak at $f=0.79 \mathrm{~Hz}$, for both residuals, is close to the oscillatory stick-slip frequency. The second peak, for both residuals, around $f=1.55 \mathrm{~Hz}$ is the frequency at which numerical predictions and experimental data velocity signals come to be in phase.

As a second analysis, we consider a response of torsional oscillations without stick-slip, for a reference angular velocity of $\omega_{\text {ref }}=55 R P M(5.75$ $\mathrm{rad} / \mathrm{s}$ ) and a normal contact force value of $N_{2}=10 \mathrm{~N}$.

Notwithstanding the first numerical model failed in reproducing the system experimental behavior (Fig. 6.10), we can see a qualitative agreement between experiment and second numerical model (Fig. 6.11), as the model predicts the same oscillatory response observed in the experimental data. Note, that there are small differences, the second model predicts an oscillation period 


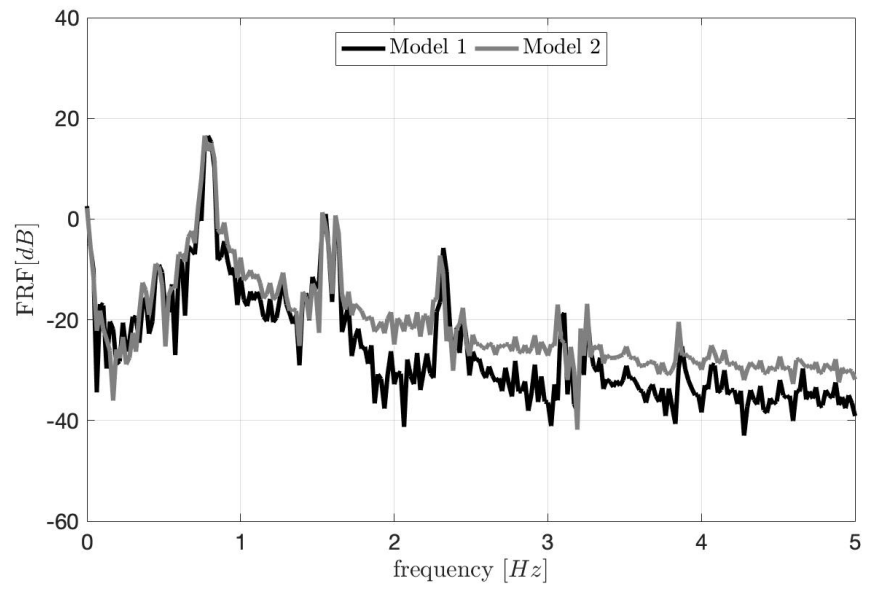

Figure 6.7: Amplitude spectrum of the residual data.

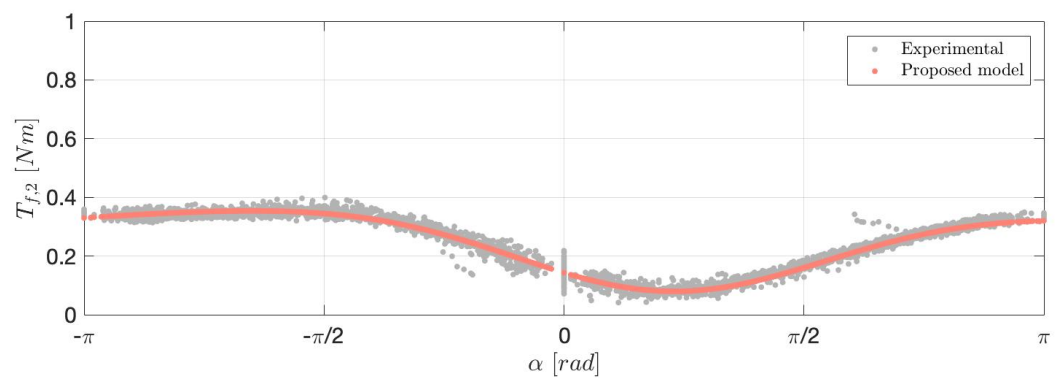

Figure 6.8: Experimental friction torque as a function of $\alpha$ for $\omega_{\text {ref }}=55 R P M$ $(5.76 \mathrm{rad} / \mathrm{s})$ and $N_{2}=10 \mathrm{~N}$.

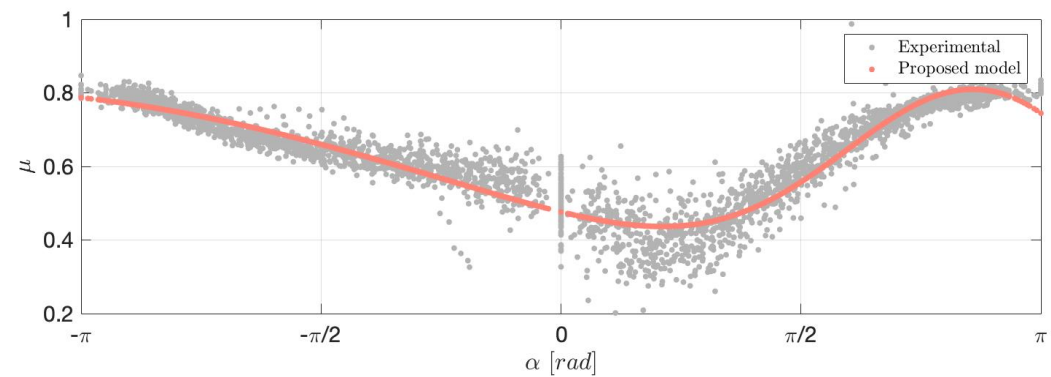

Figure 6.9: Experimental friction coefficient as a function of $\alpha$ for $\omega_{\text {ref }}=55$ $R P M(5.76 \mathrm{rad} / \mathrm{s})$ and $N_{2}=10 \mathrm{~N}$.

$11.6 \%$ greater and an oscillation amplitude $6.9 \%$ smaller than experimental ones. We also observe these differences when comparing the phase portraits.

Once again the calculated root mean square errors are high values because the signals come in and out of phase. The RMSE between the experimental data and the numerical simulation using the first model is equal to 5.8602 $\mathrm{rad} / \mathrm{s}$, and between the experimental data and the numerical simulation using 


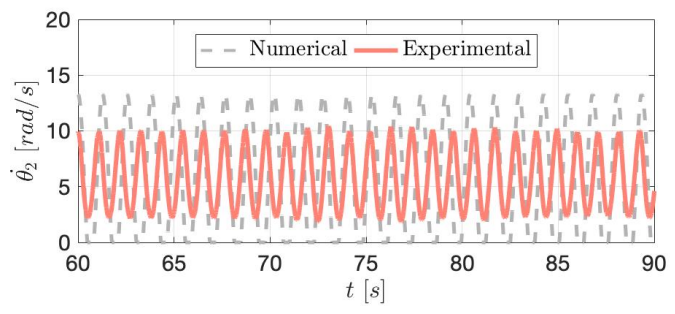

6.10(a): D2 velocity

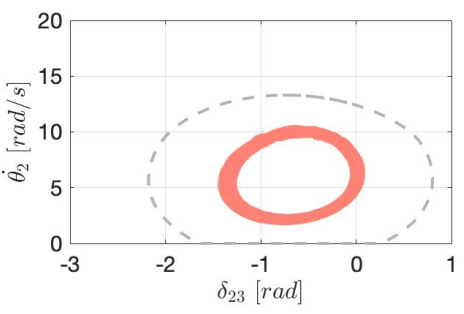

6.10(b): D2 phase portrait

Figure 6.10: (a) Experimental (continuous) and numerical (dashed) angular velocity, and (b) experimental (continuous) and numerical (dashed) phase portraits of disc D2 for $\omega_{\text {ref }}=55 R P M(5.76 \mathrm{rad} / \mathrm{s})$ and $N_{2}=10 \mathrm{~N}$.

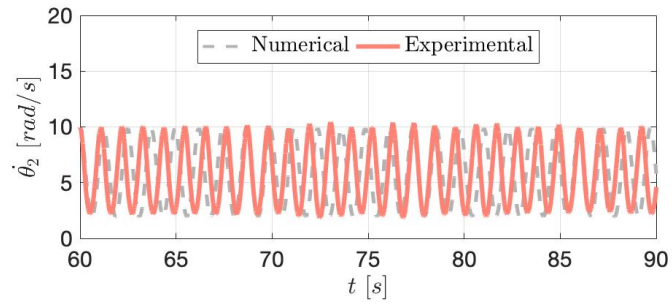

6.11(a): D2 velocity

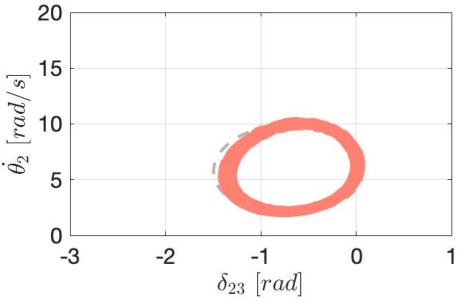

6.11(b): D2 phase portrait

Figure 6.11: (a) Experimental (continuous) and numerical (dashed) angular velocity, and (b) experimental (continuous) and numerical (dashed) phase portraits of disc D2 for $\omega_{r e f}=55 R P M(5.76 \mathrm{rad} / \mathrm{s})$ and $N_{2}=10 \mathrm{~N}$.

the second model is equal to $3.9690 \mathrm{rad} / \mathrm{s}$.

From the FFT of disc D2 angular velocity, depicted in Fig. 6.12, we remark the agreement between experiments and numerical results. In Fig. 6.12, there is a major peak at $f=0.92 \mathrm{~Hz}$ in the numerical FRF, which is close to the first peak observed in the responses from both first and second friction models, $f=0.77 \mathrm{~Hz}$ and $f=0.82 \mathrm{~Hz}$, respectively.

Figure 6.13 presents the amplitude spectrum of the residual between the recorded and simulated results. The first peaks are at $f=0.79 \mathrm{~Hz}$ for the first model residual, and at $f=0.81 \mathrm{~Hz}$ for the second model residual, which are the frequencies of torsional oscillations numerically simulated with the two models. There is a second peak at $f=0.92 \mathrm{~Hz}$, for both residuals, that is the oscillatory torsional frequency of the experimental data. Moreover, we see a third peak at $f=1.56 \mathrm{~Hz}$ for the first model residual, and at $f=1.83 \mathrm{~Hz}$ for the second model residual, which are the frequencies at which numerical predictions and experimental data velocity signals come to be in phase.

Despite the agreement between experiments and numerical predictions for the second model, it is necessary to notice that none of the proposed models 


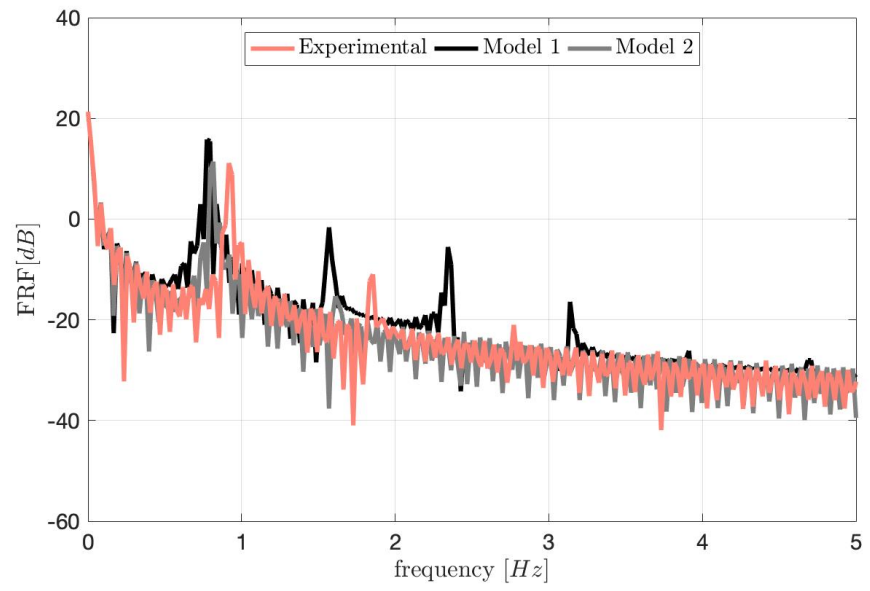

Figure 6.12: Amplitude spectrum of the angular velocity of disc D2.

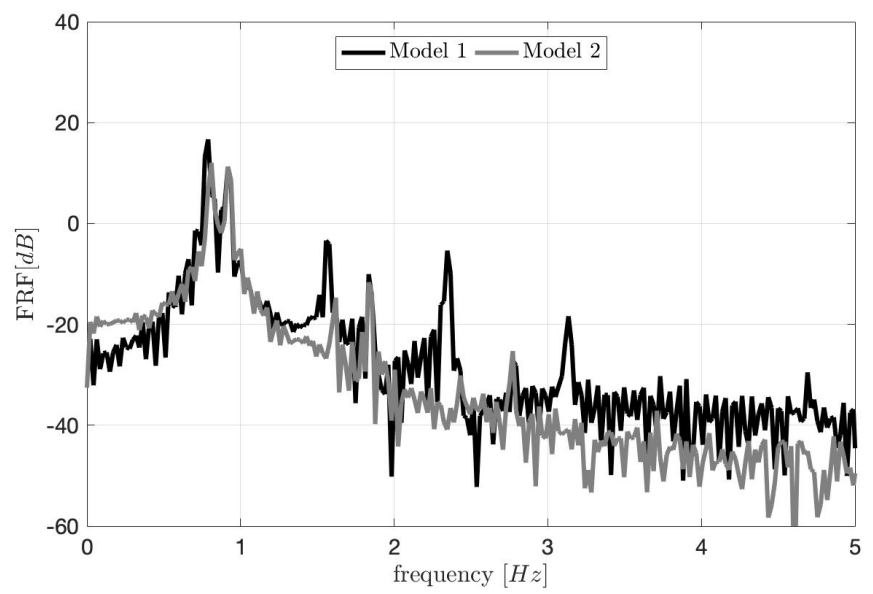

Figure 6.13: Amplitude spectrum of the residual data.

reproduce the fluctuations of the friction torque observed on the experimental responses.

\section{4}

\section{Nonlinear numerical analysis}

As stated in the experimental analysis, it is possible to observe different types of torsional vibrations for different normal contact values and reference angular velocities. We noticed that, usually, it is possible to obtain stick-slip responses for lower values of reference angular velocity and higher values of normal contact force. In this section, we use the second proposed mathematical model to study the influence of these parameters on the system response.

To observe the influence of the imposed velocity on the torsional vibrations, we varied it in the range from 0 to $60(6.28) R P M(\mathrm{rad} / \mathrm{s})$ for $N_{2}=10 \mathrm{~N}$. 
Then we constructed a bifurcation diagram to identify the type of response for different $\omega_{\text {ref }}$. Figure 6.14 presents the bifurcation diagram.

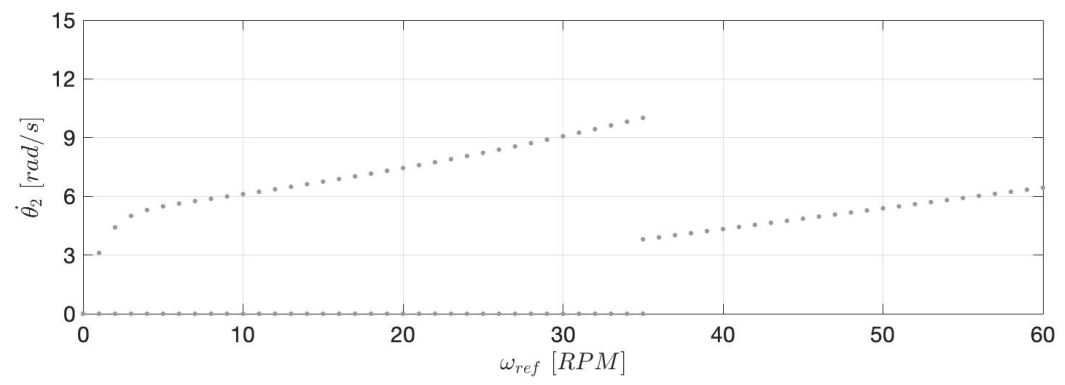

Figure 6.14: Bifurcation diagram with respect to reference angular velocity, $\omega_{\text {ref }}$, for $N_{2}=10 \mathrm{~N}$.

As $\omega_{\text {ref }}$ increases so do the amplitudes of stick-slip oscillations until it vanishes and we can only observe torsional oscillations. We expected this behavior because of experimental observations and field observations.

Similarly, we repeated the analysis to observe the influence of $N_{2}$ on the type of response. We varied it from 0 to $50 \mathrm{~N}$ for $\omega_{\text {ref }}=55 R P M$. The same parameters of torque friction curve are used for all of these cases, as $T_{f, 2}$ depends on $N_{2}$ (Eq. 6-2). In the previous chapter, we observed that $N_{2}$ varies with the disc angle, although, for simplicity, in this analysis, we assume it to be constant. Figure 6.15 presents the bifurcation diagram with respect to $N_{2}$.

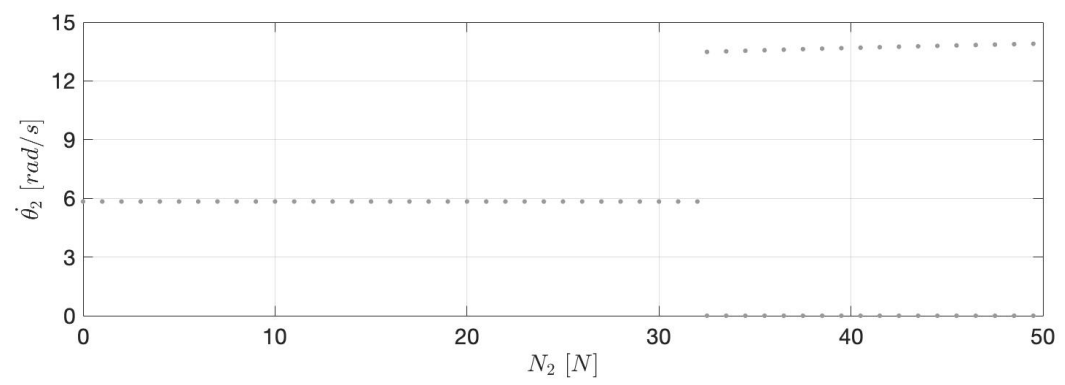

Figure 6.15: Bifurcation diagram with respect to normal contact force, $N_{2}$, for $\omega_{\text {ref }}=55 R P M$.

From Fig. 6.15, we notice that for the lower values of $N_{2}$ there are torsional oscillations. As $N_{2}$ increases so do the amplitudes of torsional oscillations, and stick-slip phenomenon appears. 


\section{5}

\section{Conclusions}

In this chapter, we have proposed two friction models based on the same idea to reproduce the hysteretic characteristics observed experimentally. Then we compared the experimental observations with the numerical results computed via the lumped parameters method. We proved that both proposed friction models provide good qualitative and quantitative agreements with experiments. Besides the comparison between experiments and numerical predictions, we also studied the influence of the nonlinear control parameters on the type of response of the system, which includes the influences of both reference angular velocity and normal contact force. From these analyses, we can conclude that the stick-slip phenomenon occurs in particular conditions. It is much more likely to appear for low values of reference velocity and high values of normal contact force. 


\section{Conclusions and future work}

This research aimed to develop and experimentally validate mathematical friction models to be used in the study of drill string dynamics. We based our models on our laboratory experimental setup, that is capable of reproducing full-scale system torsional behavior including stick-slip phenomenon.

Although the experimental apparatus limitations, it well simulates the torsional behavior presented by drill strings during the drilling process using simple brake systems. The study included the mathematical modeling of the test rig via the lumped parameters method and the identification of system parameters, such as the stiffness and damping properties of the flexible shafts. Moreover, it presented an investigation of the influence of the friction function complexity on the system response.

We experimentally proved that different types of system response exist, such as torsional oscillations, and stick-slip phenomenon. We conducted experimental tests to investigate how nonlinear control parameters, such as angular reference velocity and contact normal force, influence the system dynamics, and which combinations of these parameters result in stick-slip. We concluded that stick-slip is present in specific ranges of parameters, which indicates that a proper combination of parameters can avoid it.

A large number of dry friction models is used to describe the interaction between drill bits and rocks. However, an adequate model is necessary for a careful analysis of systems with friction. The experimental and numerical analysis of this dissertation focused on various phenomena characterizing the dry friction processes, including hysteretic effects.

We used the experimental system response to study its dynamic behavior. Subsequently, we studied the experimental friction torque using the data acquired, proving that it depends not only on the relative velocity between the contact surfaces but also on the relative acceleration between them. From the data attained by the experiments, we proposed two friction models based on the same idea, these models enable one to reproduce various frictional phenomena observed in the experimental results, including hysteresis, non-reversibility, and Stribeck effect.

The comparisons between numerical and experimental data confirmed that 
one of the proposed dry friction models is a good approximation of the observed frictional phenomena. However, we should point out that the proposed model does not capture the fluctuations of the friction torque. This mathematical friction model successfully reproduced the torsional oscillations observed in the experimental tests conducted unlike other friction models previously used in [22] and [25].

Besides the comparison between experiments and numerical predictions, we also numerically studied the influence of the control parameters on the type of response of the system, which includes the influences of both reference angular velocity and normal contact force. From these investigations, we concluded that the stick-slip phenomenon is much more likely to appear for low values of reference velocity and high values of normal contact force.

As a continuation of this work, we aim to improve the friction model in order to reproduce with greater precision the dynamics of the experimental system. Moreover, we intend to verify any possible control strategy applying the model developed in this work, and their following experimental validation. 


\section{Bibliography}

[1] INTERNATIONAL ENERGY AGENCY (IEA). World Energy Outlook 2018. Technical Report, IEA, 2018.

[2] BP. BP Statistical Review of World Energy. Report 67, 57p., BP, 2018.

[3] U.S. ENERGY INFORMATION ADMINISTRATION. International Energy Statistics. , 2018. Acess: December, 2018.

[4] KRIESELS, P. C., KEULTJES, W. J. G., DUMONT, P., ISSAN HUNEIDI, OWOEYE, O. O., HARTMANN, R. A.. Cost Savings through an Integrated Approach to Drillstring Vibration Control. In: SPE/IADC MIDDLE EAST DRILLING TECHNOLOGY CONFERENCE, Abu Dhabi, United Arab Emirates, 1999.

[5] BOURGOYNE JR., A. T., MILLhEIM, K. K., CHENEVERT, M. E., YOUNG JR., F. S.. Applied Drilling Engineering. Society of Petroleum Engineers, Dallas, 1st edition, 1991.

[6] THOMAS, J. E.. Fundamentos de Engenharia de Petróleo. Editora Interciência, Rio de Janeiro, 2nd edition, 2004.

[7] RICHARD, T., GERMAY, C., DETOURNAY, E.. Self-excited stick-slip oscillations of drill bits. Comptes Rendus Mécanique, 332:619-626, 2004.

[8] LIAO, C., BALACHANDRAN, B., KARKOUB, M.. Drill-String Dynamics: Reduced-Order Models. In: ASME 2009 INTERNATIONAL MECHANICAL ENGINEERING CONGRESS AND EXPOSITION, Florida, USA, 2009.

[9] LÓPEZ, E.. Bit-sticking phenomena in a multidegree-of-freedom controlled drillstrings. Technical Report, University of Manchester, 2010.

[10] THOMPSON, J. M. T., SILVEIRA, M., VAN DER HEIJDEN, G. H. M., WIERCIGROCH M.. Helical post-buckling of a rod in a cylinder: with applications to drill-strings. Proceedings of The Royal Society, 468:1591-1614, 2012. 
[11] SAldivar, B., BOUSSAADA, I., MONDiÉ, S., NiCUleSCO, S. I.. An Overview on the Modeling of Oilwell Drilling Vibrations. IFAC Proceedings Volumes, 47:5169-5174, 2014.

[12] JANSEN, J. D.. Nonlinear dynamics of oilwell drillstrings. Ph.D. Thesis, Delft University, Delft, 1993.

[13] DYKSTRA, M.. Nonlinear Drillstring Dynamics. Ph.D. Thesis, University of Tulsa, Oklahoma, 1996.

[14] CHRISTOFOROU, A.P., YIGIT, A.S.. Fully coupled vibrations of actively controlled drillstrings. Journal of Sound and Vibration, 267:1029-1045, 2003.

[15] KHULIEF, Y.. Finite element dynamic analysis of drillstrings. Finite elements in analysis and design, 41:1270-1288, 2005.

[16] DYKSTRA, M.. Nonlinear Drillstring and Thrasher Dynamics. M.Sc. Dissertation, Delft University of Technology, Netherlands, 1996.

[17] BAILEY, J. J., FINNIE, I.. An Analytical Study of Drillstring Vibration. Journal of Engineering for Industry, p. 122-128, 1960.

[18] CLOSE, D. A., OWENS, S. C., MACPHERSON, J.D.. Measurement of BHA Vibration Using MWD. In: SPE/IADC CONFERENCE, Dallas, 1988.

[19] FRANCA, L. F.. Self-Excited Percussive-Rotary Drilling in Hard Rocks. Ph.D. Thesis, Pontifícia Universidade Católica do Rio de Janeiro, Rio de Janeiro, 2004.

[20] FREDY, C.A.. Dinâmica de estruturas unidimensionais esbeltas utilizando o contínuo de Cosserat. Ph.D. Thesis, Pontifícia Universidade Católica do Rio de Janeiro, Rio de Janeiro, 2006.

[21] CAYRES, B. C.. Numerical and experimental analysis of nonlinear torsional dynamics of a drilling system. M.Sc. Dissertation, Pontifícia Universidade Católica do Rio de Janeiro, Rio de Janeiro, 2013.

[22] CAYRES, B. C.. Nonlinear dynamic analysis of dry friction-induced torsional vibration in a drill-string experimental set-up. Ph.D. Thesis, Pontifícia Universidade Católica do Rio de Janeiro, Rio de Janeiro, 2018. 
[23] RITTO, T. G.. Numerical analysis of the nonlinear dynamics of a drill-string with uncertainty modeling. Ph.D. Thesis, Pontifícia Universidade Católica do Rio de Janeiro, Rio de Janeiro, 2010.

[24] CUNHA JR, A. B.. Modeling and uncertainty quantification in the nonlinear stochastic dynamics of horizontal drillstrings. Ph.D. Thesis, Pontifícia Universidade Católica do Rio de Janeiro, Rio de Janeiro, 2015.

[25] SAMPAIO, G. R.. Dynamics and control of stick-slip and torsional vibrations of flexible shaft driven systems applied to drillstrings. Ph.D. Thesis, Pontifícia Universidade Católica do Rio de Janeiro, Rio de Janeiro, 2017.

[26] RITTO,T. G., AGUIAR, R. R., HBAIEB, S.. Validation of a drill string dynamical model and torsional stability. Meccanica, 52:2959-2967, 2017.

[27] JANSEN, J. D., VAN DEN STENN, L.. Active Damping of Self-excited Torsional Vibrations in Oil well Drill strings. Journal of Sound and Vibration, 179:647-668, 1995.

[28] TUCKER, R.W., WANG, C.. An integrated model for drill-string dynamics. Journal of Sound and Vibration, 224:123-165, 1999.

[29] NAVARRO-LÓPEZ, E.M.; CORTÉS, D.. Sliding-mode control of a multi-dof oilwell drillstring with stick-slip oscillations. In: AMERICAN CONTROL CONFERENCE, 2007.

[30] PATIL, P.A.; TEODORIU, C.. Model development of torsional drillstring and investigating parametrically the stick-slips influencing factors. Journal of Energy Resources Technology, 135:013-103, 2013.

[31] PATIL, P.A.; TEODORIU, C.. A comparative review of modelling and controlling torsional vibrations and experimentation using laboratory setups. Journal of Petroleum Science and Engineering, 112:227238, 2013.

[32] LEINE, R.; NIJMEIJER, H. Lecture notes in applied and computational mechanics. In: PFEIFFER \& WRIGGERS, editor, DYNAMICS AND BIFURCATIONS OF NON-SMOOTH MECHANICAL SYSTEMS, volumen 18. Springer, Netherlands, 2004. 
[33] MARQUES, F., FLORES, P., CLARO, J. C., LANKARANI, H. M.. A survey and comparison of several friction force models for dynamic analysis of multibody mechanical systems. Nonlinear Dynamics, 86:1407-1443, 2016.

[35] WIERCIGROCH, M., SIN, V. W. T., LIEW, Z. F. K.. Non-reversible dry friction oscillator: design and measurements. Proc. Inst. Mech. Eng., 213:527-534, 1999.

[36] WOJEWODA, J.;, STEFANSKI, A., WIERCIGROCH, M., KAPITANIAK, T.. Hysteretic effects of dry friction: modelling and experimental studies. Philosophical Transactions of the Royal Society of London A: Mathematical, Physical and Engineering Sciences, 366:747-765, 2008.

[37] BOWDEN, F. P.. Friction : an introduction to tribology. Heinemann, London, 1st edition, 1974.

[38] COULOMB, C. A.. Théorie des machines simples, en ayant égard au frottement de leurs parties, et à la roideur des cordages. Mémoire de Mathématique et de Physique. Paris, 1785.

[39] Zeitschrift des Vereines Deutscher Ingenieure Die wesentlichen Eigenschaften der Gleitund Rollenlager. 46:1342-1348, 1903.

[40] KARNOPP, D.. Computer simulation of stick-slip friction in mechanical dynamic systems. Journal of Dynamic Systems, Measurement and Control, 107:100-103, 1985.

[41] LEINE, R.I., VAN CAMPEN, D.H., DE KRAKER, A., VAN DEN STEEN, L. tick-slip vibrations induced by alternate friction models. Nonlinear Dynamics, 16:41-54, 1998.

[42] HALSEY, G. W., KILLINGSTAD, A.. Drillstring torsional vibrations: comparison between theory and experiment on a full-scale research drilling rig. In: SPE ANNUAL TECHNICAL CONFERENCE AND EXHIBITION, New Orleans, Louisiana, 1986.

[43] HANSON, J. M., HANSEN, W. R.. Dynamics modeling of PDC bits. In: SPE/IADC DRILLING CONFERENCE, Amsterdam, Netherlands, 1995.

[44] MIHAJLOVIĆ, N., VAN VEGGEL, A. A., VAN DE WOUW, N., NIJMEIJER, H.. Analysis of Friction-Induced Limit Cycling in an Experimental Drill-String System. Journal of Dynamic Systems, Measurement and Control, 126:709-720, 2004. 
[45] KAPITANIAK, M.. Nonlinear Dynamics of Drill-Strings. Ph.D. Thesis, University of Aberdeen, Aberdeen, 2015.

[46] REAL, F. F., LOBO, D. M., RITTO, T. G., PINTO, F. C.. Experimental analysis of stick-slip in drilling dynamics in a laboratory test-rig. Journal of Petroleum Science and Engineering, 2018.

[47] Galvanetto, U., BISHOP, S. R.. Dynamics of a Simple Damped Oscillator Undergoing Stick-Slip Vibrations. Meccanica, 34:337-347, 1999.

[48] GALVANETTO, U., BISHOP, S. R.. Computational techniques for nonlinear dynamics in multiple friction oscillators. Comput. Methods Appl. Mech. Engrg., 163:373-382, 1998.

[49] SAHA, A., WAHI, P., WIERCIGROCH, M., STEFAŃSKI, A.. A modified LuGre friction model for an accurate prediction of friction force in the pure sliding regime. International Journal of Non-Linear Mechanics, 80:122-131, 2016.

[50] MAGNUS, K.. Vibrations. Black and Son limited, Glasgow, 1st edition, 1965.

[51] INMAN, D. J.. Engineering Vibration. Pearson, Upper Saddle River, New Jersey, 4th edition, 2014.

[52] ENGEL ELEKTROANTRIEBE. Funktions und Abgleichbeschreibung für 4-Quadranten-Servoverstärker in getakteter C-MOSTransistortechnik, 1998.

[53] JAUREGUI, R., SILVA, F.. Numerical validation methods. In: NUMERICAL ANALYSIS-THEORY AND APPLICATION, In Tech, 2011. 